Universidade de São Paulo

Instituto de Química de São Carlos

Departamento de Físico-Química

\title{
Eletrorredução de nitrato em eletrodos de platina modificados por paládio.
}

\author{
Janaína de Souza Garcia
}

Tese apresentada ao Instituto de Química de São Carlos, da Universidade de São Paulo, para obtenção do Título de Doutor em Ciências - FísicoQuímica.

Orientador: Prof. Dr. Edson A. Ticianelli. 
Aos meus pais,

que me apoiaram na decisão

de seguir este caminho. 


\section{Agradecimentos}

Gostaria de agradecer antes de tudo a meus pais que, no momento em que eu decidi fazer doutorado, me apoiaram, entendendo que este seria o caminho que me faria feliz e realizada profissionalmente. Ao meu irmão e ao Airton que me ajudou a tomar essa decisão.

Ao Prof. Dr. Francisco Nart, o Chico, que aceitou me orientar contrariando sua decisão de não aceitar mais alunos naquele ano. Agradeço ao Chico também pelas conversas em grupo no Pão de Queijo e por tudo que ele teve tempo de nos ensinar.

Aos amigos do grupo de Eletroquímica: Marcinha, Kênia, Sabrina, Roberto, Jay, Demétrius, Eduardo, Felipe, Maristela, Lafon, Luis Gustavo, Valdecir, Jonas, Luciano, Flávio, Kleber, Vinicius, Flávio Colmati, Daniel Scooby e em especial Jana, Amanda, Will, Cassandra e Melina pela maior proximidade e amizade. Não posso deixar de agradecer ao carinho de outros amigos, como a Márcia, Paty, Thiago, Lidiane, Bianca, Ariane, Leleco, Dani, Marcelo, Amanda, Ivan, Frank, Well e Fabinho.

Ao Prof. Dr. Juan Feliu pelo grande apoio e toda a orientação e ensinamentos desde a minha visita ao grupo de Electroquímica da Universidad de Alicante. Não posso deixar de agradecer aos professores Victor Climent e Enrique Herrero, que também me ajudaram muito e com quem eu sei que posso contar sempre que necessário. 
Aos amigos do grupo de Alicante Antonio, Jose Manuel, Javier H., Fran, José Solla, Ana, Carlos, Marga, Paramaconi, Nuria e aos queridos Carlos, Intissar e Vitali, três grandes amigos que fiz na Espanha. Muchas gracias a todos.

Ao Prof. Dr. Edson Ticianelli que me recebeu como aluna num momento difícil e desde então vem me orientando na conclusão dessa tese. Aos professores Ernesto, Germano, Hamilton e Fábio, pelas discussões (às vezes tranqüilas, às vezes alteradas) sobre vários assuntos, envolvendo desde ciência até a cor da bancada do laboratório.

Enfim, a todos aqueles que de uma forma ou de outra contribuíram para que terminasse essa tese.

A Deus por mais essa etapa da minha vida que se conclui e pelas seguintes que tenho certeza que vou superar.

A todos muito obrigada. 
"A sabedoría está em não pensares que saber aquilo que não sabes" sócrates 


\section{RESUMO}

O estudo da eletrorredução de nitrato teve início na década de 70 e o catalisador mais estudado para esta reação é a platina, embora, para fins ambientais, o paládio seja mais indicado por apresentar maior seletividade para a formação de $\mathrm{N}_{2}$. Neste trabalho a eletrorredução de nitrato foi estudada em eletrodos de Pd, Pt e Pt com camadas de Pd. Primeiramente foi feito um estudo com nanopartículas de Pt, Pd e Pt com uma monocamada de Pd dispersas em carbono, mas a dificuldade em sugerir um mecanismo nesse tipo de eletrodo levou à utilização de eletrodos monocristalinos, que tem a superfície conhecida. Foram feitos estudos eletroquímicos em eletrodos de $\mathrm{Pd}(\mathrm{hkl})$ que não apresentaram grande atividade frente a redução de nitrato, uma vez que o potencial inferior não foi menor que 0,2 V, para evitar excessiva absorção de hidrogênio. Em Pt(hkl) os resultados obtidos estão de acordo com os publicados na literatura e comprovam a sugestão de que o produto final é $\mathrm{NH}_{4}{ }^{+}$. Para observar a atividade do paládio frente à reação, foram utilizados eletrodos monocristalinos de Pt (hkl) com multicamadas de paládio, que se comportam como monocristais de paládio, mas sem absorver hidrogênio. Nestes materiais foram feitos estudos eletroquímicos e de FTIR. Verificou-se que a atividade dos eletrodos depende da estrutura e do eletrólito, mas a definição de um mecanismo fica comprometida pelo fato do solvente $\left(\mathrm{H}_{2} \mathrm{O}\right.$ ou $\left.\mathrm{D}_{2} \mathrm{O}\right)$ favorecer a formação de um produto ou outro, embora tenha sido comprovada a formação de $\mathrm{NO}_{(\text {ads })}$ em todos os casos. 


\section{ABSTRACT}

The study of nitrate electro-reduction started in the 70 s and the most studied catalyst for this reaction is platinum, however because of environmental reasons, palladium is more indicated since it has higher selectivity for the formation of $\mathrm{N}_{2}$. In this work the nitrate electro-reduction was studied on Pd, Pt and Pt modified with $\mathrm{Pd}$ layers. First, a study involving carbon-supported nanoparticles of Pt, Pd and Pt with a $\mathrm{Pd}$ single layer was carried out, but the difficulty suggesting a reaction mechanism for this kind of electrode has driven to the use of single crystals, because of their defined surface structure. So, electrochemical studies were made on $\mathrm{Pd}(\mathrm{hkl})$ electrodes, but these materials did not present great activity for nitrate reduction, because the electrode potential was not decreased below $0,2 \mathrm{~V}$, to avoid large hydrogen absorption. For Pt(hkl) the obtained results are in agreement with those published previously, confirming the suggestion that $\mathrm{NH}_{4}{ }^{+}$is the final product. To characterize the palladium activity for this reaction, $\mathrm{Pt}(\mathrm{hkl})$ single crystals with palladium multilayer were employed, because these materials have a behavior similar to palladium single crystals, but without hydrogen absorption. Electrochemical and FTIR experiments were done to characterize the $i$ vs $E$ responses and to follow the reaction intermediates and products. It was seen that the activity depends on the electrode structure and the electrolyte, but the mechanism determination pointed to a uncertain situation where the solvent $\left(\mathrm{H}_{2} \mathrm{O}\right.$ or $\left.\mathrm{D}_{2} \mathrm{O}\right)$ drives to the formation of one product or another, although the production of $\mathrm{NO}_{(\text {ads })}$ has been observed in all cases. 


\section{LISTA DE FIGURAS}

Figura 1: Representação da célula unitária (a) e dos três planos de base de um cristal cúbico de face centrada - (b) [111], (c) [100] e (d) [110] - e dos modelos de esferas rígidas correspondentes.

Figura 2: FTIR - ATR das espécies envolvidas na reação de redução do nitrato. Espectros compostos por 100 scans com resolução de $8 \mathrm{~cm}^{-1}$. Luz "p". Background: espectro da água. .37

Figura 3: Redução de nitrato em Pt ETEK. Velocidade de varredura: $2 \mathrm{mVs}^{-1}$. Curva pontilhada: branco sem nitrato. Concentração de nitrato: 0,1 $\mathrm{M}$ de $\mathrm{NaNO}_{3} \ldots . . .39$

Figura 4: Redução de nitrato em Pd E-TEK. Velocidade de varredura: $2 \mathrm{mVs}^{-1}$. Curva pontilhada: branco sem nitrato. Concentração de nitrato: $0,1 \mathrm{M}$ de $\mathrm{NaNO}_{3} \ldots \ldots .40$

Figura 5: Voltamogramas de nanopartículas comerciais (E-TEK) de Pt, Pd e Pt com monocamada de Pd. Eletrólito suporte: $0,1 \mathrm{M} \mathrm{H}_{2} \mathrm{SO}_{4}$. Velocidade de varredura: $50 \mathrm{mVs}^{-1}$.

Figura 6: Redução de nitrato em Pt E'TEK com uma monocamada de Pd. Velocidade de varredura: $2 \mathrm{mVs}^{-1}$. Curva pontilhada: branco sem nitrato. Concentração de nitrato: $0,1 \mathrm{M}$ de $\mathrm{NaNO}_{3}$

Figura 7: Voltamograma Pt(111) com (curva sólida) e sem (curva pontilhada) 0,1 $\mathrm{M}$ de $\mathrm{NaNO}_{3}$ em solução. Eletrólito suporte $\mathrm{H}_{2} \mathrm{SO}_{4}$ (a) e $\mathrm{HClO}_{4}$ (b) $0,1 \mathrm{M}$; velocidade de varredura: $2 \mathrm{mVs}^{-1}$ para a redução de nitrato e $50 \mathrm{mVs}^{-1}$ para o branco (o branco foi dividido por 25 para comparação com a redução de nitrato).

Figura 8: Voltamograma $\mathrm{Pt}(100)$ com (curva sólida) e sem (curva pontilhada) $0,1 \mathrm{M}$ de $\mathrm{NaNO}_{3}$ em solução. Eletrólito suporte $\mathrm{H}_{2} \mathrm{SO}_{4}$ (a) e $\mathrm{HClO}_{4}$ (b) $0,1 \mathrm{M}$; velocidade de varredura: $2 \mathrm{mVs}^{-1}$ para a redução de nitrato e $50 \mathrm{mVs}^{-1}$ para o branco (o branco foi dividido por 25 para comparação com a redução de nitrato).

Figura 9: Voltamograma $\mathrm{Pt}(110)$ com (curva sólida) e sem (curva pontilhada) $0,1 \mathrm{M}$ de $\mathrm{NaNO}_{3}$ em solução. Eletrólito suporte $\mathrm{H}_{2} \mathrm{SO}_{4}$ (a) e $\mathrm{HClO}_{4}$ (b) $0,1 \mathrm{M}$; velocidade de varredura: $2 \mathrm{mVs}^{-1}$ para a redução de nitrato e $50 \mathrm{mVs}^{-1}$ para o branco (o branco foi dividido por 25 para comparação com a redução de nitrato).

Figura 10: FTIR da redução de nitrato em $\mathrm{Pt}(111)$ em $\mathrm{HClO}_{4}$ 0,1 $\mathrm{M}$ e $\mathrm{KNO}_{3}$ 0,1 M. (a) varredura negativa e (b) varredura positiva. Referência 0,9 V. Espectros compostos por 100 scans com resolução de $8 \mathrm{~cm}^{-1}$. Luz "p". 
Figura 11: FTIR da redução de nitrato em $\mathrm{Pt}(111)$ em $\mathrm{H}_{2} \mathrm{SO}_{4} 0,1 \mathrm{M}+\mathrm{KNO}_{3} 0,1 \mathrm{M}$ em $\mathrm{D}_{2} \mathrm{O}$. Potencial $0,5 \mathrm{~V}$ (na varredura positiva) e referência $0,9 \mathrm{~V}$. Espectros compostos por 100 scans com resolução de $8 \mathrm{~cm}^{-1}$. Luz "p".

Figura 12: Voltamogramas (a) $\mathrm{Pd}(111)$, (b) $\mathrm{Pd}(100)$ e (c) $\mathrm{Pd}(110)$ em $\mathrm{H}_{2} \mathrm{SO}_{4}$ 0,1 M com (curva sólida) e sem (curva pontilhada) $0,1 \mathrm{M}$ de $\mathrm{KNO}_{3}$ em solução. Velocidade de varredura: (a) e (b) $10 \mathrm{mVs}^{-1}$; (c) e inserto em (a) e (b) $2 \mathrm{mVs}^{-1}$.

Figura 13: Depósito de paládio em $\mathrm{Pt}(111) . \theta \cong 1$. Solução: $2,5 \cdot 10^{-6} \mathrm{M} \mathrm{PdSO}_{4}$ em $\mathrm{H}_{2} \mathrm{SO}_{4}$ 0,1 M (linha preta). Linha vermelha: branco $\mathrm{Pt}(111)$. Linhas pontilhadas: mesmas curvas multiplicadas por 20. Velocidade de varredura $50 \mathrm{mVs}^{-1}$.

Figura 14: Voltametria cíclica de multicamadas de paládio em $\operatorname{Pt}(111)$. Solução: $2,5 \cdot 10^{-6} \mathrm{M} \mathrm{PdSO}_{4} \mathrm{em} \mathrm{H}_{2} \mathrm{SO}_{4}$ 0,1 M (linha preta). Linha vermelha: branco Pt(111). Velocidade de varredura $50 \mathrm{mVs}^{-1}$.

Figura 15: Voltametria cíclica de multicamadas de paládio em $\mathrm{Pt}(111)$ em $\mathrm{HClO}_{4}$ 0,1 M (linha preta). Linha vermelha: branco Pt(111). Velocidade de varredura 50 $\mathrm{mVs}^{-1}$.

Figura 16: Voltamogramas de redução de nitrato em $\mathrm{Pt}(111)$ com multicamadas de Pd. (a) $\mathrm{HClO}_{4} \quad 0,1 \mathrm{M}+\mathrm{KNO}_{3} 0,1 \mathrm{M}$ e (b) $\mathrm{H}_{2} \mathrm{SO}_{4} \quad 0,1 \mathrm{M}+\mathrm{NaNO}_{3}$ 0,1 M. Velocidade de varredura: $2 \mathrm{mVs}^{-1}$. Curva pontilhada: branco sem nitrato. .56

Figura 17: (a) Carga referente à redução de nitrato em $\mathrm{Pt}(111)$ modificada por $\mathrm{Pd}$ a 2 $\mathrm{mVs}^{-1}$ em $\mathrm{H}_{2} \mathrm{SO}_{4}$ 0,1 M (preto) e $\mathrm{HClO}_{4}$ 0,1 M (vermelho); (b) Voltamograma de redução de nitrato em $\mathrm{Pt}(111)$ com multicamadas de $\mathrm{Pd}$ em $\mathrm{H}_{2} \mathrm{SO}_{4} \quad 0,1 \mathrm{M}+$ $\mathrm{NaNO}_{3} 0,1 \mathrm{M}$ a $20 \mathrm{mVs}^{-1}$ e branco sem nitrato (curva pontilhada).

Figura 18: Redução de uma camada de $\mathrm{NO}_{(\text {ads })}$ em $\mathrm{Pt}(111)$ com multicamadas de $\mathrm{Pd}$ em $\mathrm{H}_{2} \mathrm{SO}_{4} 0,1 \mathrm{M}$ a $2 \mathrm{mVs}^{-1}$

Figura 19: FTIR da redução de nitrato em $\mathrm{Pt}(111)$ com multicamadas de $\mathrm{Pd}$ em $\mathrm{H}_{2} \mathrm{SO}_{4}$ 0,1 M e KNO $30,1 \mathrm{M}$. (a) $\mathrm{H}_{2} \mathrm{O}$ e (b) $\mathrm{D}_{2} \mathrm{O}$. Referência 0,9 V. Espectros compostos por 200 scans com resolução de $4 \mathrm{~cm}^{-1}$. Luz "p". .59

Figura 20: FTIR da redução de nitrato em $\mathrm{Pt}(111)$ com multicamadas de $\mathrm{Pd}$ em $\mathrm{HClO}_{4}$ 0,1 M e $\mathrm{KNO}_{3}$ 0,1 M. (a) $\mathrm{H}_{2} \mathrm{O}$ e (b) $\mathrm{D}_{2} \mathrm{O}$. Referência 0,9 V. Espectros compostos por 200 scans com resolução de $4 \mathrm{~cm}^{-1}$. Luz "p".

Figura 21: Depósito de paládio em $\mathrm{Pt}(100) . \theta<1$. Solução: $2,5 \cdot 10^{-6} \mathrm{M} \mathrm{PdSO}_{4}$ em $\mathrm{H}_{2} \mathrm{SO}_{4}$ 0,1 M (linha preta). Linha vermelha: branco Pt(100). Velocidade de varredura $50 \mathrm{mVs}^{-1}$......

Figura 22: Voltametria cíclica de multicamadas de paládio em $\operatorname{Pt}(100)$. Solução: $2,510^{-6} \mathrm{M} \mathrm{PdSO}_{4} \mathrm{em} \mathrm{H}_{2} \mathrm{SO}_{4}$ 0,1 M (linha preta). Linha vermelha: branco $\mathrm{Pt}(100)$. Velocidade de varredura $50 \mathrm{mVs}^{-1}$.

Figura 23: Voltametria cíclica de multicamadas de paládio em $\mathrm{Pt}(100)$ em $\mathrm{HClO}_{4}$ 0,1 M (linha preta). Linha vermelha: branco Pt(100). Velocidade de varredura 50 $\mathrm{mVs}^{-1}$. 
Figura 24: Voltamogramas de redução de nitrato em $\mathrm{Pt}(100)$ com multicamadas de Pd. (a) $\mathrm{HClO}_{4} \quad 0,1 \mathrm{M}+\mathrm{KNO}_{3} 0,1 \mathrm{M}$ e (b) $\mathrm{H}_{2} \mathrm{SO}_{4} \quad 0,1 \mathrm{M}+\mathrm{NaNO}_{3} \quad 0,1 \mathrm{M}$. Velocidade de varredura: $2 \mathrm{mVs}^{-1}$. Curva pontilhada: branco sem nitrato.

Figura 25: (a) Carga referente à redução de nitrato em $\mathrm{Pt}(100)$ modificada por $\mathrm{Pd}$ a 2 $\mathrm{mVs}^{-1}$ em $\mathrm{H}_{2} \mathrm{SO}_{4}$ 0,1 M (preto) e $\mathrm{HClO}_{4}$ 0,1 M (vermelho - carga dividida por 3); (b) Voltamograma de redução de nitrato em $\mathrm{Pt}(100)$ com multicamadas de $\mathrm{Pd}$ em $\mathrm{H}_{2} \mathrm{SO}_{4} \quad 0,1 \mathrm{M}+\mathrm{NaNO}_{3} \quad 0,1 \mathrm{M}$ a $20 \mathrm{mVs}^{-1}$ e branco sem nitrato (curva pontilhada).

Figura 26: Voltamogramas de redução de nitrato em $\mathrm{Pt}(100)$ com multicamadas de $\mathrm{Pd}$ em $\mathrm{HClO}_{4} \quad 0,1 \mathrm{M}+\mathrm{KNO}_{3} \quad 0,1 \mathrm{M}$ em diferentes velocidades de varredura. Inserto: cálculo do coeficiente de Tafel (potencial do pico versus o logaritmo da velocidade de varredura).

Figura 27: Redução de uma camada de $\mathrm{NO}_{(\text {ads })}$ em $\mathrm{Pt}(100)$ com multicamadas de $\mathrm{Pd}$ em $\mathrm{H}_{2} \mathrm{SO}_{4} 0,1 \mathrm{M}^{2} 2 \mathrm{mVs}^{-1}$

Figura 28: FTIR da redução de nitrato em $\mathrm{Pt}(100)$ com multicamadas de $\mathrm{Pd}$ em $\mathrm{H}_{2} \mathrm{SO}_{4}$ 0,1 M e KNO $30,1 \mathrm{M}$. (a) $\mathrm{H}_{2} \mathrm{O}$ e (b) $\mathrm{D}_{2} \mathrm{O}$. Referência 0,9 V. Espectros compostos por 200 scans com resolução de $4 \mathrm{~cm}^{-1}$. Luz "p".

Figura 29: FTIR da redução de nitrato em $\mathrm{Pt}(100)$ com multicamadas de $\mathrm{Pd}$ em $\mathrm{HClO}_{4}$ 0,1 M e $\mathrm{KNO}_{3}$ 0,1 M. (a) $\mathrm{H}_{2} \mathrm{O}$ e (b) $\mathrm{D}_{2} \mathrm{O}$. Referência 0,9 V. Espectros compostos por 200 scans com resolução de $4 \mathrm{~cm}^{-1}$. Luz "p". .70

Figura 30: Depósito de paládio em $\mathrm{Pt}(110)$. Solução: $2,5 \cdot 10^{-6} \mathrm{M} \mathrm{PdSO}_{4} \mathrm{em} \mathrm{H}_{2} \mathrm{SO}_{4} 0,1$ M. Uma curva mostrada para cada 20 . Velocidade de varredura $50 \mathrm{mVs}^{-1} \ldots . . .71$

Figura 31: Carga total entre 0,06 e $0,4 \mathrm{~V}$ dos voltamogramas apresentados na Figura 30 para o depósito de $\mathrm{Pd}$ em $\mathrm{Pt}(111)$. .72

Figura 32: Voltamogramas de $\mathrm{Pt}(110)$ modificado por diferentes quantidades de Pd. Inserto: evolução da carga total como mostrada na Figura 31 e as cargas de cada voltamograma estão indicadas com a mesma

Figura 33: a) Carga deslocada por $\mathrm{CO}$ a $0,1 \mathrm{~V}$ em $0,1 \mathrm{M} \mathrm{H}_{2} \mathrm{SO}_{4}(\mathrm{q}(\mathrm{CO})$ ) e a carga total entre 0,06 e 0,4 V dividida por $2\left(q_{t o t a l} / 2\right)$ de eletrodos de $\operatorname{Pt}(110)$ com diferentes coberturas de $\left(\theta_{\mathrm{Pd}}\right)$. b) Potencial de Carga Total (pctz) dos mesmos eletrodos de (a).

Figura 34: Oxidação de $\mathrm{CO}$ em $\mathrm{Pt}(110)$ modificada por Pd. Inserto: mesmo que a Figura 31 e os símbolos indicam a carga correspondente à cobertura de $\mathrm{Pd}$ de cada oxidação de CO.

Figura 35: a) Espectro de FTIR in situ registrado em 0,10 V para uma camada satura de $\mathrm{CO}$ adsorvido em diferentes coberturas de $\mathrm{Pd}$; potencial de referência: $1.0 \mathrm{~V}$ após a oxidação do $\mathrm{CO}$; Eletrólito suporte: $0,1 \mathrm{M} \mathrm{H}_{2} \mathrm{SO}_{4}$. b) Mesmo que Figura 31 e os símbolos indicam a carga correspondente a cada cobertura de Pd para cada espectro apresentado em (a). 
Figura 36: Séries de espectros de FTIR obtidos durante a oxidação de CO: a) $\mathrm{Pt}(110)$; b) $\mathrm{Pt}(110)$ modificado por $\mathrm{Pd}$ com carga total anterior à mínima; c) Pt(110) modificado por Pd com carga total mínima; d) Pt(110) modificado por Pd com carga total posterior à mínima (somente $\mathrm{Pd}$ na superfície do eletrodo). Insertos em b-d mostram a carga total de cada depósito de Pd. Eletrólito suporte: $\mathrm{H}_{2} \mathrm{SO}_{4} 0,1 \mathrm{M}$, velocidade de varredura $1 \mathrm{mVs}^{-1}$, 1 espectro a cada 5 $\mathrm{mV}$, resolução $8 \mathrm{~cm}^{-1}$.

Figura 37: Voltametria cíclica de multicamadas de paládio em $\operatorname{Pt}(110)$. Solução: $2,5 \cdot 10^{-6} \mathrm{M} \mathrm{PdSO}_{4} \mathrm{em} \mathrm{H}_{2} \mathrm{SO}_{4}$ 0,1 M (linha preta). Linha vermelha: branco Pt(110). Velocidade de varredura $50 \mathrm{mVs}^{-1}$.

Figura 38: Voltametria cíclica de multicamadas de paládio em $\mathrm{Pt}(110)$ em $\mathrm{H}_{2} \mathrm{SO}_{4} 0,1$ M (linha preta). Linha vermelha: branco Pt(110). Velocidade de varredura 50 $\mathrm{mVs}^{-1}$.

Figura 39: Voltamogramas de redução de nitrato em $\mathrm{Pt}(110)$ com multicamadas de Pd. (a) $\mathrm{HClO}_{4} \quad 0,1 \mathrm{M}+\mathrm{KNO}_{3} 0,1 \mathrm{M}$ e (b) $\mathrm{H}_{2} \mathrm{SO}_{4} \quad 0,1 \mathrm{M}+\mathrm{NaNO}_{3} \quad 0,1 \mathrm{M}$. Velocidade de varredura: $2 \mathrm{mVs}^{-1}$. Curva pontilhada: branco sem nitrato. 81

Figura 40: (a) Carga referente à redução de nitrato em $\mathrm{Pt}(110)$ modificada por $\mathrm{Pd}$ a 2 $\mathrm{mVs}^{-1}$ em $\mathrm{H}_{2} \mathrm{SO}_{4}$ 0,1 M (preto) e $\mathrm{HClO}_{4}$ 0,1 M (vermelho); (b) Voltamograma de redução de nitrato em $\mathrm{Pt}(110)$ com multicamadas de $\mathrm{Pd}$ em $\mathrm{H}_{2} \mathrm{SO}_{4}$ 0,1 $\mathrm{M}+$ $\mathrm{NaNO}_{3} 0,1 \mathrm{M}$ a $20 \mathrm{mVs}^{-1}$ e branco sem nitrato (curva pontilhada)..... .82

Figura 41: Voltamogramas de redução de nitrato em $\mathrm{HClO}_{4} 0,1 \mathrm{M}+\mathrm{KNO}_{3} 0,1 \mathrm{M}$ em $\mathrm{Pt}$ (110) com multicamadas de $\mathrm{Pd}$. (a) $10 \mathrm{mVs}^{-1}$ e (b) $50 \mathrm{mVs}^{-1}$. Curva pontilhada: branco sem nitrato.

Figura 42: Redução de uma camada de $\mathrm{NO}_{(\mathrm{ads})}$ em $\mathrm{Pt}(110)$ com multicamadas de $\mathrm{Pd}$ em $\mathrm{H}_{2} \mathrm{SO}_{4} 0,1 \mathrm{M}$ a $2 \mathrm{mVs}^{-1}$

Figura 43: FTIR da redução de nitrato em $\mathrm{Pt}(110)$ com multicamadas de $\mathrm{Pd}$ em $\mathrm{H}_{2} \mathrm{SO}_{4} 0,1 \mathrm{M}$ e $\mathrm{KNO}_{3}$ 0,1 M. (a) $\mathrm{H}_{2} \mathrm{O}$ e (b) $\mathrm{D}_{2} \mathrm{O}$. Referência 0,9 V. Espectros compostos por 200 scans com resolução de $4 \mathrm{~cm}^{-1}$. Luz "p".

Figura 44: FTIR da redução de nitrato em $\mathrm{Pt}(110)$ com multicamadas de $\mathrm{Pd}$ em $\mathrm{HClO}_{4}$ 0,1 M e KNO $30,1 \mathrm{M}$. (a) $\mathrm{H}_{2} \mathrm{O}$ e (b) $\mathrm{D}_{2} \mathrm{O}$. Referência 0,9 V. Espectros compostos por 200 scans com resolução de $4 \mathrm{~cm}^{-1}$. Luz "p".

Figura 45: FTIR da redução de nitrato em $\mathrm{Pt}(110)$ com multicamadas de $\mathrm{Pd}$ em $\mathrm{HClO}_{4}$ 0,1 M e $\mathrm{KNO}_{3}$ 0,1 M. Preto: $\mathrm{H}_{2} \mathrm{O}$; vermelho: $\mathrm{D}_{2} \mathrm{O}$; (a) luz "p" e (b) luz "s". $\mathrm{E}=0,15 \mathrm{~V}$ e $\mathrm{E}_{\text {ref }}=0,9 \mathrm{~V}$. Espectros compostos por 200 scans com resolução de $4 \mathrm{~cm}^{-1}$. 


\section{LISTA DE ABREVIATURAS E SIGLAS}

FTIR: "Fourier Transform Infrared Spectroscopy" - Espectroscopia de Infravermelho com Transformada de Fourier

pctz: $\quad$ Potencial de Carga Total Zero

Pt/C: $\quad$ nanopartículas de Pt suportadas em Carbono Vulcan

$\mathrm{Pd} / \mathrm{C}: \quad$ nanopartículas de Pd suportadas em Carbono Vulcan

$\mathrm{NO}_{\text {(ads): } \quad \quad \mathrm{NO} \text { adsorvido }}$

$\mathrm{NO}_{(\text {sol) }}: \quad \mathrm{NO}$ em solução

Pt(111)/Pd: $\mathrm{Pt}(111)$ com multicamadas de Pd

Pt(100)/Pd: Pt(100) com multicamadas de Pd

Pt(110)/Pd: $\mathrm{Pt}(110)$ com multicamadas de Pd

$\mathrm{CO}_{\llcorner}-\mathrm{Pt}: \quad \mathrm{CO}$ adsorvido linearmente em Pt

$\mathrm{CO}_{\mathrm{B}}-\mathrm{Pd}: \quad \mathrm{CO}$ adsorvido em ponte (bridge) em Pd

$\theta_{\mathrm{Pd}}: \quad$ cobertura de $\mathrm{Pd}$ 


\section{SUMÁRIO}

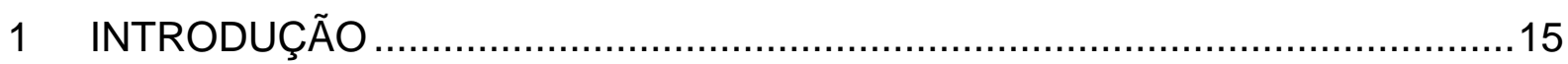

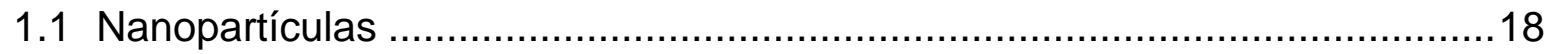

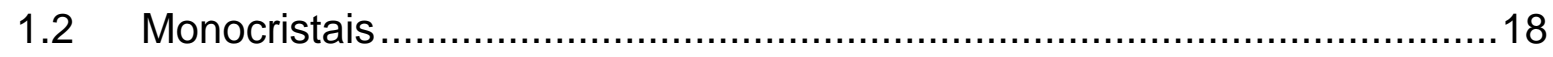

1.3 Catalisadores Modificados por Ad-átomos..............................................20

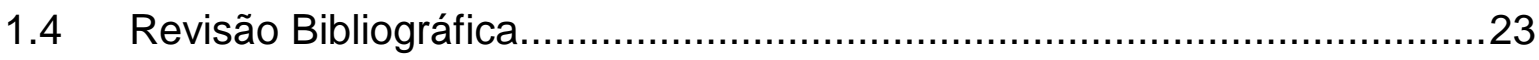

1.4.1 A Reação de Redução do Íon Nitrato ………......................................23

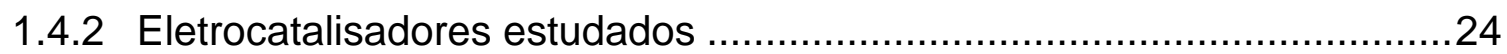

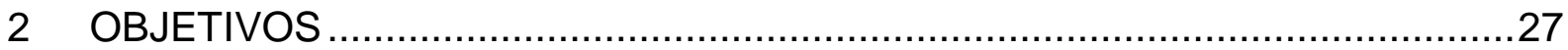

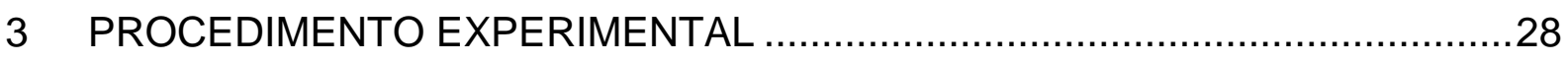

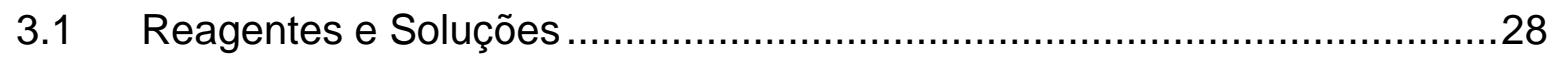

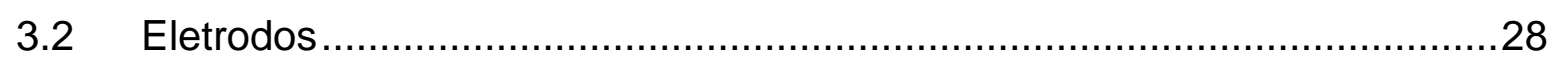

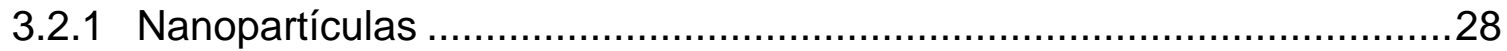

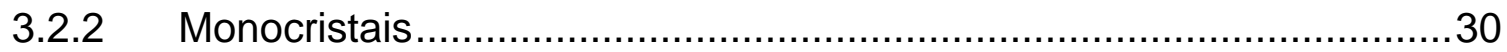

3.3 Estudos Eletroquímicos ….............................................................

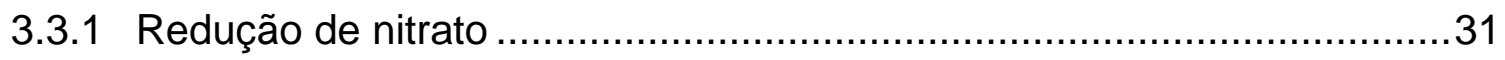

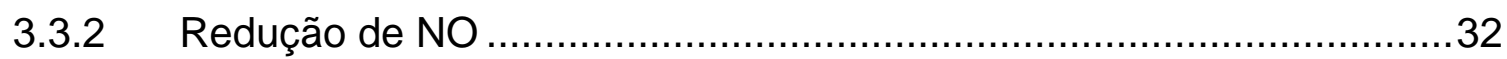

3.3.3 Depósito de paládio em monocristais de Pt.......................................32

3.3.3.1 Carga deslocada por CO.........................................................3

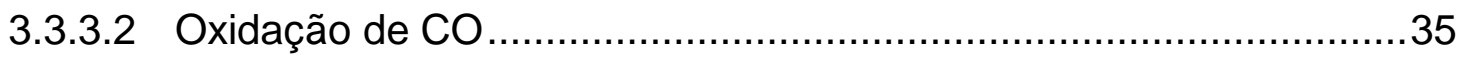

3.4 Estudos Espectroscópicos de Infravermelho in situ ...................................35

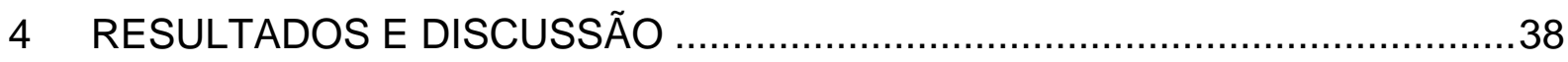


4.1 Eletrorredução de nitrato em nanopartículas de Pt, Pd e Pt com monocamada de $\mathrm{Pd}$ 38

4.2 Eletrorredução de nitrato em eletrodos monocristalinos de Platina 43

4.3 Eletrorredução de nitrato em eletrodos monocristalinos de Paládio 49

4.4 Eletrorredução de nitrato em eletrodos monocristalinos de Platina com depósitos de Paládio 52

4.4.1 Pt(111) modificado por paládio .........................................................52

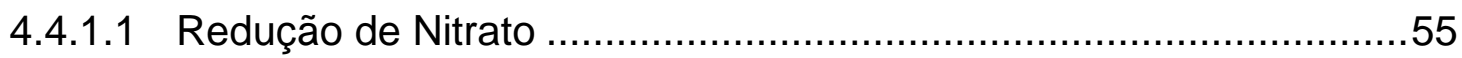

4.4.2 Pt(100) modificado por paládio .....................................................62

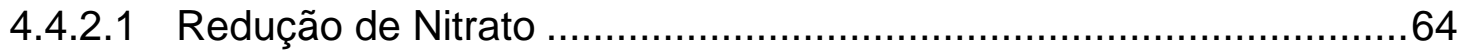

4.4.3 Pt(110) modificado por paládio ……………...............................70

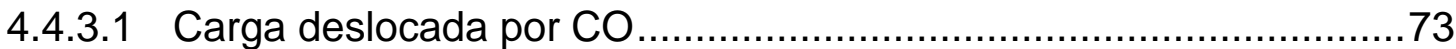

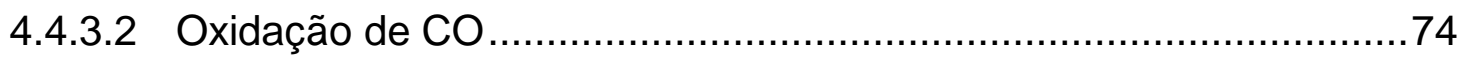

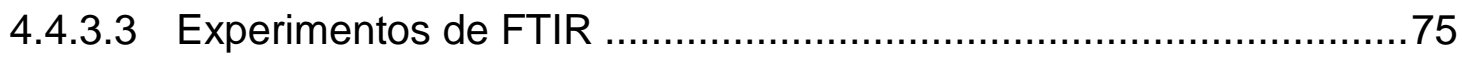

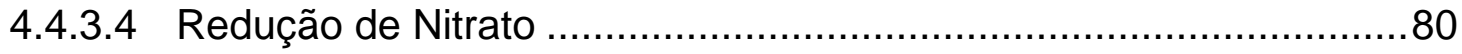

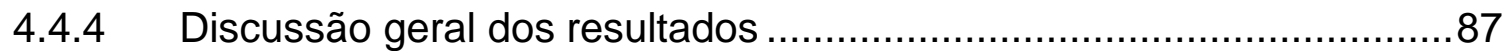

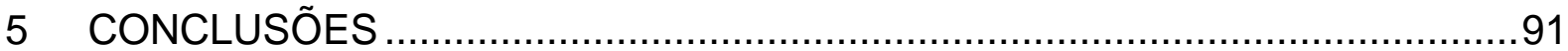




\section{INTRODUÇÃO}

O estudo da redução eletroquímica de íons nitrato teve início no final da década de 1970 e em princípio tinha como principal interesse os produtos da redução do nitrato, que podem ser muito úteis $\left(\mathrm{N}_{2} \mathrm{O}\right.$ é usado como anestésico; $\mathrm{NH}_{3}$ como fonte de nitrogênio em fertilizantes, $\mathrm{NH}_{2} \mathrm{OH}$ na preparação do precursor do Nylon $^{\circledR}$, etc). Por outro lado, a redução de nitrato também encontrava interesse como forma da sua eliminação em efluentes de usinas nucleares (nitrato de urânio é utilizado como precursor do combustível) [1-7].

Os problemas ambientais causados pela contaminação de cursos d'água por lixiviação dos compostos nitrogenados que geram nitratos, provenientes do uso intensivo de adubos inorgânicos [8], também passou a ser um dos interesses de promover esta reação [1-5, 7, 9].

nitrato no organismo de recém nascidos (até 3 meses de idade) pode ser convertido a nitrito por ação bacteriana. O nitrito é tóxico porque se liga fortemente à hemoglobina, dificultando o transporte de oxigênio e causando a síndrome do bebê azul. Em adultos o nitrato é convertido, no sistema intestinal, a nitrosaminas que são substâncias carcinogênicas [8].

A quantidade permitida de nitrato em águas superficiais para uso humano varia de acordo com o país. Na Europa o índice permitido de nitrato dissolvido é de $50 \mathrm{mg} \mathrm{L}^{-1}$ [8]. No Brasil a Agencia Nacional de Vigilância Sanitária (Anvisa) fixou em $10 \mathrm{mg} \mathrm{L}^{-1}$ (em nitrogênio) o teor de nitrato em águas para uso público e $0,08 \mathrm{mg} \mathrm{L}^{-1}$ 
de nitrogênio amoniacal [10]. Em geral em área de intensa atividade agrícola na Europa, a quantidade de íons nitrato dissolvida na água pode chegar a $200 \mathrm{mg} \mathrm{L}^{-1}$ [8]. Portanto, para o uso de mananciais próximos a estas regiões se fará necessário, de forma crescente, promover processos de desnitrificação durante o tratamento de água para uso humano, para evitar riscos à saúde [8].

A remoção de nitratos de água potável é uma importante área de estudo, mas os processos de desnitrificação constituem uma tecnologia ainda em desenvolvimento. Basicamente dois processos são mais comumente utilizados: a desnitrificação por ação de bactérias e a desnitrificação catalítica em fase líquida [8].

O processo de desnitrificação microbiológica em geral apresenta boa eficiência e boa seletividade, gerando apenas pequenas quantidades de subprodutos como nitrogênio amoniacal. É muito indicado para remoção de nitrato em efluentes municipais e industriais, mas esta tecnologia não tem sido recomendada para o tratamento de água para consumo humano. $\mathrm{O}$ uso de bactérias pode causar a infecção da água, por serem difíceis de serem completamente eliminadas, e deixar pequenas quantidades de compostos orgânicos na água tratada o que leva ao aumento do consumo de cloro no tratamento [8].

O processo de remoção catalítica do nitrato oferece uma alternativa com vantagem econômica em relação ao tratamento biológico para purificação de água potável. Neste processo o nitrato é convertido seletivamente, via intermediários, a nitrogênio, em um reator em fase líquida, sob pressão de 7 bar, em temperaturas amenas $(278$ - 298 K) e sob um fluxo de hidrogênio. Vários catalisadores bimetálicos já foram estudados para esta reação (Pd-Cu, Pd-Sn, Pd-In, Pt-Cu e $\left.\mathrm{Pd}-\mathrm{CeO}_{2}[7,8]\right)$, mas que ainda não apresentam seletividade para a produção de 
nitrogênio. Este processo parece ser muito promissor, mas ainda sub-produtos, como amônia, comprometem o bom desempenho da desnitrificação. Em catalisadores de $\mathrm{Pd}$ e $\mathrm{Pd}-\mathrm{Cu}$, a formação de amônia poderia ser evitada diminuindo a pressão parcial do hidrogênio no reator, mas isso nem sempre promove o resultado desejado, indicando que ainda é necessário encontrar processos onde a desnitrificação não leve a formação de produtos tóxicos [8].

Uma alternativa praticamente ainda inexplorada é a redução eletroquímica do nitrato. Entretanto, para que a desnitrificação eletroquímica seja possível, ainda muitos estudos necessitam ser feitos sobre a cinética e mecanismos de redução de nitrato em eletrodos seletivos, que permitam a redução do nitrato a produtos inertes, como $\circ \mathrm{N}_{2}$. Outros problemas envolvem a necessidade de uso de eletrólitos fáceis de serem removidos da água, mas sem dúvida o processo eletroquímico pode permitir um controle mais preciso das condições reacionais, através do controle do potencial do eletrodo. No caso específico da redução de nitrato em meio ácido utilizando eletrodos de platina, ródio e platina-ródio, foi possível demonstrar que os produtos da reação são fortemente dependentes do potencial do eletrodo [5]. Com isso é possível antever que a redução eletroquímica de íons nitrato pode ser muito interessante no desenvolvimento de tecnologias de desnitrificação de águas superficiais. 


\subsection{Nanopartículas}

A superfície ativa do catalisador pode ser aumentada com o uso de nanopartículas. Quanto menores as partículas, maior a área exposta do material, o que diminui a quantidade necessária para a mesma área superficial. Nanocatalisadores possuem propriedades específicas diferentes do mesmo material em partículas maiores ou em eletrodos maciços e podem ser de grande utilidade em aplicações comerciais, ainda mais por utilizarem menor quantidade de metal. Como para a maioria das reações os metais nobres são os melhores catalisadores, a utilização de eletrodos maciços, que utilizam grande quantidade de metal, se torna economicamente inviável para aplicações comerciais, o que faz das nanopartículas uma boa opção para muitos dos casos.

\subsection{Monocristais}

Apesar de nanopartículas serem mais indicadas para aplicações comerciais, o estudo do mecanismo de reações em nanopartículas é complicado, justamente pelas propriedades diferentes que estas apresentam, decorrentes muitas vezes do fato de estas apresentarem superfícies monocristalinas com orientações preferenciais. Para o estudo de mecanismos de reação a utilização de monocristais é mais indicada, pois estes possuem superfícies bem definidas e conhecidas, facilitando o estudo das interações entre metal, reagentes e produtos. Com isso, neste trabalho, foram também utilizados eletrodos constituídos de monocristais de platina ou paládio, preparados conforme descrito mais adiante. 
Monocristais são estruturas com arranjos de átomos que se repetem periodicamente. Este arranjo que se repete é chamado de célula unitária. A célula unitária possui um arranjo definido de átomos que se repetem tridimensionalmente, formando um cristal. As células unitárias podem ser descritas por três vetores da rede com origem em um dos seus vértices.

Para a escolha e orientação de superfícies cúbicas utiliza-se um sistema de notação para especificar as faces de um cristal. Esta notação, denominada de Índices de Miller, consiste em estabelecer a orientação do plano de uma face relativamente aos eixos da célula unitária através da utilização dos menores números inteiros das intersecções com os eixos do plano do cristal [11]. A Figura 1 ilustra a célula unitária para um sistema cúbico de face centrada (CFC) e a representação das faces de baixo índice de Miller. Este sistema representa a estrutura tanto a platina como o paládio.

a) célula unitária

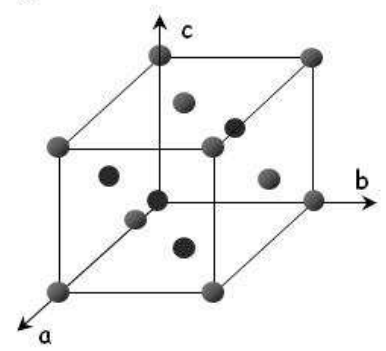

c) $[100]$
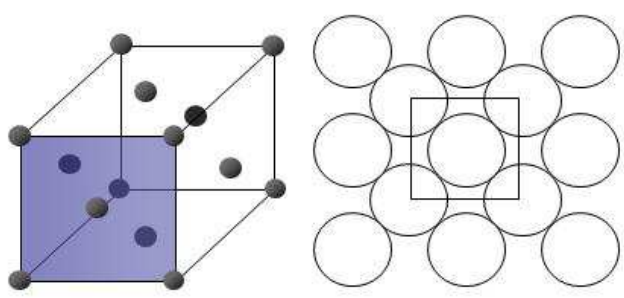

b) [111]

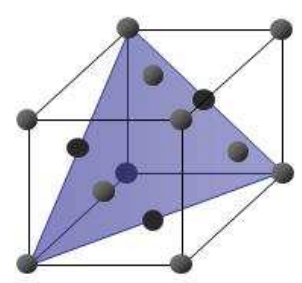

d) [110]
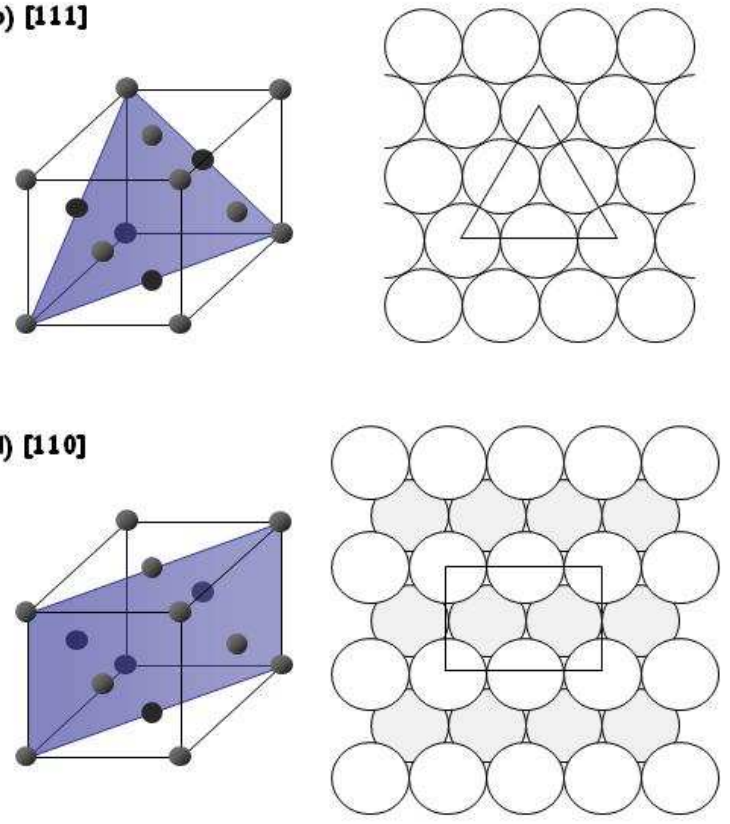

Metal (segundo plano) 


\subsection{Catalisadores Modificados por Ad-átomos}

É possível melhorar a atividade eletrocatalítica de eletrodos modificando sua superfície através de ad-átomos. Com isso o catalisador pode adquirir propriedades diferentes dependendo da ordem do depósito (subcamada, monocamada ou multicamadas).

Os depósitos podem ser feitos utilizando o processo de "upd" ("underpotencial deposition”) [12-19] ou através de adsorções irreversíveis [4, 20-26]. O primeiro método, na maioria das vezes, está limitado ao depósito de uma monocamada de um metal em um substrato de outro metal. Já os sistemas com adsorção irreversível têm a vantagem de o metal adsorvido permanecer na superfície do eletrodo em uma grande faixa de potencial, mesmo na ausência de íons deste em solução [26].

O depósito irreversível de paládio em monocristais de platina vem sendo estudado há vários anos [27-30], uma vez que o paládio é ativo como catalisador para várias reações, mas o trabalho com monocristais de paládio tem uma série de dificuldades, como a absorção de hidrogênio e o fato de não poderem ser tratados pelo método de chama ("flame annealing technique" [31]) [28, 32]. A forma com que o crescimento das camadas ocorre pode permitir que a reatividade do depósito de paládio em monocristais de $\mathrm{Pt}$ seja comparada àquela dos monocristais de $\mathrm{Pd}$ correspondentes [29]. O depósito não é restrito a subcamada ou monocamada, sendo possível o crescimento de mais camadas e permitindo o depósito de um volume maior de metal, cujas propriedades podem ser comparadas a eletrodos maciços [32]. Na maioria das vezes, a primeira camada costuma apresentar propriedades particulares, diferentes tanto das do metal suporte como daquelas do metal depositado, devido às interações com os átomos do substrato [28, 30]. 
O depósito irreversível é feito normalmente de três formas: 1) depósito espontâneo, feito pelo contato do eletrodo com uma solução do metal a ser depositado, em circuito aberto; 2) depósito forçado, reduzindo o metal com um agente redutor como, por exemplo, hidrogênio; 3) depósito eletroquímico, variando o potencial do eletrodo numa solução contendo íons do metal. Outra alternativa é o depósito por deslocamento galvânico, no qual os íons de um metal nobre deslocam outro metal (menos nobre) depositado no eletrodo [33, 34].

O crescimento de um metal A sobre um substrato B pode seguir três modelos diferentes [35]:

1) Frank - van der Merwe ou camada por camada: ocorre em sistemas com desordem zero ou quando A e B são idênticos;

2) Stranski-Krastanov: ilhas cristalinas tridimensionais começam a crescer depois que uma ou algumas monocamadas de A são formadas. A maioria dos sistemas segue esse modelo que ocorre porque a força da ligação de A em A puro é maior que a força da ligação de $A$ em uma camada de $A$ em B. Essa diferença na energia de ligação está relacionada com o fato de uma camada de A em B sofrer influência eletrônica de B ou porque a cristalografia do substrato B força a primeira camada de A a assumir ligações tensas.

3) Volmer-Weber: ilhas 3d de A puro crescem mesmo com baixas coberturas, sem uma primeira monocamada ser formada antes. Isso pode acontecer quando a força de ligação de A com B é menor que a energia de atração de $A \operatorname{com} A$. 
As características mais importantes que influenciam o modo como 0 crescimento do ad-átomo $\mathrm{A}$ acontece na superfície do substrato são: (a) a natureza da interação lateral de $A$ com $A$ e (b) a variação da energia de $A$ conforme este se movimenta lateralmente ao longo da superfície. Este último fator é determinado pela rugosidade em escala atômica do substrato $B$, mas também depende do comprimento e da natureza da ligação A-B [35].

Quando as interações laterais são repulsivas, os ad-átomos $A$ tendem a assumir uma estrutura aproximadamente hexagonal, o que maximiza a distância entre os átomos A-A. Quanto menor a repulsão, menor a distorção da estrutura hexagonal para igualar com a estrutura do substrato $\mathrm{B}$.

Já quando as interações laterais são atrativas, como no caso do paládio, os ad-átomos se juntam em ilhas. Com metais que tem a mesma estrutura do substrato, com parâmetro de rede similar (com uma diferença máxima entre 7 e 9\%) essas ilhas $2 \mathrm{~d}$ normalmente crescem de forma pseudomórfica, ou seja, os ad-átomos assumem a mesma posição que os átomos da próxima camada do substrato assumiriam. Isso é o que ocorre com o paládio depositado em platina.

Com isso, uma opção para o estudo da atividade do paládio frente à reação de redução de nitrato é a utilização de monocamadas e multicamadas de paládio em monocristais de Pt, já bastante conhecidos [20, 36-40]. Por ser mais controlado, o depósito eletroquímico é normalmente escolhido para depósitos de monocamadas e para aqueles em que um crescimento mais ordenado se faz necessário, como no caso deste estudo. 


\subsection{Revisão Bibliográfica}

\subsubsection{A Reação de Redução do Íon Nitrato}

O grande número de produtos e intermediários que podem ser formados a partir da redução do nitrato torna complexo o estudo desta reação [2, 3]. Além disso, o mecanismo de reação e a natureza dos produtos depende fortemente do $\mathrm{pH}$, potencial do eletrodo, da natureza do eletrodo e dos aditivos moleculares ou iônicos presentes na solução [2, 3, 5].

A seletividade da redução do nitrato é importante, uma vez que pode ser reduzido a um grande número de produtos estáveis: $\mathrm{NO}_{2}, \mathrm{HNO}_{2}, \mathrm{NO}, \mathrm{N}_{2} \mathrm{O}, \mathrm{N}_{2}$, $\mathrm{NH}_{2} \mathrm{OH}$ e $\mathrm{NH}_{3}$. Em aplicações ambientais somente o $\mathrm{N}_{2}$ deve ser produzido [1]. Estudos relacionam os produtos finais da reação de redução de nitrato com a presença ou não de NO em solução [2, 41, 42]. As Equações 1 - 12 mostram um esquema de reação deduzido a partir de estudos já publicados [1, 2, 4, 41, 42]. A sequência descreve duas rotas de reação, uma a partir de $\mathrm{NO}_{(\mathrm{ads})}$ levando à formação de amônia e outra a partir de $\mathrm{NO}$ em solução que leva à formação de $\mathrm{N}_{2} \mathrm{O}$ e nitrogênio molecular [43].

A primeira etapa é a redução de nitrato a nitrito e deste a $\mathrm{NO}_{(\mathrm{ads})}$ :

$$
\begin{aligned}
& \mathrm{NO}_{3}^{-}+2 \mathrm{H}^{+}+2 \mathrm{e}^{-} \rightarrow \mathrm{H}_{2} \mathrm{O}+\mathrm{NO}_{2}^{-} \\
& \mathrm{NO}_{2}^{-}+2 \mathrm{H}^{+}+\mathrm{e}^{-} \rightarrow \mathrm{H}_{2} \mathrm{O}+\mathrm{NO}_{(\text {ads })}
\end{aligned}
$$

$\mathrm{NO}_{\text {(ads) }}$ pode reagir para formar $\mathrm{NH}_{4}{ }^{+}$por duas rotas diferentes:

$$
\begin{aligned}
& \mathrm{NO}_{(\text {ads }}+\mathrm{H}^{+}+\mathrm{e}^{-} \rightarrow \mathrm{HNO}_{(\text {ads })} \\
& \mathrm{HNO}_{(\text {ads }}+\mathrm{H}^{+}+\mathrm{e}^{-} \rightarrow \mathrm{H}_{2} \mathrm{NO}_{(\mathrm{ads})} \\
& \mathrm{H}_{2} \mathrm{NO}_{(\text {ads })}+4 \mathrm{H}^{+}+3 \mathrm{e}^{-} \rightarrow \mathrm{H}_{2} \mathrm{O}+\mathrm{NH}_{4}^{+}
\end{aligned}
$$




$$
\begin{array}{llll}
\mathrm{NO}_{\text {(ads) }}+\mathrm{H}^{+}+\mathrm{e}^{-} & \rightarrow \mathrm{NOH}_{\text {(ads) }} & \text { (Equação 6) } \\
\mathrm{NOH}_{\text {(ads) }}+2 \mathrm{H}^{+}+2 \mathrm{e}^{-} \rightarrow \mathrm{NH}_{2} \mathrm{OH} & \text { (Equação 7) } \\
\mathrm{NH}_{2} \mathrm{OH}+3 \mathrm{H}^{+}+2 \mathrm{e}^{-} \rightarrow \mathrm{H}_{2} \mathrm{O}+\mathrm{NH}_{4}^{+} & \text {(Equação 8) }
\end{array}
$$

Ou o NO pode dessorver primeiro e reagir para formar $\mathrm{N}_{2} \mathrm{O}$ e $\mathrm{N}_{2}$ :

$$
\begin{aligned}
& \mathrm{NO}_{(\text {ads) }} \quad \leftrightarrows \quad \mathrm{NO}_{(\text {sol) }} \\
& \mathrm{NO}_{(\text {sol) }}+\mathrm{NO}_{(\text {ads })}+\mathrm{H}^{+}+\mathrm{e}^{-} \rightarrow \mathrm{HN}_{2} \mathrm{O}_{2(\text { (ads) }} \\
& \mathrm{HN}_{2} \mathrm{O}_{2 \text { (ads) }}+\text { ? } \rightarrow \mathrm{N}_{2} \mathrm{O} \\
& \mathrm{N}_{2} \mathrm{O}+2 \mathrm{H}^{+}+2 \mathrm{e}^{-} \rightarrow \mathrm{H}_{2} \mathrm{O}+\mathrm{N}_{2}
\end{aligned}
$$

Vários fatores como concentração de nitrato, $\mathrm{pH}$ e material do eletrodo influenciam na rota da reação. Esse é um dos fatores que torna o estudo dessa reação difícil. Com relação à identificação dos produtos por FTIR, o principal problema é o fato de uma mesma banda poder ser atribuída a mais de um produto e de um mesmo composto ter mais de uma frequência de vibração.

\subsubsection{Eletrocatalisadores estudados}

A platina tem sido estudada como catalisador para a reação eletroquímica de redução do nitrato há mais de 100 anos e foi o único metal para o qual um mecanismo de reação foi proposto $[1,2,5,6,44]$. Os mecanismos propostos para outros metais são baseados nos da platina (Equações 1 -12).

Existe uma distinção na literatura entre dois mecanismos de redução de nitrato em Pt: um mecanismo de redução direta que se desenvolve em todas as concentrações de nitrato e um mecanismo indireto que se desenvolve somente em altas concentrações de ácido nítrico (>1 M) na presença de nitrito [1]. Devido ao fato de que a redução de $\mathrm{NO}_{3}{ }^{-}$é acelerada na presença de $\mathrm{HNO}_{2}$, muitos autores 
sugerem que a reação acontece através do ânion $\mathrm{NO}_{2}^{-}[4,6,44]$ e que esta seria a etapa limitante (Equação 1) [1, 4].

O paládio também tem sido estudado como catalisador para a reação de eletrorredução do nitrato, observando-se que apresenta uma atividade semelhante à da Pt $[4,41]$. Na eletrorredução de óxido nítrico o paládio se mostrou mais ativo e mais seletivo para a produção de $\mathrm{N}_{2}$ que outros metais, mas ainda não existe um mecanismo que explique sua seletividade na redução de $\mathrm{NO}$ a $\mathrm{N}_{2}$ [41]. De Vooys et al. [41] relacionaram seu melhor desempenho à sua alta atividade em reduzir $\mathrm{N}_{2} \mathrm{O}$ a $\mathrm{N}_{2}$ em altos potencias $(0,4-0,7 \mathrm{~V})$ e sua baixa atividade em reduzir $\mathrm{N}_{2} \mathrm{O}$ a $\mathrm{NH}_{3}$ em baixos potenciais $(0-0,3 \mathrm{~V})$. Foi observado também que existe uma relação entre a seletividade do metal em produzir $\mathrm{N}_{2}$ a partir de $\mathrm{NO}$ e sua atividade em reduzir $\mathrm{N}_{2} \mathrm{O}$ e, além disso, que nem $\mathrm{N}_{2}$ nem $\mathrm{N}_{2} \mathrm{O}$ são formados a partir de $\mathrm{NO}$ adsorvido. Sugerese, portanto, que o $\mathrm{N}_{2}$ é formado pela redução de $\mathrm{N}_{2} \mathrm{O}$, isto é, em série com a formação de $\mathrm{N}_{2} \mathrm{O}[41,42]$. Vários estudos reportam que somente houve formação de $\mathrm{N}_{2} \mathrm{O}$ e $\mathrm{N}_{2}$ quando $\mathrm{NO}$ estava presente na solução [2, 41, 42], sendo que a atividade do catalisador se mostrou inversamente proporcional à estabilidade da ligação NO-metal, ou seja, quanto mais fracamente o NO estiver adsorvido, maior a quantidade de $\mathrm{NO}$ em solução e maior a atividade para a produção de $\mathrm{N}_{2} \mathrm{O}$ e $\mathrm{N}_{2}[2,41]$.

Em metais de transição a energia de adsorção do NO é alta e não se observa NO na solução; já em cobre a energia de adsorção é menor e NO é observado na solução. Contudo, em eletrodos de $\mathrm{Cu}$ a produção de NO a partir da redução de nitrato em meio ácido aumenta com a corrente, mas não é observada a formação de $\mathrm{N}_{2} \mathrm{O}$. Isto é atribuído ao fato do eletrodo se dissolver nestas condições sendo que isso ocorre antes que o $\mathrm{NO}$ seja reduzido a $\mathrm{N}_{2} \mathrm{O}$ e este a $\mathrm{N}_{2}$ [2]. 
Já em catalisadores de paládio com uma monocamada de Cu é possível observar a redução de $\mathrm{NO}$ a $\mathrm{N}_{2} \mathrm{O}$, sendo que possivelmente o $\mathrm{Cu}$ cuida da rápida redução do nitrato a NO, liberando este na solução, e o paládio, que é o catalisador mais seletivo para a redução de $\mathrm{NO}$ e $\mathrm{N}_{2} \mathrm{O}$ a $\mathrm{N}_{2}$, atua quando o $\mathrm{NO}$ é liberado na solução [2, 45]. 


\section{OBJETIVOS}

O objetivo deste trabalho é estudar a reação de redução de nitrato em eletrodos de $\mathrm{Pt}(\mathrm{hkl})$ com e sem a presença de multicamadas de paládio. A caracterização da atividade catalítica dos diferentes materiais frente à reação de interesse foi efetuada por meio da técnica de voltametria cíclica. Por outro lado, os mecanismos reacionais foram investigados com ajuda da caracterização dos intermediários por meio de espectroscopia de infravermelho com transformada de Fourier (FTIR), tanto utilizando água como água deuterada como solvente.

Os estudos foram iniciados com a utilização de nanopartículas de Pt, Pd e Pt com uma monocamada de Pd, mas a dificuldade em sugerir um mecanismo nesse tipo de eletrodo levou à utilização dos eletrodos monocristalinos, que tem a superfície muito bem conhecida. 


\section{PROCEDIMENTO EXPERIMENTAL}

\subsection{Reagentes e Soluções}

As soluções foram preparadas a partir de ácido sulfúrico concentrado (suprapuro, Merck), sulfato de paládio (p.a., Sigma-Aldrich), nitrito de sódio (p.a., Sigma-Aldrich), nitrato de sódio (p.a., Synth) ou nitrato de potássio (suprapuro, Merck) e água ultra-pura (Elga-Vivendi ou Milli $\mathrm{Q}, 18,2 \mathrm{M} \Omega \mathrm{cm}$ ). Foi utilizada a concentração de $0,1 \mathrm{M}$ de $\mathrm{H}_{2} \mathrm{SO}_{4}, \mathrm{HClO}_{4}$ e nitrato $\left(\mathrm{KNO}_{3}\right.$ ou $\left.\mathrm{NaNO}_{3}\right)$. As soluções foram desoxigenadas com Argônio (5N, Air Liquide).

A célula e toda a vidraria foram limpas pela sua imersão numa solução de permanganato de potássio por 12 h, seguido por enxágüe com uma solução de peróxido de hidrogênio e ácido sulfúrico. Finalmente, tudo foi enxaguado repetidamente e fervido com água ultra-pura.

\subsection{Eletrodos}

\subsubsection{Nanopartículas}

Os eletrodos de camada ultra fina foram preparados a partir de catalisadores comerciais $\mathrm{E}^{-} \mathrm{TEK}^{\circledR}$ com $20 \%$ de Pt dispersos em carbono Vulcan e $20 \%$ de $\mathrm{Pd}$ 
dispersos em carbono Vulcan, com tamanho médio de partículas em torno de 2,68 e $3,64 \mathrm{~nm}$, respectivamente ${ }^{1}$.

Foram preparadas suspensões dos catalisadores em água, com concentração de $1 \mathrm{mg} / \mathrm{mL}$. Para a preparação dos eletrodos foram depositados $14 \mu \mathrm{L}$ da suspensão em um eletrodo de carbono vítreo de $0,196 \mathrm{~cm}^{2}$ de área. Depois de seco foram depositados $14 \mu \mathrm{L}$ de solução $0,05 \mathrm{M}$ de Nafion $^{\circledR}$ para evitar que o catalisador se desprendesse.

Para o depósito de paládio em platina, no caso das nanopartículas, o método eletroquímico, que forma uma camada mais ordenada, não pode ser usado uma vez que o Pd também se deposita no carbono, tendo sido, portanto, usado o método de deslocamento galvânico de uma monocamada de Cu. Para este procedimento foi utilizada uma célula eletroquímica de multi-compartimentos e atmosfera controlada de argônio. Em um eletrodo preparado com a suspensão de nanopartículas de Pt foi depositada uma monocamada de cobre em regime de subtensão (UPD, UnderPotential Deposition) [19], em solução de $\mathrm{CuSO}_{4} 10^{-3} \mathrm{M} \mathrm{em} \mathrm{H}_{2} \mathrm{SO}_{4}$ 0,1 M. O eletrodo, já com a monocamada de $\mathrm{Cu}$, foi enxaguado e colocado em contato com uma solução $10^{-3} \mathrm{M}$ de $\mathrm{PdSO}_{4}$ em $0,1 \mathrm{M}$ de $\mathrm{H}_{2} \mathrm{SO}_{4}$, para que $0 \mathrm{Pd}^{2+}$ deslocasse galvanicamente o cobre e formasse assim a monocamada de paládio [33, 34]. Depois de enxaguado, o eletrodo estava pronto para ser usado.

\footnotetext{
${ }^{1}$ BARRETA, L. F. N. Dissertação (Mestrado). Instituto de Química de São Carlos, Universidade de São Paulo, São Carlos. Em fase de elaboração, 2009.
} 


\subsubsection{Monocristais}

Os monocristais foram preparados de acordo com o método de Clavilier [31]. Este método utiliza um monocristal, obtido pela fundição (utilizando chama de propano e oxigênio) da extremidade de um fio de platina $(99,99 \%)$ formando uma gota que, quando se esfria lentamente, adquire a forma de um monocristal esférico.

O monocristal é então posicionado com o auxílio de um goniômetro com quatro eixos de rotação e de um feixe de laser que, refletindo no monocristal, permite a localização das faces (111) e (100) deste. Uma vez posicionado, o eletrodo é fixado (com uma resina epóxi), cortado e polido por uma lixa perpendicular ao laser. O polimento final é feito com uma pasta de partículas de diamante com diâmetros entre $6 \mu \mathrm{m}$ e 0,25 $\mu \mathrm{m}$ [11].

O eletrodo obtido possui uma superfície plana, circular, com área entre 3 e $4 \mathrm{~mm}^{2}$ e orientada com uma precisão de 3'. Neste trabalho foram utilizadas as faces de baixo índice de Miller (Pt(111), $\mathrm{Pt}(100)$ e $\mathrm{Pt}(110))$ conforme apresentado na Figura 1.

Antes de cada experimento o monocristal foi tratado termicamente em uma chama de butano, fornecida por um bico de Bunsen comum, por cerca de um minuto, para eliminar as espécies adsorvidas no eletrodo e ordenar os átomos da platina. Após este período o eletrodo foi esfriado em um tratamento de $\mathrm{Ar}+\mathrm{H}_{2}$ e então mergulhado em água saturada com essa mistura de gases. Uma gota de água foi mantida no eletrodo para a transferência deste do tratamento para a célula eletroquímica, com a finalidade de proteger o eletrodo da adsorção de impurezas. 


\subsection{Estudos Eletroquímicos}

A célula eletroquímica utilizada para os experimentos continha quatro entradas, sendo uma central para o eletrodo e outras laterais para o "Luggin", que continha o Eletrodo Reversível de Hidrogênio (fio de platina platinizado, em contato com o eletrólito, com $\mathrm{H}_{2}$ borbulhado ou gerado), para o borbulhador de $\mathrm{Ar}$ e para o contra-eletrodo (fio de platina). O eletrodo de trabalho foi posicionado na célula formando um menisco para que somente o plano desejado estivesse em contato com o eletrólito.

As medidas foram feitas utilizando-se um potenciostato "Princeton Applied Research" (modelo 362) ou um potenciostato modelo "microAutolab".

\subsubsection{Redução de nitrato}

Antes do estudo da reação de redução do nitrato, os eletrodos foram tratados termicamente (no caso dos monocristais) e ciclados até estabilização do voltamograma. No caso dos eletrodos modificados por paládio, em outra célula, foi feito o depósito como escrito na seção 3.3 .3 e, posteriormente, um novo voltamograma foi registrado numa célula livre de paládio. Nesta mesma célula, mantendo o eletrodo suspenso na atmosfera controlada da célula, foi adicionada a quantidade de $\mathrm{KNO}_{3}$ ou $\mathrm{NaNO}_{3}$ suficiente para uma concentração final de $0,1 \mathrm{M}$ de $\mathrm{NO}_{3}{ }^{-}$, borbulhando $\mathrm{Ar}$ até que todo o sal estivesse dissolvido.

$\mathrm{O}$ contato do eletrodo com a solução de nitrato foi em $0,7 \mathrm{~V}$ ou potenciais mais positivos, para evitar a formação de espécies. Realizou-se a varredura de 
potenciais até $0,06 \mathrm{~V}$ e depois até o limite superior, sendo o ciclo encerrado no mesmo potencial do contato.

\subsubsection{Redução de NO}

O estudo da redução de $\mathrm{NO}$ adsorvido pode ser útil para determinar o mecanismo de reação da redução do nitrato, uma vez que o NO pode ser um dos produtos formados e/ou um intermediário para a formação de $\mathrm{N}_{2}$ [1, 2], além de estar envolvido no processo de redução em platina [41, 42].

Para estudar a redução do NO, utilizou-se uma camada saturada adsorvida, formada pela imersão do eletrodo em uma solução de $\mathrm{NaNO}_{2}[46,47]$, em circuito aberto. A solução utilizada foi $1 \times 10^{-2} \mathrm{M}$ e o tempo de imersão foi de 2 a 3 minutos. A formação do NO pode ser descrita pelo processo apresentado na Equação 13 [48]:

$3 \mathrm{HNO}_{2} \leftrightarrows \mathrm{NO}_{3}{ }^{-}+2 \mathrm{NO}_{(\text {ads })}+\mathrm{H}_{3} \mathrm{O}^{+}$ (Equação 13)

O eletrodo foi então enxaguado e levado para a célula eletroquímica, sendo o contato do eletrodo com o eletrólito $\left(\mathrm{H}_{2} \mathrm{SO}_{4} 0,1 \mathrm{M}\right)$ feito em $\mathrm{E}=0,7 \mathrm{~V}$. A velocidade de varredura foi de $2 \mathrm{mVs}^{-1}$, para que todos os processos envolvidos pudessem ser vistos [42, 49].

\subsubsection{Depósito de paládio em monocristais de Pt}

Foi utilizado o método eletroquímico para efetuar a deposição de paládio em $\mathrm{Pt}$, buscando multicamadas. Neste método, o eletrodo de platina é normalmente 
tratado, conforme descrito na seção 3.2.1, e levado à célula eletroquímica com $0,1 \mathrm{M}$ de $\mathrm{H}_{2} \mathrm{SO}_{4}$, para verificação do perfil voltamétrico. Uma vez confirmado que o eletrodo está bem orientado e o sistema limpo, é feita a adição de $\mathrm{PdSO}_{4}$ ao eletrólito suporte, em baixa concentração (entre $2,5 \times 10^{-6}$ e $5,85 \times 10^{-6} \mathrm{M}$ ), e são feitos vários ciclos, entre 0,06 e 0,8 V, observando-se a mudança no perfil voltamétrico do eletrodo.

Para os casos da $\mathrm{Pt}(111)$ e $\mathrm{Pt}(100)$, a primeira camada de paládio apresenta picos em potenciais diferentes daqueles da Pt e a segunda possui picos em potenciais diferentes dos dois anteriores, o que permite saber quando o depósito cobriu totalmente a platina e quando houve a deposição da primeira camada de paládio [28, 30, 36-40].

Já para a Pt(110) o depósito de paládio não apresenta picos bem definidos, nem estes estão em potenciais diferentes dos da Pt. Ou seja, tanto a primeira camada, como as camadas seguintes, são difíceis de serem identificadas, além do que o perfil voltamétrico não apresenta grandes variações em função da quantidade de paládio depositada [28, 36, 38]. A metodologia desenvolvida para a determinação da cobertura de paládio em $\mathrm{Pt}(110)$ será descrita posteriormente, na seção 4.

\subsubsection{Carga deslocada por CO}

Esta técnica foi utilizada no estudo do depósito de paládio em $\operatorname{Pt}(110)$. Consiste na dosagem de $\mathrm{CO}$ próximo à superfície do eletrodo, a um potencial constante. Devido ao fato de as moléculas de CO se adsorverem muito fortemente nos metais do grupo da platina, este desloca qualquer outra espécie iônica que estiver adsorvida no eletrodo, gerando uma reação de transferência de carga oposta 
à gerada no processo de adsorção dessas espécies. Assim, durante a adsorção do CO, uma corrente flui através do circuito, decaindo a zero quando a superfície do eletrodo está completamente bloqueada pelo CO. A carga obtida pela integração dessa corrente está relacionada à quantidade e à carga das espécies adsorvidas na superfície do eletrodo $[25,30,37,50]$.

A técnica é especialmente útil para se identificar o potencial no qual a carga deslocada é zero, conhecido como "potencial de carga total zero" [25, 30, 37]. Este potencial pode ser obtido subtraindo a carga deslocada da integral da corrente voltamétrica $(j(E))$, conforme descreve a Equação 14:

$q(E)=\int_{E_{c o}}^{E} \frac{|j(E)|}{v} \mathrm{~d} E-q_{\operatorname{dis}\left(E_{c o}\right)}$

onde $E_{C O}$ é o potencial no qual o deslocamento de $C O$ é feito, $v$ é a velocidade de varredura e $q_{d i s\left(E_{C O}\right)}$ a carga deslocada pelo CO no potencial $E_{C O}$. Os valores de $q(E)$ negativos podem ser definidos como correspondentes ao processo de adsorção de hidrogênio, conforme descrito na Equação 15, enquanto os valores positivos são referentes ao processo de adsorção oxidativa de ânions (Equação 16) [37].

$$
\begin{aligned}
& \mathrm{Pt}(110)+\mathrm{H}_{3} \mathrm{O}^{+}+\mathrm{e}^{-} \rightarrow \mathrm{Pt}(110)-\mathrm{H}+\mathrm{H}_{2} \mathrm{O} \\
& \mathrm{Pt}(110)+\mathrm{A}^{\mathrm{Z}}+\rightarrow \mathrm{Pt}(110)-\mathrm{A}^{\mathrm{n-z}}+\mathrm{ne}^{-}
\end{aligned}
$$

O potencial no qual ocorre a inversão de sinal da carga, ou seja, quando a carga for igual a zero, é definido como "potencial de carga total zero", pctz. 
O mesmo sistema descrito na seção 3.3 foi utilizado para os experimentos de deslocamento por $\mathrm{CO}$. Um tubo de vidro foi utilizado para auxiliar a dosagem de $\mathrm{CO}$ próximo ao eletrodo e o eletrólito usado foi $\mathrm{H}_{2} \mathrm{SO}_{4}$ 0,1 M. O eletrodo foi polarizado e, com o monitoramento da corrente, $\mathrm{CO}$ foi dosado na célula, bem próximo ao eletrodo. Foi mantido o fluxo de $\mathrm{CO}$ até que a corrente fosse zero, indicando que o $\mathrm{CO}$ não estava mais adsorvendo no eletrodo. A carga gerada pela adsorção do CO foi utilizada para a determinação da quantidade de espécies adsorvidas na superfície do eletrodo neste determinado potencial.

\subsubsection{Oxidação de CO}

Após da adsorção de CO durante o deslocamento por CO, o sistema foi limpo deste contaminante borbulhando argônio na solução durante 15 minutos, com o eletrodo mergulhado para evitar contaminação. Após esse período, o potencial foi variado a partir do qual foi feita a adsorção do $\mathrm{CO}$ até um valor em que todo o $\mathrm{CO}$ estivesse oxidado.

Este estudo foi usado para entender a mudança na força de interação CO-metal em função do aumento da cobertura de Pd.

\subsection{Estudos Espectroscópicos de Infravermelho in situ}

Os estudos de FTIR foram realizados utilizando um espectrômetro Nicolet Magna 850 equipado com um detector MCT. A célula espectroeletroquímica utilizada possuía uma janela prismática de $\mathrm{CaF}_{2}$ com ângulo de $60^{\circ}$. Um fio de platina foi utilizado com contra eletrodo e um eletrodo reversível de hidrogênio $(E R H)$ como 
referência. Os experimentos foram realizados com a configuração de camada fina (o eletrodo foi pressionado contra o prisma deixando somente uma camada fina de solução entre o eletrodo e o prisma) e temperatura ambiente.

Os espectros apresentados nesta tese, salvo quando mencionado, são compostos por 200 interferogramas coletados com resolução de $4 \mathrm{~cm}^{-1}$. São apresentados como absorbâncias, de acordo com $A=-\log \left(R / R_{0}\right)$ onde $R$ e $R_{0}$ são as reflectâncias correspondentes ao espectro de "single beam" obtidos nos potenciais da análise e de referência, respectivamente. $O$ espectro de referência $\left(R_{0}\right)$ foi coletado a $0,9 \mathrm{~V}$, logo depois do contato do eletrodo com a solução de nitrato neste mesmo potencial, evitando o acúmulo de espécies adsorvidas que podem ser formadas em potenciais mais baixos e, uma vez formadas, são difíceis de serem removidas. O potencial foi baixado de $50 \mathrm{em} 50 \mathrm{mV}$ e os outros espectros foram coletados nos potenciais de interesse (R). As espécies consumidas durante 0 processo aparecem como bandas negativas e as produzidas como bandas positivas. Bandas bipolares são espécies presentes tanto no potencial de referência como no potencial de medida, mas que apresentam variação da frequência vibracional com a variação do potencial.

Para melhor identificação dos produtos obtidos foram feitos espectros de ATR (Attenuated Total Reflectance - Reflectância Total Atenuada) das espécies esperadas na reação. Foi utilizado um prisma de SeZn, com um ângulo de incidência de $45^{\circ}$. Foram utilizadas soluções $0,1 \mathrm{M}$ de $\mathrm{KNO}_{3}, \mathrm{NaNO}_{2}, \mathrm{NH}_{4} \mathrm{Cl}, \mathrm{HONH}_{2} \cdot \mathrm{HCl}$, $\mathrm{H}_{2} \mathrm{SO}_{4}$ e $\mathrm{HClO}_{4}$ em água. $\mathrm{O}$ espectro da água foi usado como background $\left(\mathrm{R}_{0}\right)$. Neste caso os espectros são compostos por 100 interferogramas coletados com resolução de $8 \mathrm{~cm}^{-1}$. Os resultados são apresentados na Figura 2. Estes resultados são usados como referência ao longo deste trabalho. 


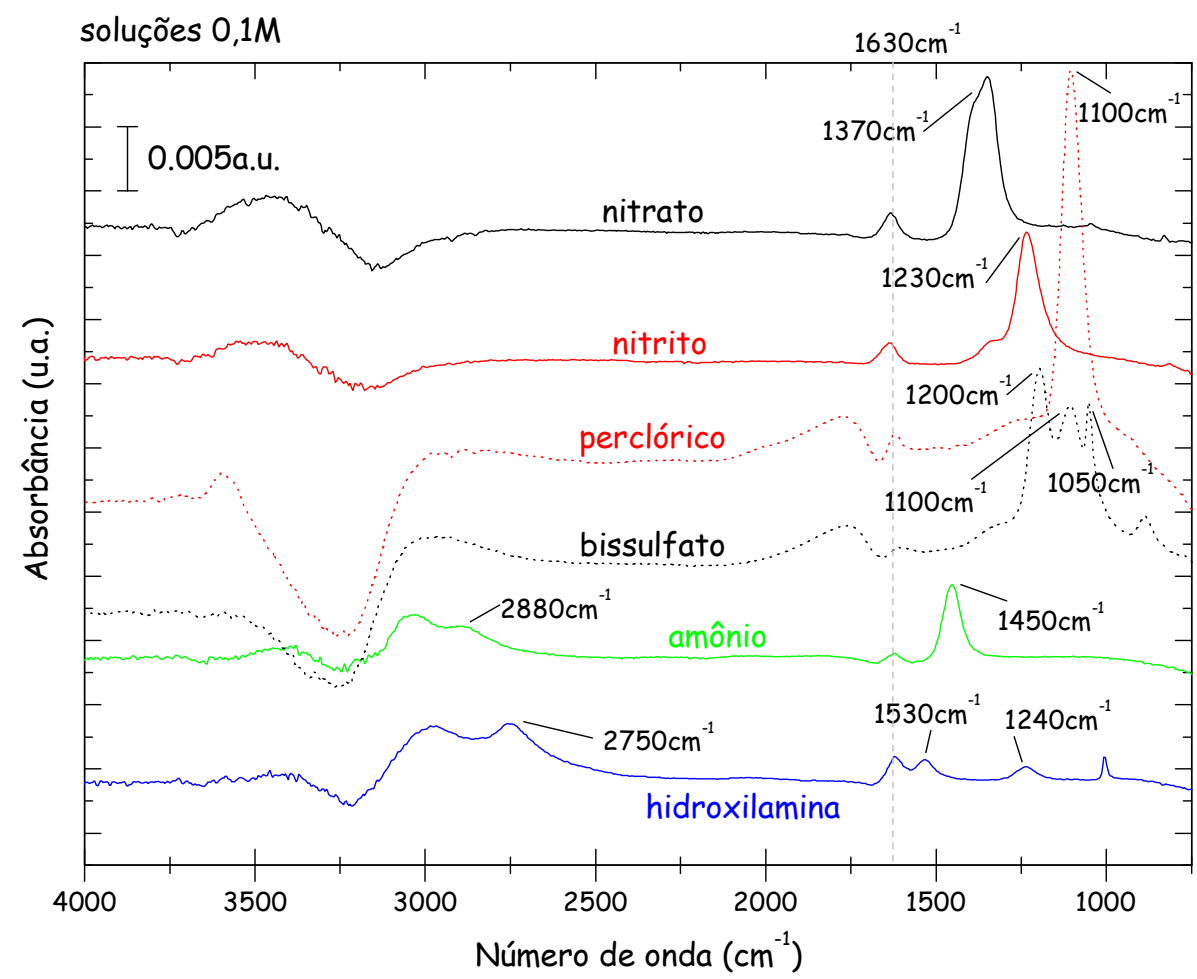

Figura 2: FTIR - ATR das espécies envolvidas na reação de redução do nitrato. Espectros compostos por 100 scans com resolução de $8 \mathrm{~cm}^{-1}$. Luz "p". Background: espectro da água. 


\section{RESULTADOS E DISCUSSÃO}

Foram feitos experimentos sobre a redução de nitrato em nanopartículas de $\mathrm{Pt}$, Pd e Pt com uma monocamada de Pd e em eletrodos monocristalinos de platina (Pt(111), Pt(100) e Pt(110)) com e sem multicamadas de paládio.

\subsection{Eletrorredução de nitrato em nanopartículas de $\mathrm{Pt}, \mathrm{Pd}$ e $\mathrm{Pt}$ com monocamada de Pd}

Nas Figuras 3 e 4 são apresentados os voltamogramas cíclicos para os eletrodos nanoparticulados de $\mathrm{Pt} / \mathrm{C}$ e $\mathrm{Pd} / \mathrm{C}$ na ausência e na presença de nitrato. $\mathrm{Na}$ Figura 3 são observados dois picos voltamétricos de redução na varredura negativa, em 0,21 e $0,12 \mathrm{~V}$, e um na varredura positiva, em $0,26 \mathrm{~V}$. Os resultados mostram que as nanopartículas de Pt possuem as maiores correntes de redução, com valor maior no primeiro ciclo. Observa-se um pico em $0,65 \mathrm{~V}$ que está provavelmente relacionado à redução de óxidos térmicos, o que daria lugar a um primeiro ciclo diferente dos demais, uma vez que a platina se reorganiza de outra maneira para o ciclo seguinte. A partir do segundo ciclo o eletrodo se apresenta um pouco bloqueado, possivelmente devido a algum produto formado no primeiro ciclo que não se reduz completamente ou dessorve.

As nanopartículas de $\mathrm{Pd}$ (Figura 4) apresentam um único pico de redução localizado em 0,08 V. Assim como a Pt, o voltamograma apresenta uma corrente de 
redução maior no primeiro ciclo, sendo o decaimento depois disto mais pronunciado neste caso. A corrente do primeiro ciclo é comparável à obtida com as nanopartículas de $\mathrm{Pt}$, mas com a redução se iniciando em potenciais menos positivos. A partir do segundo ciclo o eletrodo se mostra fortemente bloqueado e uma corrente de redução muito baixa é observada.

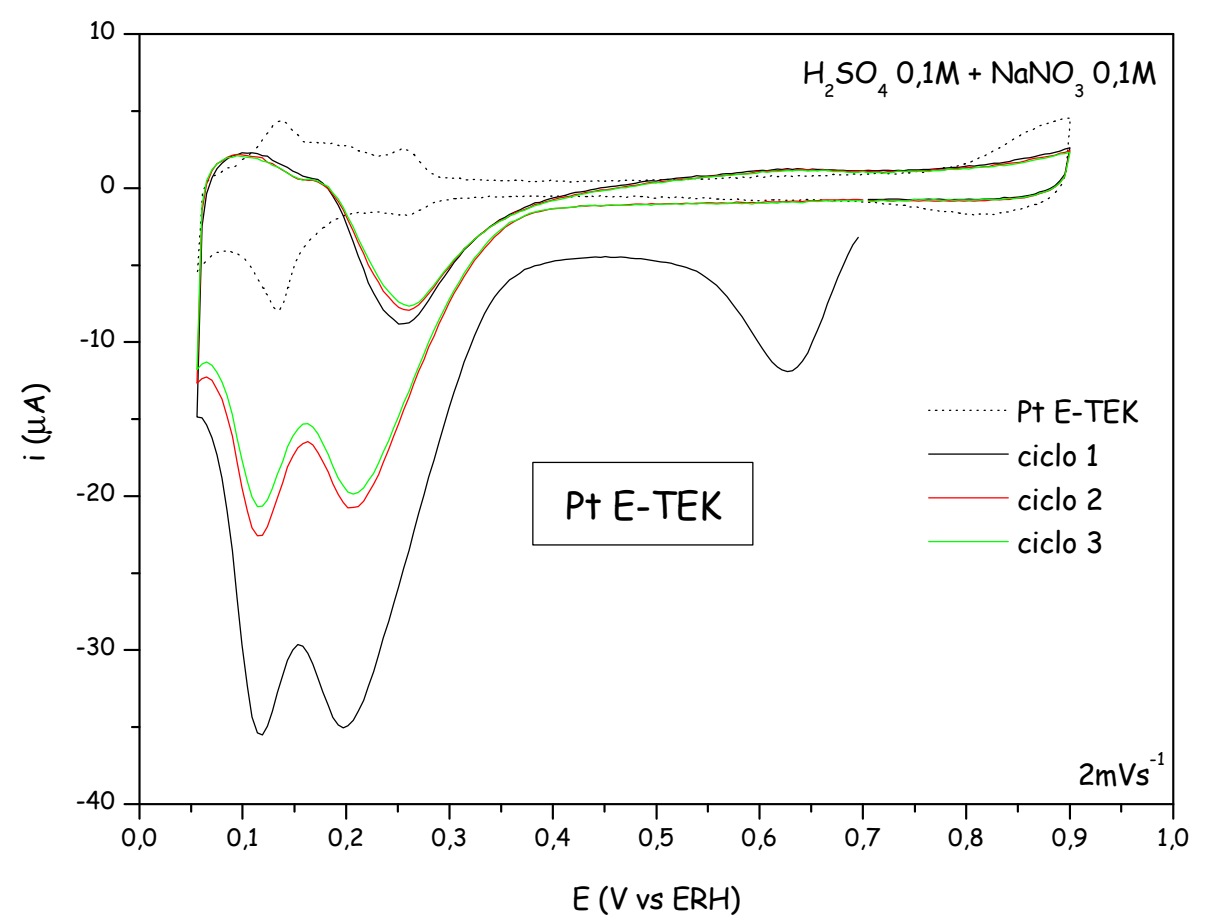

Figura 3: Redução de nitrato em Pt ETEK. Velocidade de varredura: $2 \mathrm{mVs}^{-1}$. Curva pontilhada: branco sem nitrato. Concentração de nitrato: $0,1 \mathrm{M}$ de $\mathrm{NaNO}_{3}$. 


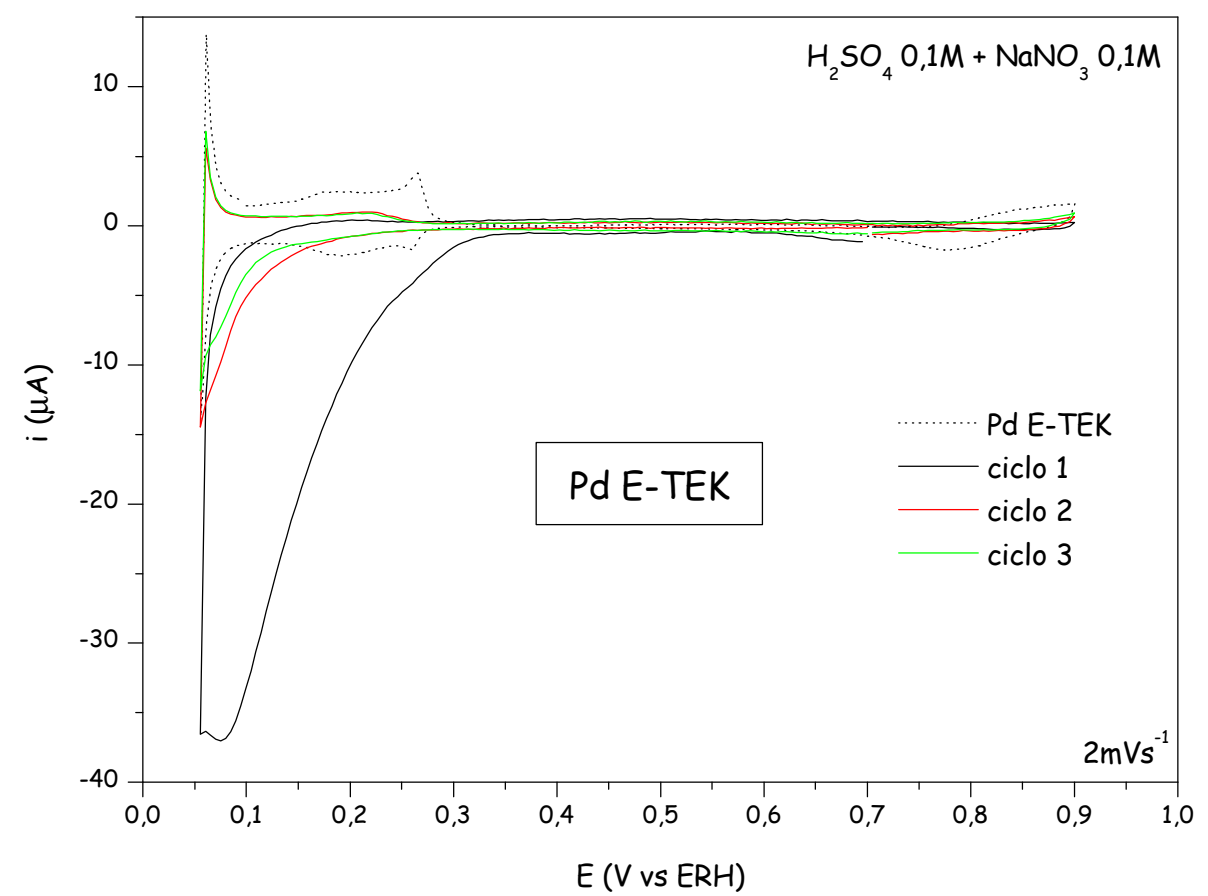

Figura 4: Redução de nitrato em Pd E-TEK. Velocidade de varredura: $2 \mathrm{mVs}^{-1}$. Curva pontilhada: branco sem nitrato. Concentração de nitrato: $0,1 \mathrm{M}$ de $\mathrm{NaNO}_{3}$.

Estudos anteriores indicam que eletrocatalisadores de paládio são mais seletivos para a produção de $\mathrm{N}_{2}$ e $\mathrm{N}_{2} \mathrm{O}$ que os de platina [4, 41], mas frente ao maior bloqueio das nanopartículas de paládio em relação às de platina mostrado nas Figuras 3 e 4, é preciso estudar outra opção para utilizar o paládio como eletrocatalisador dessa reação. O depósito de paládio em platina pode ser uma opção, uma vez que em depósitos finos, como o de uma única monocamada, o metal da superfície sofre influência do metal que compõe o substrato e a união das propriedades destes dois metais (neste caso, Pt e Pd) pode melhorar a atividade [4] ou a seletividade do catalisador.

A Figura 5 mostra o voltamograma cíclico em $\mathrm{H}_{2} \mathrm{SO}_{4} \quad 0,1 \mathrm{M}$ dos eletrodos preparados com nanopartículas de Pt, Pd e Pt com monocamada de Pd a $50 \mathrm{mVs}^{-1}$. Nota-se que após o depósito da monocamada de Pd, os picos da Pt diminuem, mas 
o perfil voltamétrico ainda é diferente daquele apresentado pelas nanopartículas de

Pd. Como somente uma camada de paládio foi depositada na platina, o resultado final contém contribuição dos dois metais, por isso a diferença em relação ao metal separado.

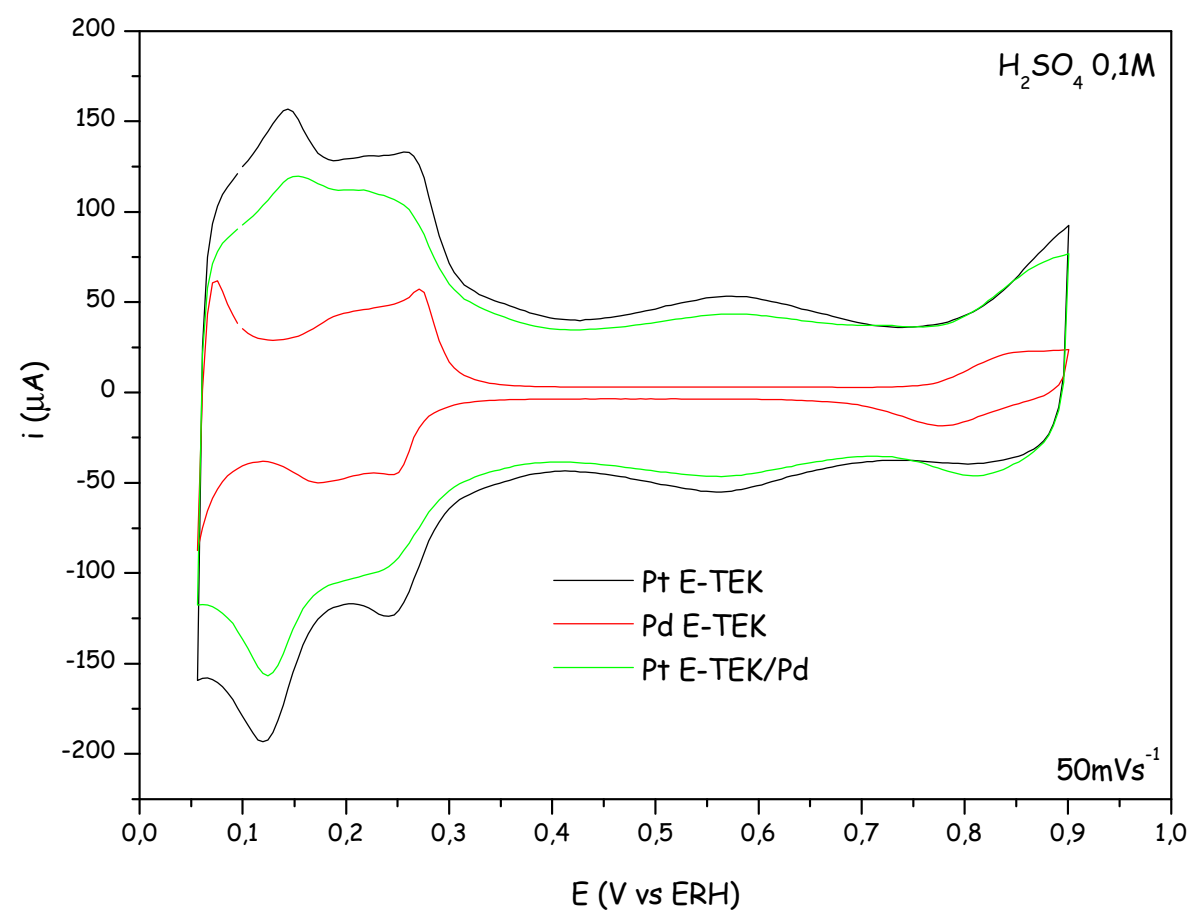

Figura 5: Voltamogramas de nanopartículas comerciais (E-TEK) de Pt, Pd e Pt com monocamada de Pd. Eletrólito suporte: $0,1 \mathrm{M} \mathrm{H}_{2} \mathrm{SO}_{4}$. Velocidade de varredura: $50 \mathrm{mVs}^{-1}$. 


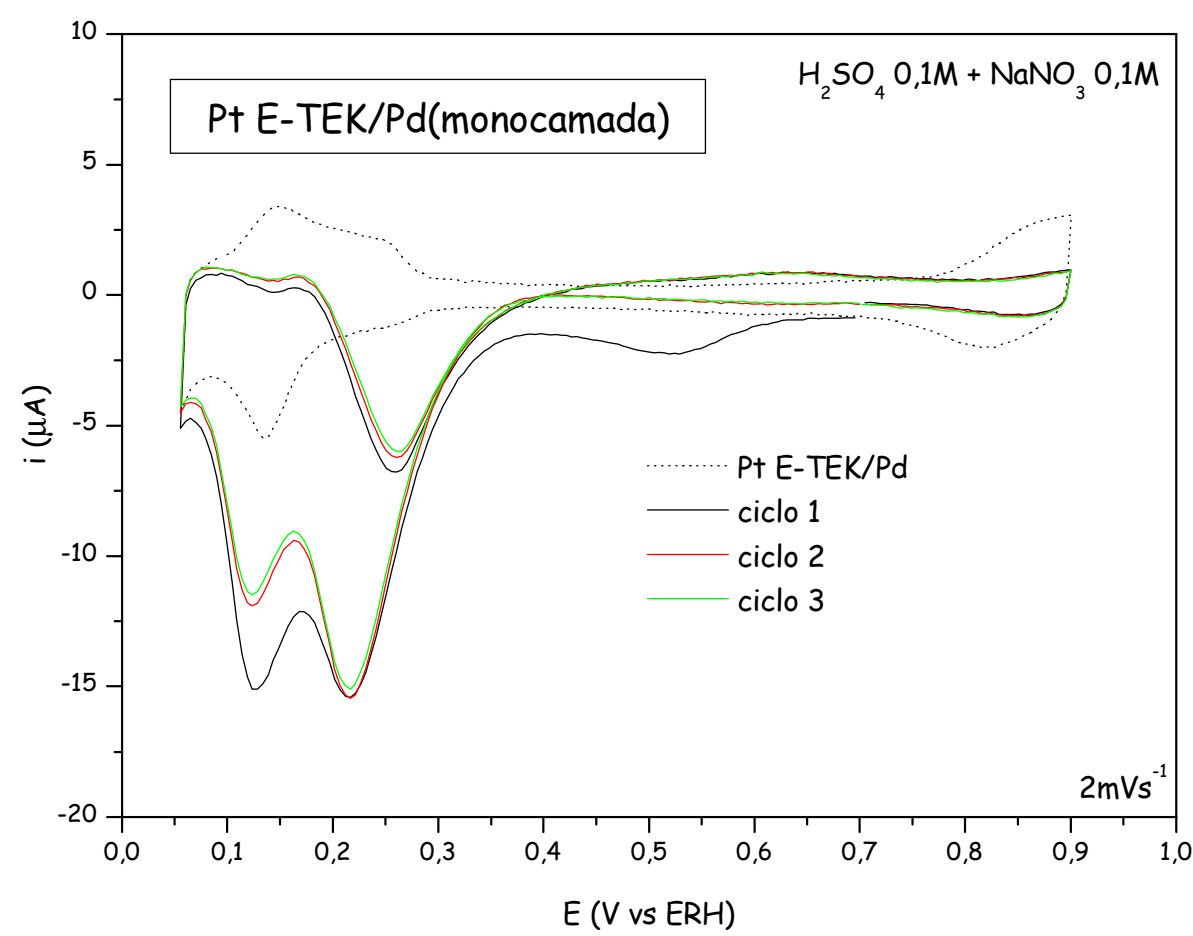

Figura 6: Redução de nitrato em Pt ETEK com uma monocamada de Pd. Velocidade de varredura: $2 \mathrm{mVs}^{-1}$. Curva pontilhada: branco sem nitrato. Concentração de nitrato: $0,1 \mathrm{M}$ de $\mathrm{NaNO}_{3}$.

Os voltamogramas de redução de nitrato no eletrodo de nanopartículas de $\mathrm{Pt}$ com monocamada de Pd são mostrados na Figura 6. O perfil é muito parecido com o das nanopartículas de platina, inclusive com os mesmos picos de redução, mas com correntes de redução menores. Isso mostra a contribuição da platina na atividade deste catalisador e a grande diferença em relação a catalisadores de Pd puro. Diferente do que foi reportado por Gootzen et al. [4], que observaram que eletrodos de Pt com subcamadas de Pd se mostraram mais ativos para a redução de nitrato que eletrodos de Pt ou Pd, as nanopartículas de Pt com uma monocamada de Pd apresentaram uma atividade menor que de nanopartículas de Pd e de Pt.

Para estudar mais detalhadamente o mecanismo de reação, um estudo utilizando monocristais como eletrocatalisadores da reação de redução de nitrato foi feito e os resultados são apresentados na seção seguinte. 


\subsection{Eletrorredução de nitrato em eletrodos monocristalinos de Platina}

O estudo da eletrorredução de nitrato em eletrodos de platina já é bastante conhecido na literatura [1-3, 51-53], mas são aqui apresentados para melhor comparação com os resultados dos eletrodos de paládio.

As Figuras 7, 8 e 9 mostram os voltamogramas para a eletrorredução de nitrato em $\mathrm{Pt}(111), \operatorname{Pt}(100)$ e $\mathrm{Pt}(110)$, respectivamente. A redução de nitrato foi feita

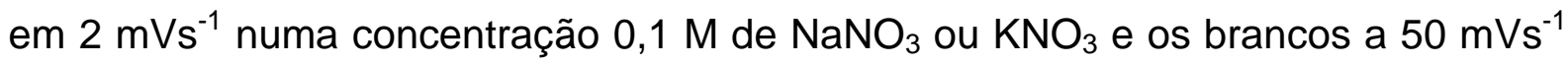
em cujo caso as corrente foram divididas por 25 para comparação com as curvas de redução de nitrato. Os resultados, tanto em $\mathrm{H}_{2} \mathrm{SO}_{4}$ (Figuras 7a, 8a e 9a) como em $\mathrm{HClO}_{4}$ (Figuras 7b, 8b e 9b) estão de acordo com os apresentados por Dima et al. [51].

Para Pt(111) (Figura 7) três picos são observados: em 0,32 V e 0,15 V na varredura negativa e em $0,28 \mathrm{~V}$ na varredura positiva. De acordo com Dima et al. [51], a redução do nitrato passa por $\mathrm{NO}_{(\text {ads })}$ [49], com uma cobertura de aproximadamente $40 \%$ de recobrimento superficial de $\mathrm{NO}$ em $\mathrm{HClO}_{4}$. Em $\mathrm{H}_{2} \mathrm{SO}_{4}$ a cobertura é menor devido à co-adsorção de sulfato. Na varredura positiva nota-se que um processo da redução de nitrato inicia-se em torno de $0,2 \mathrm{~V}$, ou seja, quando a cobertura de hidrogênio diminui, indicando que a redução necessita de sítios livres para ocorrer [51]. 

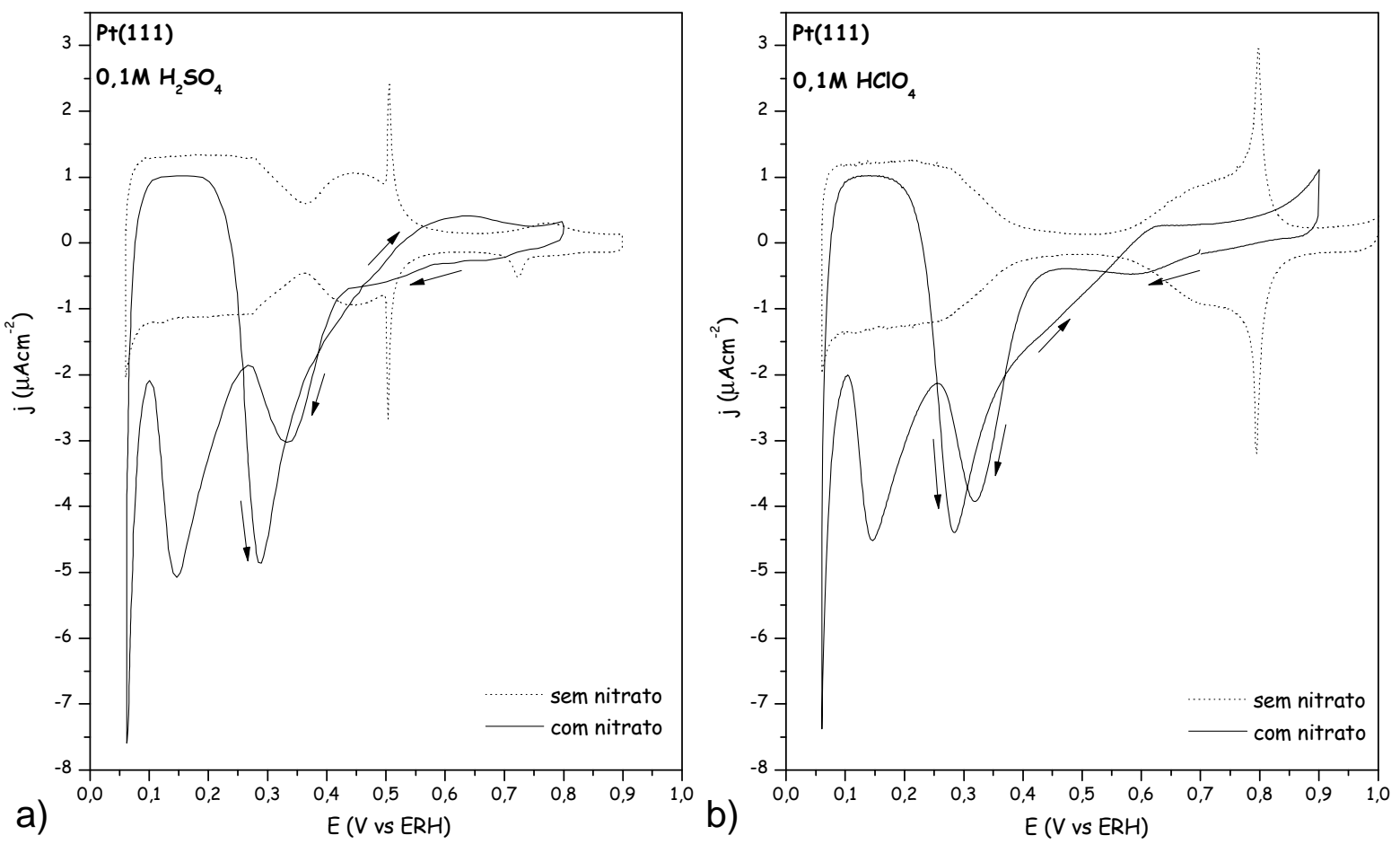

Figura 7: Voltamograma $\mathrm{Pt}(111)$ com (curva sólida) e sem (curva pontilhada) $0,1 \mathrm{M}$ de $\mathrm{NaNO}_{3}$ em solução. Eletrólito suporte $\mathrm{H}_{2} \mathrm{SO}_{4}$ (a) e $\mathrm{HClO}_{4}$ (b) $0,1 \mathrm{M}$; velocidade de varredura: $2 \mathrm{mVs}^{-1}$ para a redução de nitrato e $50 \mathrm{mVs}^{-1}$ para o branco (o branco foi dividido por 25 para comparação com a redução de nitrato).
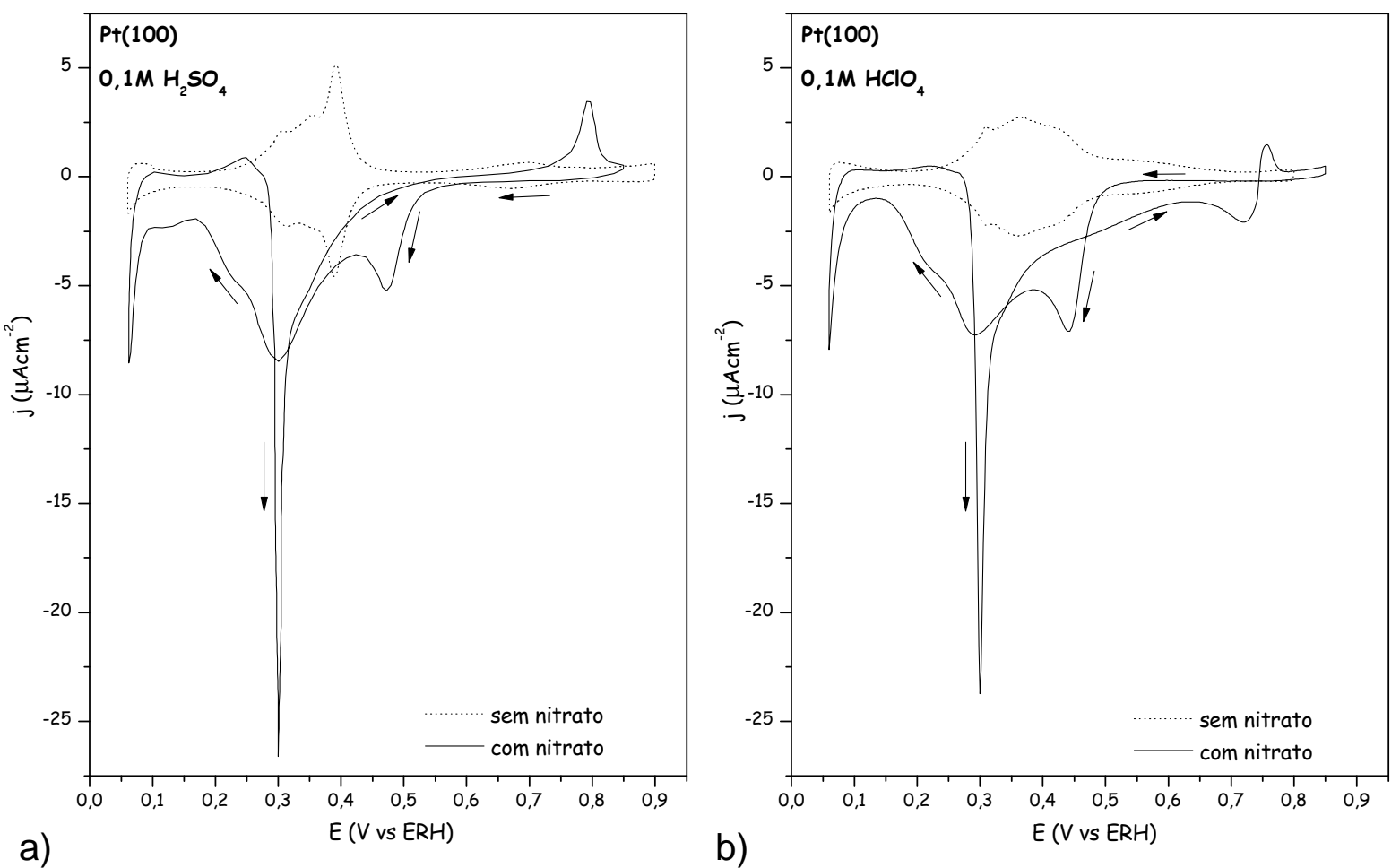

Figura 8: Voltamograma $\mathrm{Pt}(100)$ com (curva sólida) e sem (curva pontilhada) $0,1 \mathrm{M}$ de $\mathrm{NaNO}_{3}$ em solução. Eletrólito suporte $\mathrm{H}_{2} \mathrm{SO}_{4}$ (a) e $\mathrm{HClO}_{4}$ (b) $0,1 \mathrm{M}$; velocidade de varredura: $2 \mathrm{mVs}^{-1}$ para a redução de nitrato e $50 \mathrm{mVs}^{-1}$ para o branco (o branco foi dividido por 25 para comparação com a redução de nitrato). 
Em $\mathrm{Pt}(100)$, em ambos os eletrólitos, um pico afunilado aparece na varredura positiva, em 0,30 V (Figura 8), sendo este atribuído à redução de nitrato em defeitos da superfície e não em sítios (100), pois neste potencial a cobertura de hidrogênio na $\operatorname{Pt}(100)$ é de 0,75 monocamada, o que dificulta a adsorção e redução do nitrato [51]. Na varredura negativa dois picos podem ser observados em torno de $0,45 \mathrm{~V}$ tanto em $\mathrm{H}_{2} \mathrm{SO}_{4}$ (Figura 8a) como em $\mathrm{HClO}_{4}$ (Figura 8b), o que sugere uma pequena influência da co-adsorção de ânions na reação [51].

Os voltamogramas da redução de nitrato em $\mathrm{Pt}(110)$ são apresentados na Figura 9. Tanto em $\mathrm{H}_{2} \mathrm{SO}_{4}$ (Figura 9a) como em $\mathrm{HClO}_{4}$ (Figura 9b) verifica-se que o início da redução se dá a partir de $0,4 \mathrm{~V}$. O perfil voltamétrico da redução de nitrato em $\mathrm{H}_{2} \mathrm{SO}_{4}$ se caracteriza por um pico de redução em $0,12 \mathrm{~V}$, com um ombro em $0,15 \mathrm{~V}$, gerando uma corrente máxima cujo valor está em torno de $-65 \mu \mathrm{Acm}^{-2}$; outro pico de redução aparece em $0,16 \vee$ na varredura positiva, com uma corrente de $45 \mu \mathrm{Acm}^{-2}$. Este perfil também está de acordo com o obtido por Dima et al. [51]. Em $\mathrm{HClO}_{4}$ (Figura 9b) o perfil é muito parecido, com um pico em $0,16 \mathrm{~V}$ (varredura negativa) e outro em $0,17 \mathrm{~V}$ (varredura positiva), mas gerando correntes de redução muito maiores (420 $\mu \mathrm{Acm}^{-2}$ e $400 \mu \mathrm{Acm}^{-2}$, respectivamente). A carga de redução entre 0,5 e $0,06 \mathrm{~V}$ em $\mathrm{HClO}_{4}$ é cerca de $18500 \mu \mathrm{Ccm}^{-2}$, cerca de 6,5 vezes maior que a carga em $\mathrm{H}_{2} \mathrm{SO}_{4}$, que é de $2900 \mu \mathrm{Ccm}^{-2}$. Isso pode ser explicado pelo fato de a adsorção de $\mathrm{SO}_{4}{ }^{2-}$ competir com a adsorção de $\mathrm{NO}_{3}{ }^{-} \mathrm{e}$, como a adsorção de $\mathrm{ClO}_{4}{ }^{-}$ não é forte, este não compete com o $\mathrm{NO}_{3}{ }^{-}[2,41]$. 


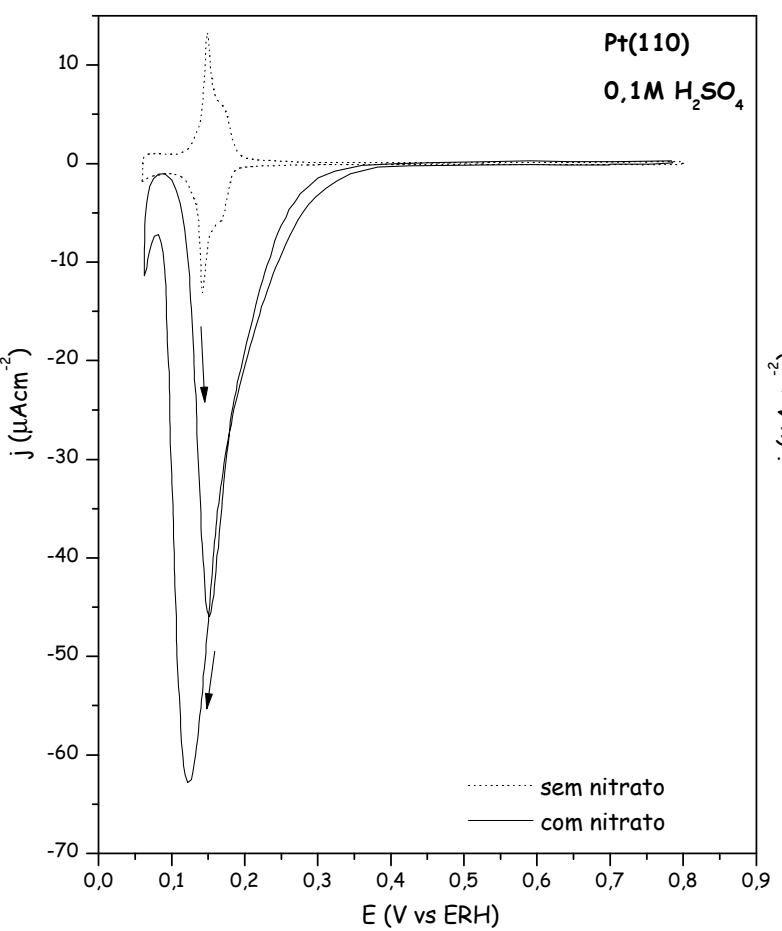

a)

a)

Figura 9: Voltamograma $\mathrm{Pt}(110)$ com (curva sólida) e sem (curva pontilhada) $0,1 \mathrm{M}$ de $\mathrm{NaNO}_{3}$ em solução. Eletrólito suporte $\mathrm{H}_{2} \mathrm{SO}_{4}$ (a) e $\mathrm{HClO}_{4}$ (b) $0,1 \mathrm{M}$; velocidade de varredura: $2 \mathrm{mVs}^{-1}$ para a redução de nitrato e $50 \mathrm{mVs}^{-1}$ para o branco (o branco foi dividido por 25 para comparação com a redução de nitrato).

Dima et al. [51] observaram que, em $\mathrm{H}_{2} \mathrm{SO}_{4}$, a $\mathrm{Pt}(110)$ não é ativa para a redução de nitrato em concentrações menores que $1 \mathrm{mM}$ de $\mathrm{NO}_{3}{ }^{-}$, enquanto que em $\mathrm{HClO}_{4}$, a $\mathrm{Pt}(110)$ é ativa mesmo nesta baixa concentração, sendo este fato explicado pela diferença entre a adsorção de $\mathrm{ClO}_{4}{ }^{-}$e a de $\mathrm{SO}_{4}{ }^{2-}$. Por FTIR, os autores conseguiram identificar somente a formação de $\mathrm{NO}_{(\text {ads) }}$ em todos os eletrodos, mas sugerem a formação de hidroxilamina em Pt(111) e amônio em todos os casos, uma vez que o produto da redução e $\mathrm{NO}_{(\text {ads) }}$ em platina é $\mathrm{NH}_{4}{ }^{+}$[49].

Neste trabalho foram feitos estudos por FTIR em $\mathrm{Pt}(111)$ para comprovar a formação de hidroxilamina e amônio a partir da redução de nitrato, mas somente 
este último, além de $\mathrm{NO}_{\text {(ads) }}$ foram observados. Os resultados em $\mathrm{HClO}_{4}$ e $\mathrm{H}_{2} \mathrm{O}$ podem ser observados na Figura 10. $O$ consumo de nitrato $\left(1370 \mathrm{~cm}^{-1}\right)$ é observado na varredura negativa a partir de $0,25 \mathrm{~V}$, que é inferior ao potencial de início de incremento da corrente de redução (Figura 7), provavelmente devido ao fato de o potencial ser baixado em saltos (de $50 \mathrm{em} 50 \mathrm{mV}$ ) e não continuamente como na varredura voltamétrica. Mesmo quando o potencial já retornou a $0,9 \vee$ ainda é possível ver a banda de consumo de nitrato, mas isso não significa que o nitrato esteja sendo consumido e sim que houve uma diminuição na concentração de nitrato na camada fina, devido à reação deste. A banda em $1250 \mathrm{~cm}^{-1}$ corresponde à vibração do $\mathrm{ClO}_{4}{ }^{-}$adsorvido que sofre pouca variação em função do potencial.

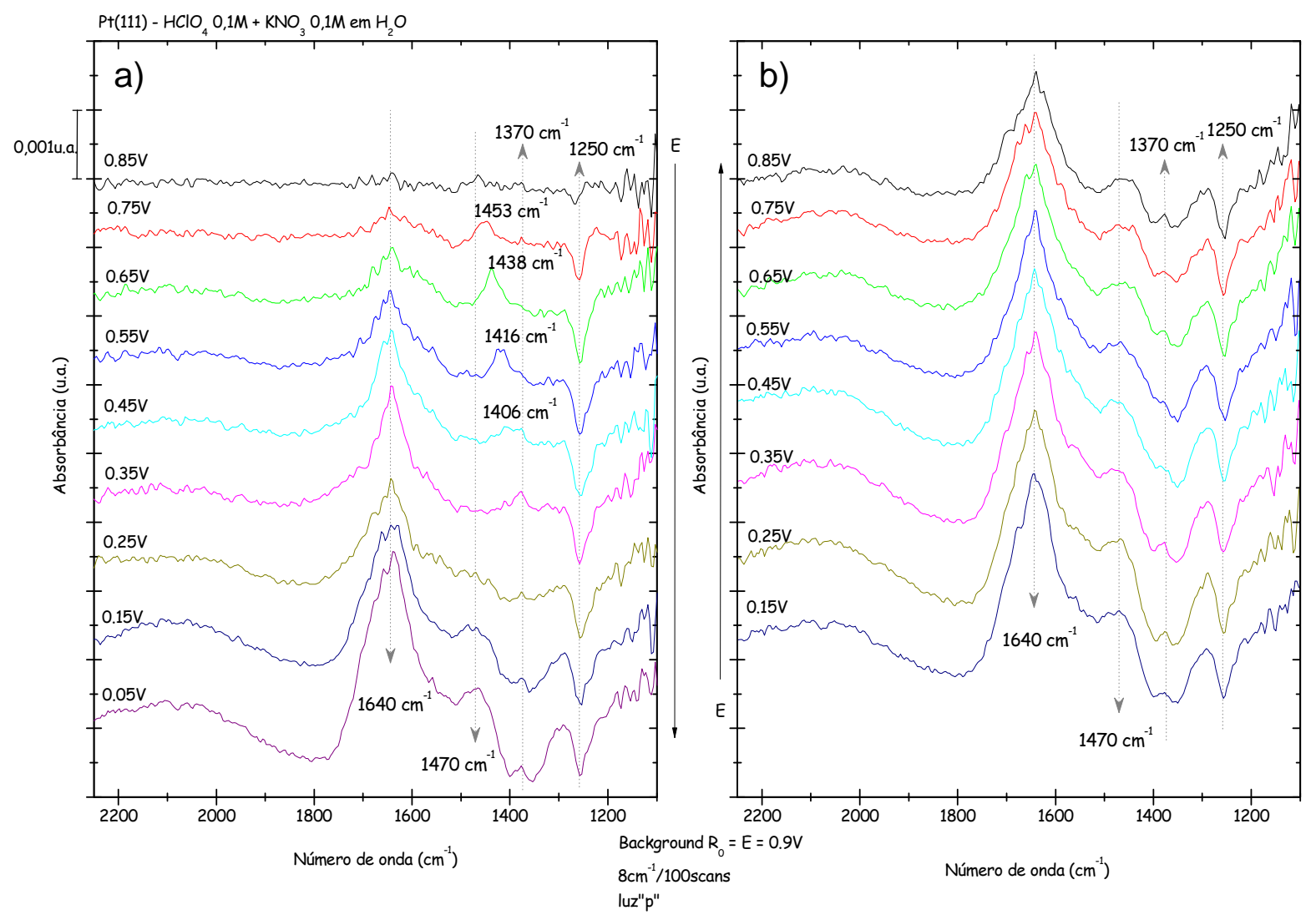

Figura 10: FTIR da redução de nitrato em $\mathrm{Pt}(111)$ em $\mathrm{HClO}_{4} 0,1 \mathrm{M}$ e $\mathrm{KNO}_{3} 0,1 \mathrm{M}$. (a) varredura negativa e (b) varredura positiva. Referência 0,9 V. Espectros compostos por 100 scans com resolução de $8 \mathrm{~cm}^{-1}$. Luz "p". 
A banda de água aparece em $1640 \mathrm{~cm}^{-1}$. As bandas positivas entre $1453 \mathrm{e}$ $1406 \mathrm{~cm}^{-1}$, que aparecem na varredura negativa entre 0,75 e $0,45 \mathrm{~V}$, podem ser atribuídas a alguma espécie adsorvida, provavelmente NO, que tem seu número de onda deslocado com a variação do potencial. A banda que aparece em $1470 \mathrm{~cm}^{-1}$, visível abaixo de $0,15 \mathrm{~V}$ e ao longo de toda a varredura positiva poderia ser atribuída à amônia, mas como o NO pode aparecer em vários números de onda diferentes, devido às diferentes formas de adsorção deste, um estudo em $\mathrm{D}_{2} \mathrm{O}$ foi feito para esclarecer a atribuição deste pico.

A Figura 11 apresenta o espectro de redução de nitrato em $\operatorname{Pt}(111)$ a $0,5 \mathrm{~V}$ em $\mathrm{H}_{2} \mathrm{SO}_{4}$ e $\mathrm{D}_{2} \mathrm{O}$. A banda em $1570 \mathrm{~cm}^{-1}$ pode ser atribuída a $\mathrm{NO}$, a de $1270 \mathrm{~cm}^{-1}$ é referente à vibração do $\mathrm{SO}_{4}^{-}$adsorvido. Já a de $1207 \mathrm{~cm}^{-1}$ pode, em princípio, ser confundida com a de $\mathrm{SO}_{4}{ }^{-}$, uma vez que o número de onda deste se desloca com o potencial e aparece como uma banda bipolar que, no entanto, fica entre 1270 e $1230 \mathrm{~cm}^{-1}$. Assim, esta banda é atribuída a $\mathrm{ND}_{4}{ }^{+}$que, segundo Nakamoto [54], aparece em torno de $1215 \mathrm{~cm}^{-1}$. Nenhuma banda que poderia ser atribuída à hidroxilamina foi observada nos espectros, tanto na Figura 10 como na Figura 11. 


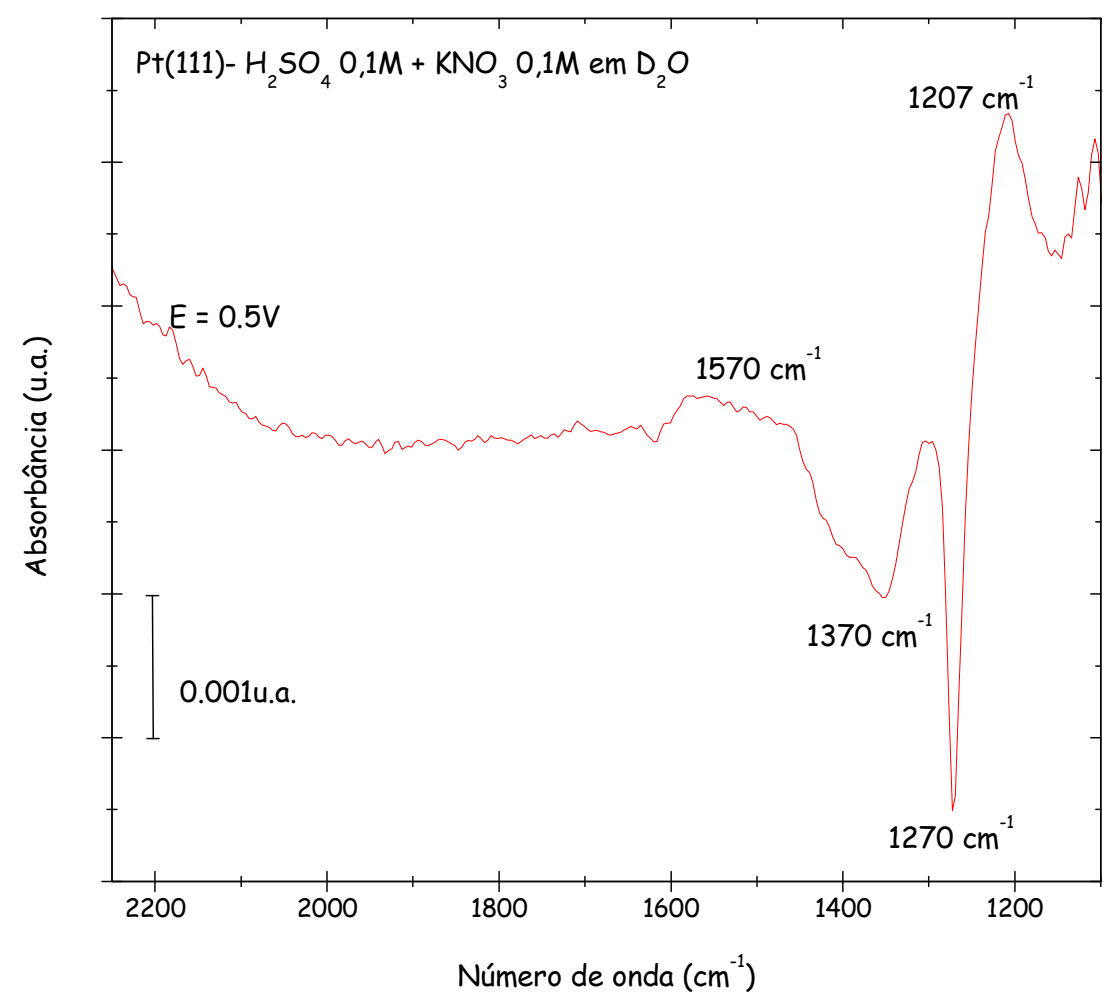

Figura 11: FTIR da redução de nitrato em $\mathrm{Pt}(111)$ em $\mathrm{H}_{2} \mathrm{SO}_{4} 0,1 \mathrm{M}+\mathrm{KNO}_{3} 0,1 \mathrm{M}$ em $\mathrm{D}_{2} \mathrm{O}$. Potencial $0,5 \mathrm{~V}$ (na varredura positiva) e referência $0,9 \mathrm{~V}$. Espectros compostos por 100 scans com resolução de $8 \mathrm{~cm}^{-1}$. Luz "p".

\subsection{Eletrorredução de nitrato em eletrodos monocristalinos de Paládio}

Neste eletrodo, devido à grande absorção de hidrogênio, a variação de potencial deve ser limitada a um mínimo de 0,2 V em todos os planos. Esta é uma limitação importante para o estudo eletroquímico do processo de eletrorredução de nitrato [43].

A Figura 12a mostra os resultados obtidos para $\mathrm{Pd}(111)$. A linha pontilhada, correspondente ao branco na ausência de nitrato, mostra um par de picos reversíveis, correspondente à adsorção de ânions, em torno de $0,25 \mathrm{~V}$, o que está de acordo com estudos anteriores [55-57]. As linhas sólidas na mesma figura 
correspondem a vários ciclos consecutivos obtidos em solução contendo $0,1 \mathrm{M}$ de $\mathrm{KNO}_{3}$. Nenhuma corrente que possa ser atribuída à redução de nitrato foi observada. A principal observação é o bloqueio progressivo dos picos de adsorção, indicando o acúmulo de um ou mais produtos formados durante exposição do eletrodo ao nitrato. Da mesma forma, o experimento feito em $2 \mathrm{mVs}^{-1}$ (Figura 12a inserto) não mostrou correntes de redução consideráveis, indicando que a ausência de correntes de redução de nitrato não é devida à limitações cinéticas e sim à acumulação de produtos na superfície, que possivelmente sejam gerados pelo processo de redução de nitrato que ocorre envolvendo correntes muito pequenas e não mensuráveis.

A Figura 12b mostra resultados equivalentes para o eletrodo de $\mathrm{Pd}(100)$. Como no caso anterior, o branco (linha pontilhada) apresenta um par de picos em torno de $0,3 \vee$ que decai rapidamente na presença de nitrato na solução (linha sólida). Resultados similares são obtidos a 10 ou $2 \mathrm{mVs}^{-1}$ (Figura 12b inserto), evidenciando mais uma vez o acúmulo de intermediários adsorvidos na superfície. Em $\operatorname{Pd}(110)$ (Figura 12c) o decaimento da corrente é menos percebido uma vez que essa superfície não apresenta picos de adsorção de ânions em sua linha de base (linha pontilhada) [55]. 

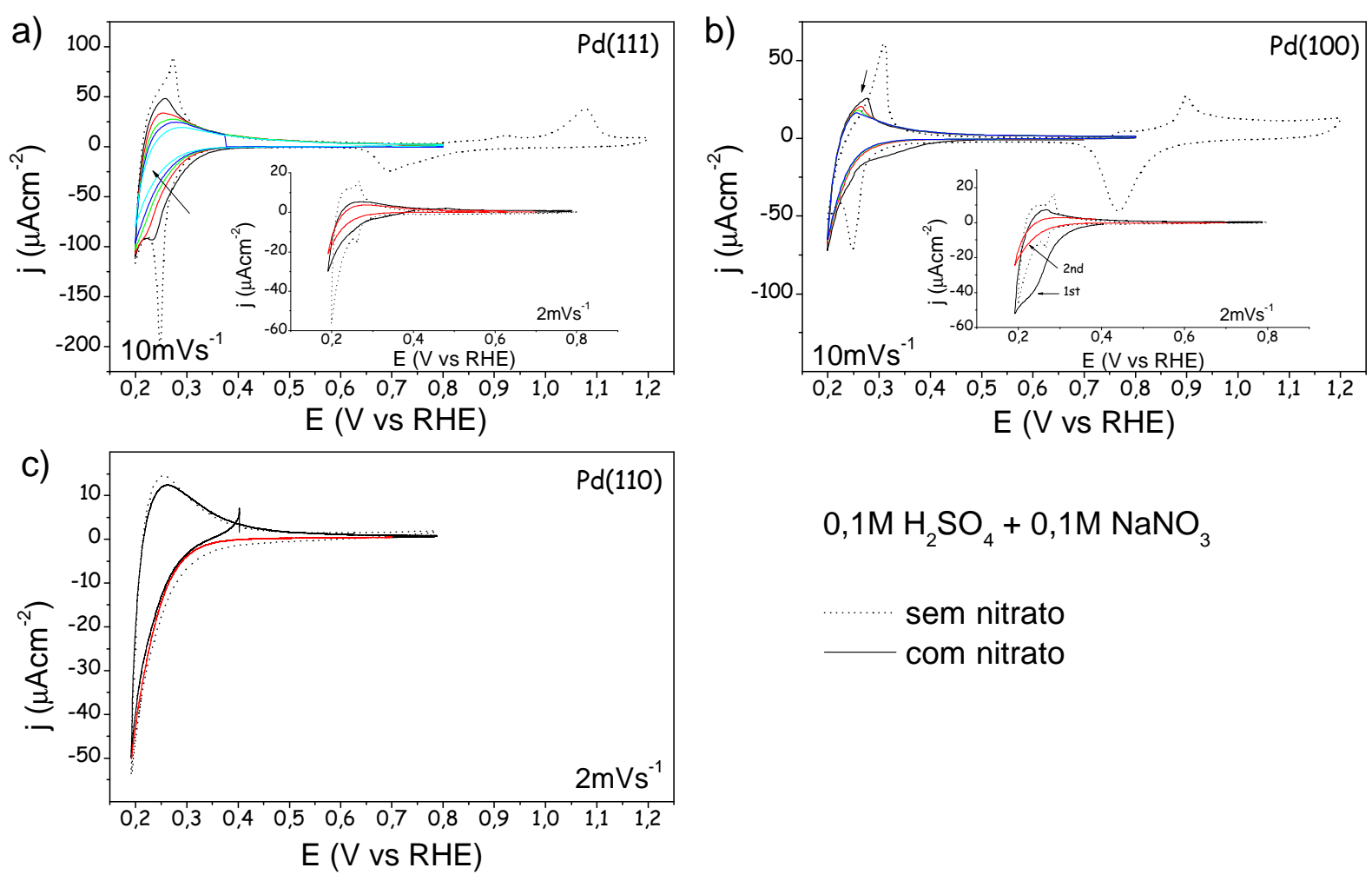

$0,1 \mathrm{M} \mathrm{H}_{2} \mathrm{SO}_{4}+0,1 \mathrm{M} \mathrm{NaNO}_{3}$

sem nitrato com nitrato

Figura 12: Voltamogramas (a) $\mathrm{Pd}(111)$, (b) $\mathrm{Pd}(100)$ e (c) $\mathrm{Pd}(110)$ em $\mathrm{H}_{2} \mathrm{SO}_{4} 0,1 \mathrm{M}$ com (curvas sólidas - coloridas) e sem (curva pontilhada) $0,1 \mathrm{M}$ de $\mathrm{KNO}_{3}$ em solução. Velocidade de varredura: (a) e (b) $10 \mathrm{mVs}^{-1}$; (c) e inserto em (a) e (b) $2 \mathrm{mVs}^{-1}$.

Se, como na platina, a redução de nitrato em paládio acontece através da formação de NO e se a reação não puder seguir até que o NO seja reduzido, podese propor que a formação de $\mathrm{NO}_{(\text {ads })}$ é a causa do bloqueio das superfícies de todos os eletrodos mostrados na

Figura 12. Uma razão para o maior acúmulo de NO nos eletrodos de paládio pode ser que o potencial limite inferior é maior neste caso para evitar a absorção de hidrogênio e o NO não é reduzido nessa faixa de potencial. Para checar essa possibilidade um eletrodo de $\operatorname{Pd}(111)$ foi ciclado como na Figura 12a até que a superfície estivesse bloqueada. Então, o potencial inferior foi estendido para $0,1 \mathrm{~V}$ (dados não mostrados). Depois desta etapa, nenhuma recuperação dos picos de 
adsorção do $\operatorname{Pd}(111)$ foi observada, sugerindo que o intermediário adsorvido não é removido, mesmo em potenciais um pouco mais baixos [43].

\subsection{Eletrorredução de nitrato em eletrodos monocristalinos de Platina com depósitos de Paládio}

Devido à limitação da absorção de hidrogênio pelos eletrodos monocristalinos de paládio, o estudo da eletrorredução de nitrato em estruturas ordenadas de paládio fica comprometido. Uma opção é trabalhar com depósitos de paládio em monocristais de platina. Estudos anteriores mostraram que o paládio se deposita em platina seguindo a orientação do substrato $[20,25,27-29,32,37,58-63]$ e que multicamadas de paládio em platina podem imitar os monocristais de paládio, mas sem absorver hidrogênio.

Neste trabalho foram realizados estudos de eletrorredução de nitrato em eletrodos monocristalinos de platina $(\mathrm{Pt}(111), \operatorname{Pt}(100)$ e $\mathrm{Pt}(110))$ com multicamadas de paládio.

\subsubsection{Pt(111) modificado por paládio}

O depósito de paládio em $\operatorname{Pt}(111)$ já foi bastante estudado e tem características definidas $[27-30,32,37,38,59-62]$. A Figura 13 apresenta os resultados voltamétricos correspondentes ao depósito de uma monocamada de paládio em Pt(111) (linha preta). As linhas pontilhadas mostram as mesmas curvas multiplicadas por 20 para melhor observação da região dos picos de adsorção de ânions na Pt(111). O voltamograma da primeira camada de paládio possui um par de 
picos de adsorção de ânions em 0,22 V e, conforme o paládio vai se depositando na platina, os picos de adsorção da $\mathrm{Pt}(111)$ em $0,5 \mathrm{~V}$ vão diminuindo.

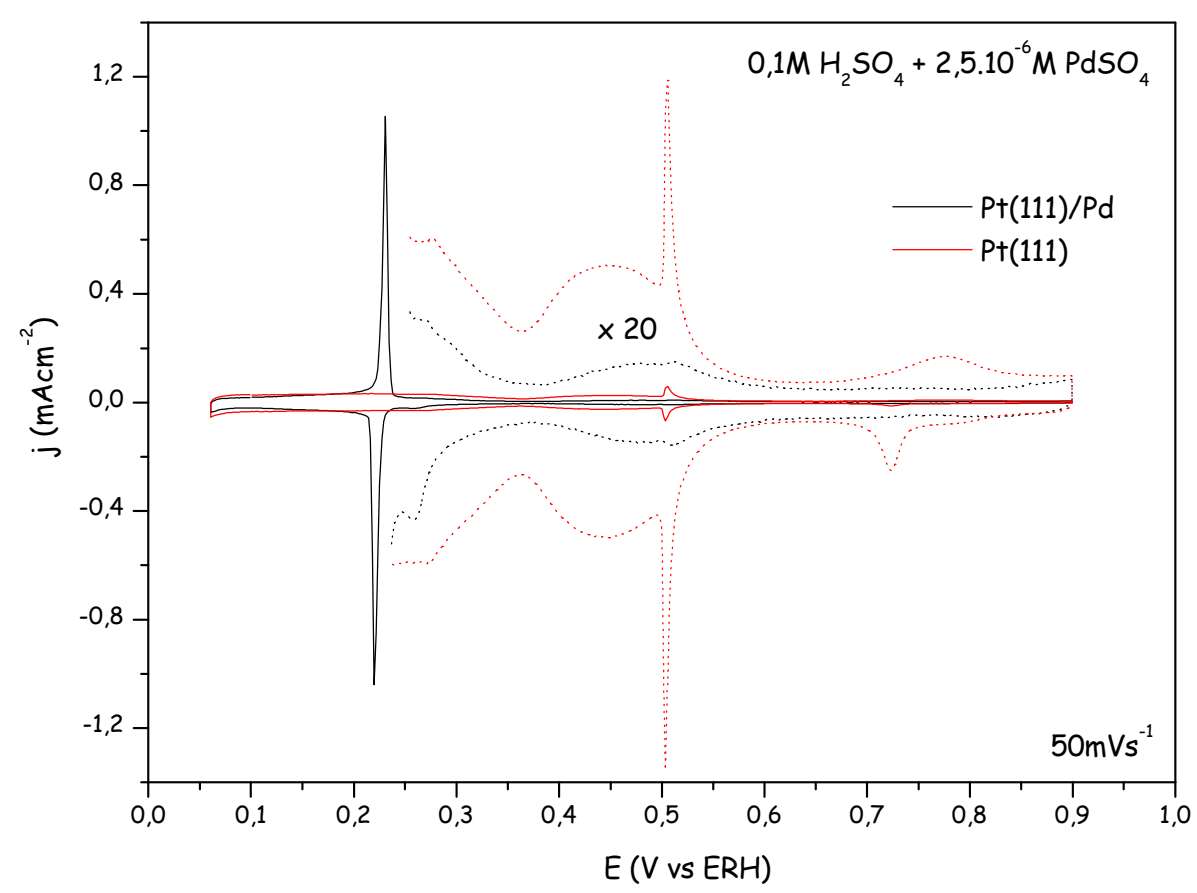

Figura 13: Depósito de paládio em $\mathrm{Pt}(111) . \theta \cong 1$. Solução: $2,510^{-6} \mathrm{M} \mathrm{PdSO}_{4} \mathrm{em}_{2} \mathrm{SO}_{4} 0,1 \mathrm{M}$ (linha preta). Linha vermelha: branco Pt(111). Linhas pontilhadas: mesmas curvas multiplicadas por 20. Velocidade de varredura $50 \mathrm{mVs}^{-1}$.

Na Figura 14 apresenta-se os voltamogramas do eletrodo de $\mathrm{Pt}(111)$ com multicamadas de $\mathrm{Pd}$ em $\mathrm{H}_{2} \mathrm{SO}_{4}$ 0,1 M. Observa-se que quando a segunda camada de paládio começa a ser formada, o par de picos em $0,22 \mathrm{~V}$ diminui e outros dois picos aparecem em 0,24 e 0,28 V, nas varreduras negativa e positiva, respectivamente [30]. Este par de picos se mantém presente independentemente da quantidade de $\mathrm{Pd}$ depositada e é relacionado à presença de multicamadas de $\mathrm{Pd}$. $\mathrm{O}$ desaparecimento completo dos picos correspondentes à adsorção de hidrogênio e ânions na primeira camada de Pd somente ocorre depois de muitos ciclos, o que aumenta as chances de contaminação do eletrodo. Por isso o depósito das 
multicamadas foi interrompido num ponto onde a contribuição da primeira camada já era pequena, conforme apresentado na Figura 14.

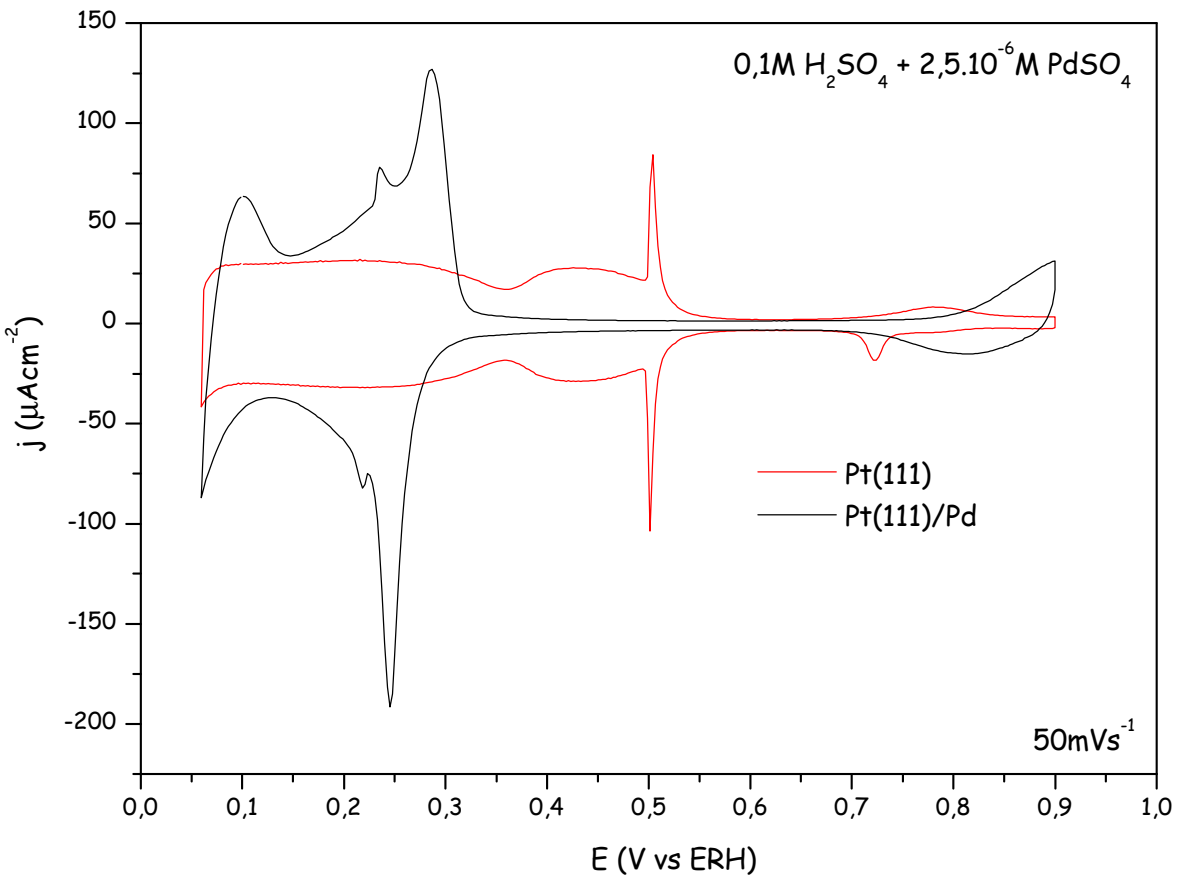

Figura 14: Voltametria cíclica de multicamadas de paládio em $\mathrm{Pt}(111)$. Solução: $2,5 \cdot 10^{-6} \mathrm{M} \mathrm{PdSO}_{4} \mathrm{em}$ $\mathrm{H}_{2} \mathrm{SO}_{4} 0,1 \mathrm{M}$ (linha preta). Linha vermelha: branco Pt(111). Velocidade de varredura $50 \mathrm{mVs}^{-1}$.

O voltamograma da $\mathrm{Pt}(111)$ assim como o do eletrodo de $\mathrm{Pt}(111)$ com multicamadas de paládio em $\mathrm{HClO}_{4}$ 0,1 M pode ser visto na Figura 15. Este perfil está de acordo com o apresentado por Feliu et al. [30]. As multicamadas são estáveis dentro dos limites de potencial utilizados neste estudo. 


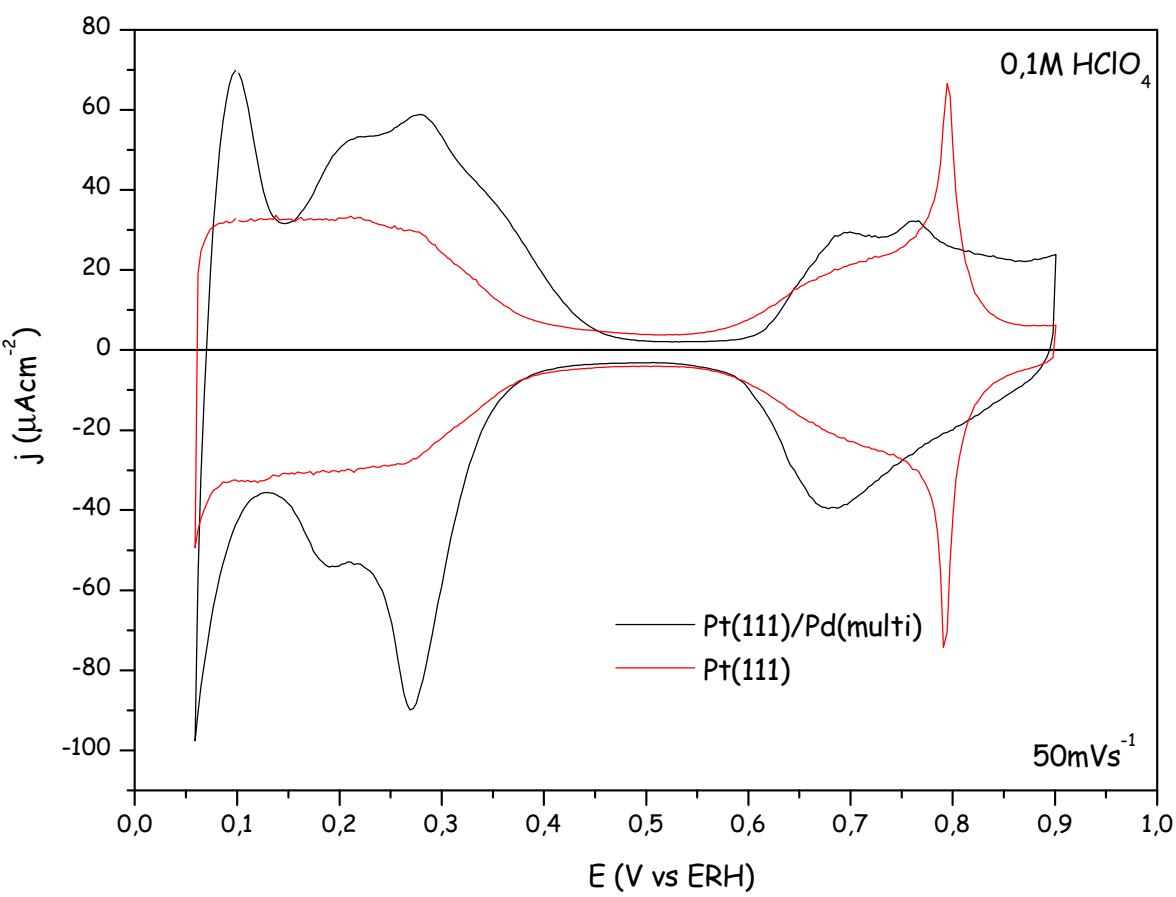

Figura 15: Voltametria cíclica de multicamadas de paládio em $\mathrm{Pt}(111)$ em $\mathrm{HClO}_{4} 0,1 \mathrm{M}$ (linha preta). Linha vermelha: branco $\mathrm{Pt}(111)$. Velocidade de varredura $50 \mathrm{mVs}^{-1}$.

Experimentos de deslocamento de carga [30] mostram que uma monocamada de hidrogênio está completa no início da evolução de hidrogênio e que adsorção significativa de ânions ocorre em potenciais altos, como em $\mathrm{Pd}(111)$ [55].

\subsubsection{Redução de Nitrato}

A Figura 16 apresenta os voltamogramas de redução de nitrato em $\operatorname{Pt}(111)$ modificada com multicamadas de $\mathrm{Pd}$ a $2 \mathrm{mVs}^{-1}$. Os perfis em $\mathrm{HClO}_{4}$ (Figura 16a) e em $\mathrm{H}_{2} \mathrm{SO}_{4}$ (Figura 16b) são semelhantes, observando-se o bloqueio dos picos de adsorção de hidrogênio e de ânions e um processo de redução na varredura negativa a partir de $0,3 \mathrm{~V}$ com máximo em torno de $0,07 \mathrm{~V}$ e na varredura positiva, um pequeno pico de redução em $0,28 \mathrm{~V}$. 

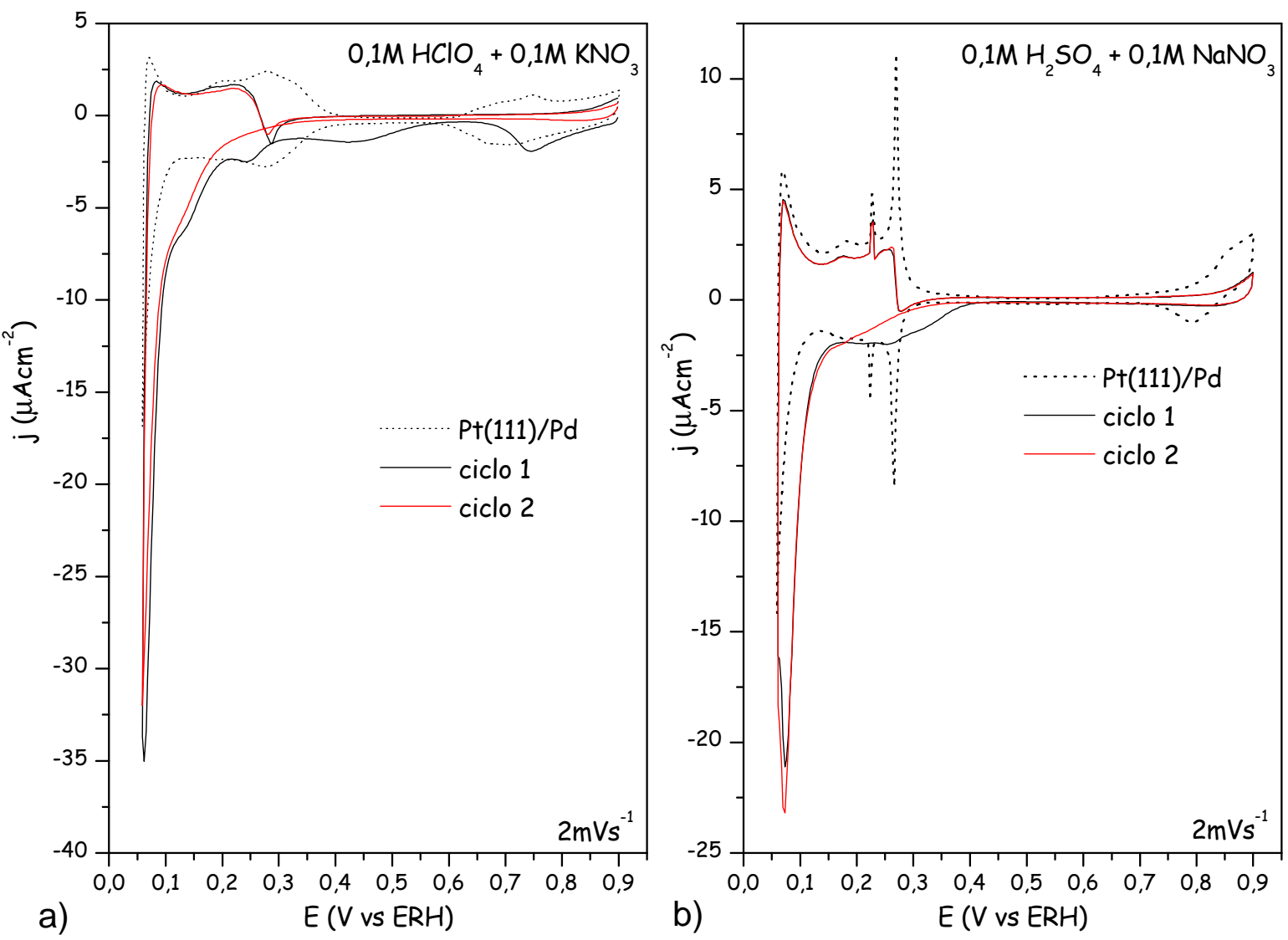

Figura 16: Voltamogramas de redução de nitrato em $\mathrm{Pt}(111)$ com multicamadas de $\mathrm{Pd}$. (a) $\mathrm{HClO}_{4}$ $0,1 \mathrm{M}+\mathrm{KNO}_{3} 0,1 \mathrm{M}$ e (b) $\mathrm{H}_{2} \mathrm{SO}_{4} 0,1 \mathrm{M}+\mathrm{NaNO}_{3} 0,1 \mathrm{M}$. Velocidade de varredura: $2 \mathrm{mVs}^{-1}$. Curva pontilhada: branco sem nitrato.

A Figura 17a mostra a evolução da carga de redução de nitrato por ciclo na região de baixo potencial $(0,20-0,05 \mathrm{~V})$ a $2 \mathrm{mVs}^{-1}$. Os valores apresentados correspondem à carga do voltamograma de redução do nitrato no ciclo correspondente menos a carga do branco na ausência de nitrato na mesma faixa de potencial. Esta carga pode ser indicativa do número de moléculas de nitrato reduzidas em um determinado ciclo. Em ácido sulfúrico a carga aumenta do primeiro para o segundo ciclo e diminui após vários ciclos. Já em ácido perclórico a carga diminui a partir do primeiro ciclo. 
A $20 \mathrm{mVs}^{-1}$ não é possível definir uma carga de redução a partir do voltamograma (Figura 17b) uma vez que a carga medida na presença de nitrato é sempre menor que a do branco nas mesmas condições experimentais, embora as correntes sejam maiores (em valor absoluto) na presença de nitrato, mas apenas na região de potenciais abaixo de $0,1 \mathrm{~V}$. Essa baixa carga não significa que a redução não aconteça, mas sim que o processo é muito lento e não compensa a diminuição de carga causada pelo bloqueio da superfície do eletrodo. Para comprovar que o processo ocorre foram feitos ciclos nessa velocidade entre 0,9 e $0,15 \mathrm{~V}$, o que resultou no bloqueio do eletrodo pela acumulação de produtos na superfície.
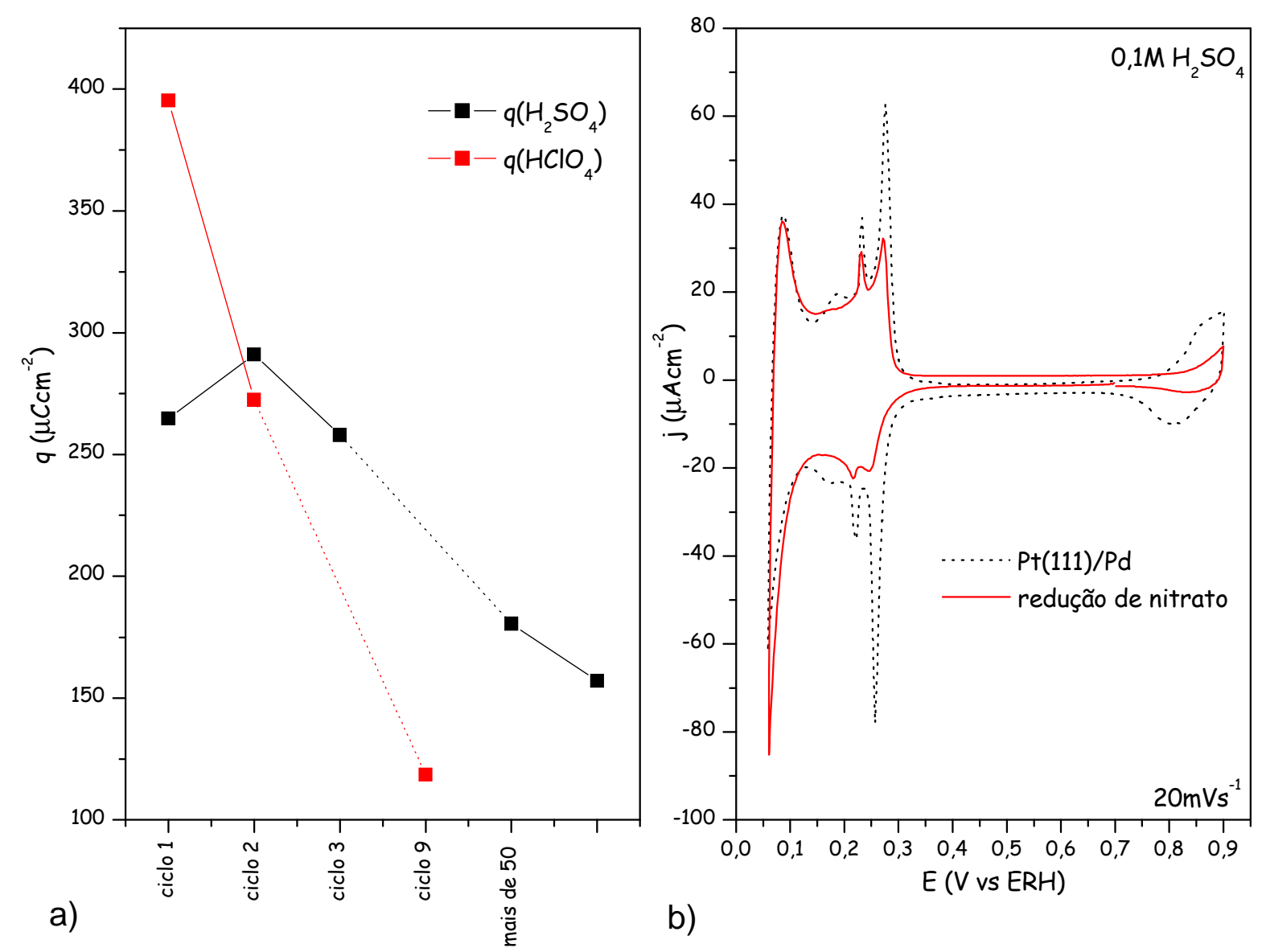

Figura 17: (a) Carga referente à redução de nitrato em $\mathrm{Pt}(111)$ modificada por $\mathrm{Pd}$ a $2 \mathrm{mVs}^{-1}$ em $\mathrm{H}_{2} \mathrm{SO}_{4}$ 0,1 M (preto) e $\mathrm{HClO}_{4}$ 0,1 $\mathrm{M}$ (vermelho); (b) Voltamograma de redução de nitrato em $\mathrm{Pt}(111)$ com multicamadas de $\mathrm{Pd}$ em $\mathrm{H}_{2} \mathrm{SO}_{4} 0,1 \mathrm{M}+\mathrm{NaNO}_{3} 0,1 \mathrm{M}$ a $20 \mathrm{mVs}^{-1}$ e branco sem nitrato (curva pontilhada). 
O potencial de carga total zero (pctz) desse eletrodo é $0,27 \vee$ [37]. Apesar do potencial de carga livre ter sido estimado estar localizado em baixos potenciais [30], a adsorção específica de ânions normalmente ocorre em potenciais mais altos que o pctz. Com isso não é esperado que ânions nitrato se adsorvam facilmente nesta faixa de potencial, o que dificulta a reação.

Na Figura 18 apresenta-se a resposta voltamétrica correspondente à redução de uma camada saturada de $\mathrm{NO}_{(\text {ads })}$ nesse mesmo eletrodo. Nota-se uma grande semelhança com o perfil da redução de nitrato (Figura 16), observando-se um pico de redução em 0,07 V. Dima et al. [51] observaram a mesma relação comparando a redução de nitrato e a de uma camada saturada de $\mathrm{NO}_{(\text {ads })}$ em $\mathrm{Pt}(111)$ e, com auxílio de estudos espectroscópicos, concluíram que a redução do nitrato passa por uma etapa de $\mathrm{NO}_{(\mathrm{ads})}$. O mesmo provavelmente ocorre neste caso, mas para confirmar este fato foram feitos estudos de FTIR.

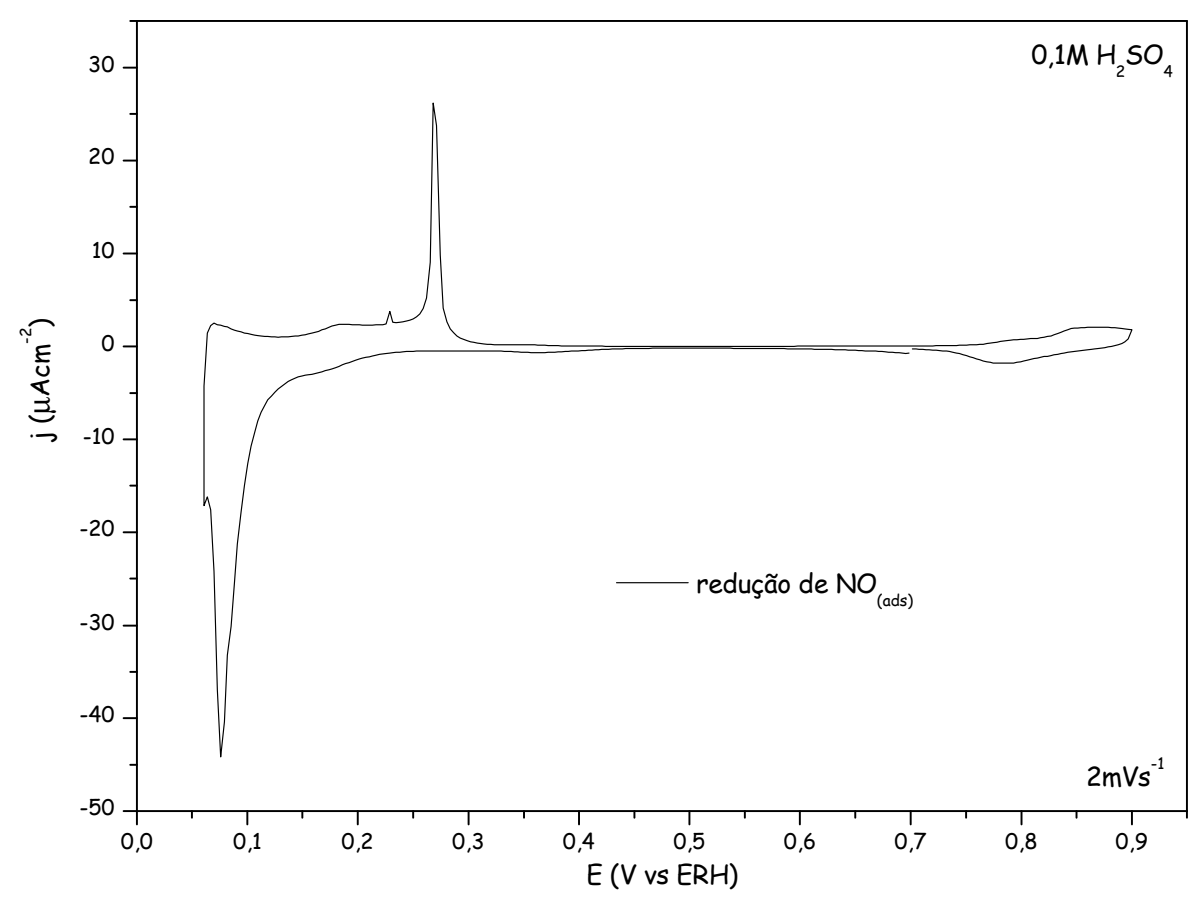

Figura 18: Redução de uma camada de $\mathrm{NO}_{(a d s)}$ em $\mathrm{Pt}(111)$ com multicamadas de $\mathrm{Pd}$ em $\mathrm{H}_{2} \mathrm{SO}_{4}$ 0,1 M a $2 \mathrm{mVs}^{-1}$. 
Os resultados espectrométricos de FTIR são mostrados nas Figuras 19 e 20. A partir destes resultados é possível confirmar que a redução de nitrato em Pt(111) modificada por multicamadas de Pd ocorre abaixo de 0,3 V, que é quando a banda de consumo de nitrato, em $1370 \mathrm{~cm}^{-1}$ aparece.

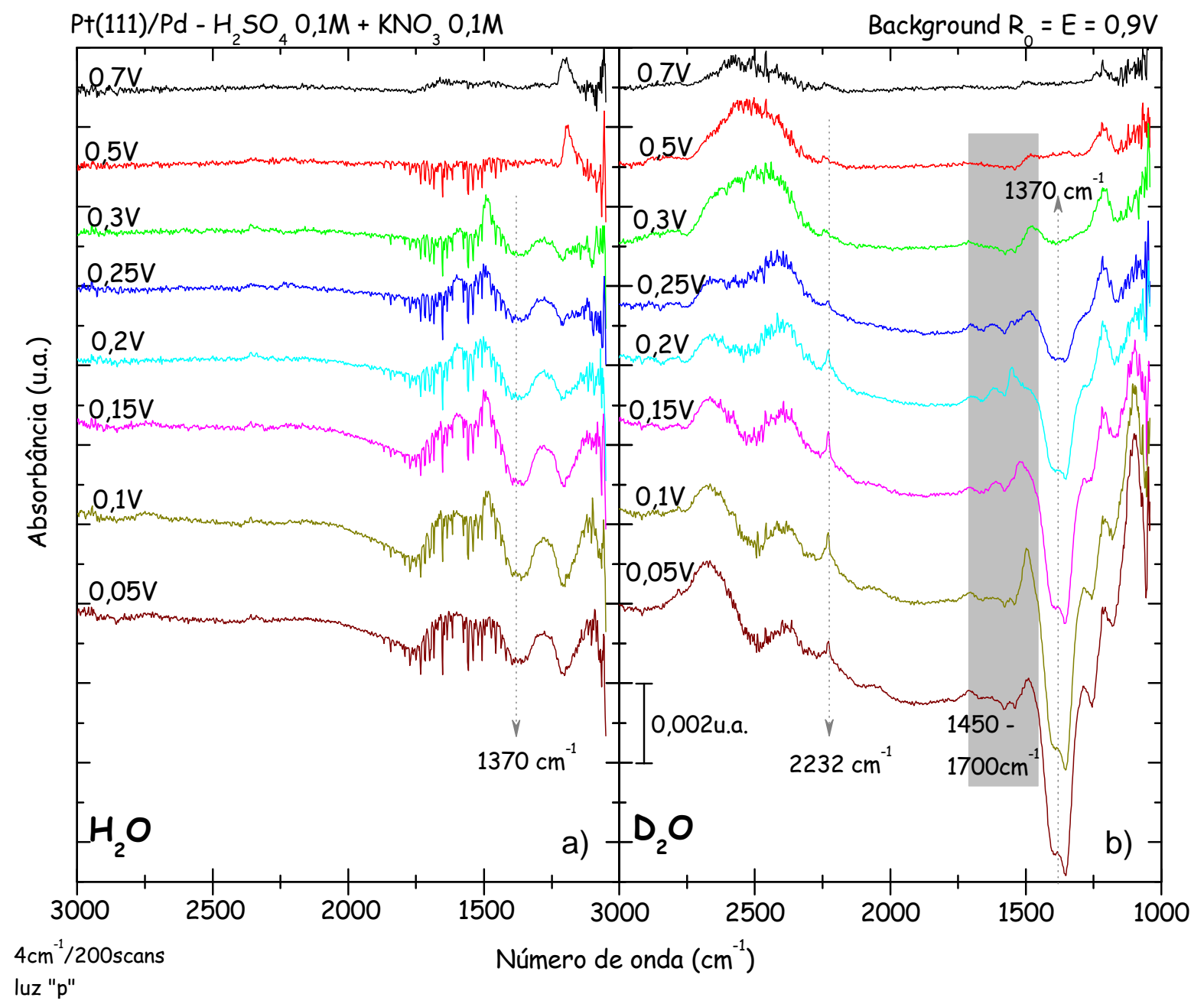

Figura 19: FTIR da redução de nitrato em Pt(111) com multicamadas de $\mathrm{Pd}$ em $\mathrm{H}_{2} \mathrm{SO}_{4}$ 0,1 $\mathrm{M}$ e $\mathrm{KNO}_{3}$ $0,1 \mathrm{M}$. (a) $\mathrm{H}_{2} \mathrm{O}$ e (b) $\mathrm{D}_{2} \mathrm{O}$. Referência 0,9 V. Espectros compostos por 200 scans com resolução de $4 \mathrm{~cm}^{-1}$. Luz "p".

Tanto em ácido sulfúrico (Figura 19a) como em ácido perclórico (Figura 20a), quando o solvente é $\mathrm{H}_{2} \mathrm{O}$, não se observa a formação de $\mathrm{N}_{2} \mathrm{O}$, que aparece como um pico em $2232 \mathrm{~cm}^{-1}$. Os únicos produtos formados aparecem na região entre 1500 
e $1750 \mathrm{~cm}^{-1}$, que coincide com a região de vibração da água e, por isso, apresenta ruídos que dificultam o seu detalhamento. Para identificar os picos presentes nessa região, foram feitos experimentos com $\mathrm{D}_{2} \mathrm{O}$ como solvente (Figuras 19b e 20b, para $\mathrm{H}_{2} \mathrm{SO}_{4}$ e $\mathrm{HClO}_{4}$, respectivamente), que tem seu número de onda de vibração deslocado para a região de 2260 a $3000 \mathrm{~cm}^{-1}$, deixando a faixa entre 1500 e $1750 \mathrm{~cm}^{-1}$ livre de ruídos.

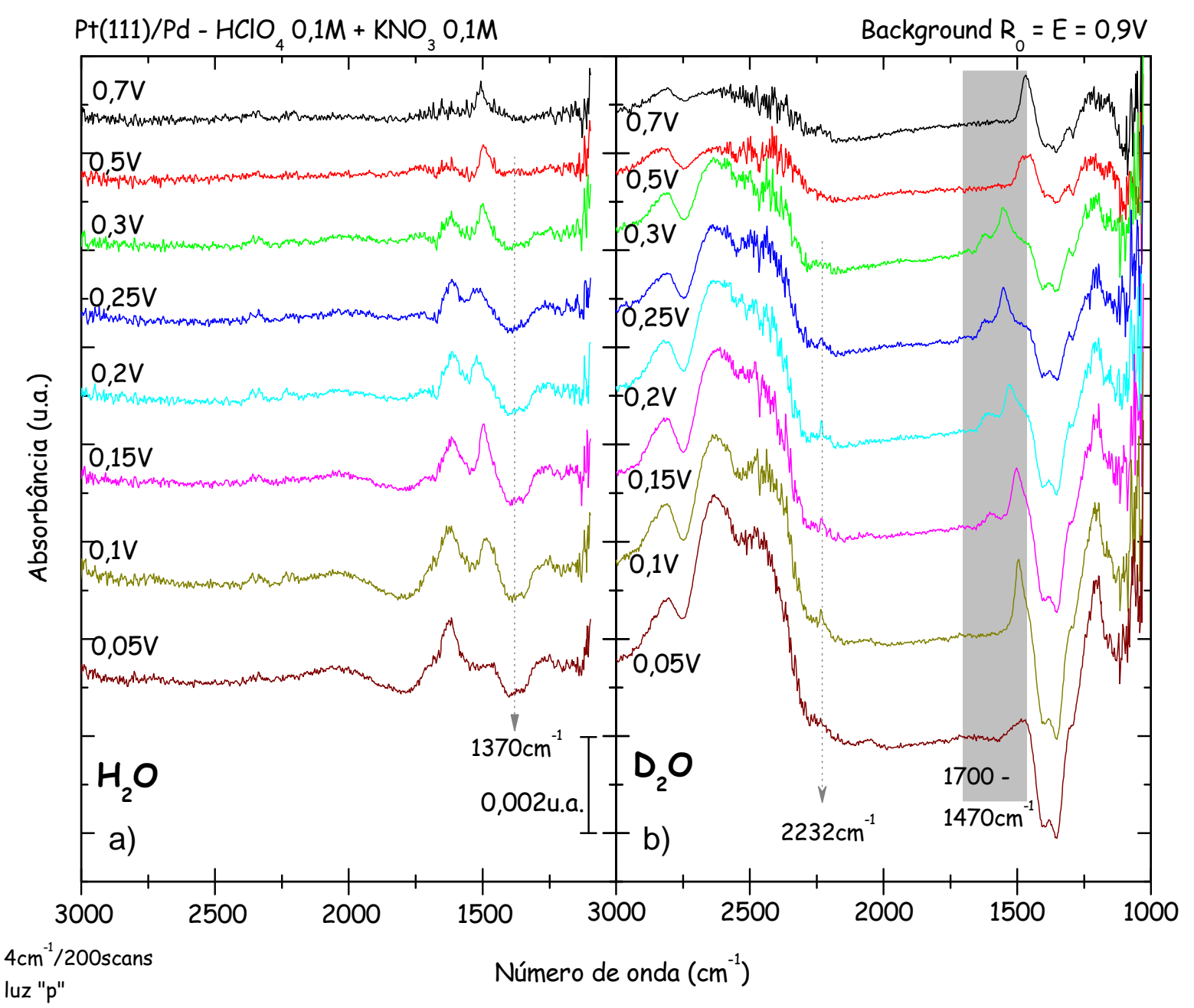

Figura 20: FTIR da redução de nitrato em $\mathrm{Pt}(111)$ com multicamadas de $\mathrm{Pd}$ em $\mathrm{HClO}_{4}$ 0,1 $\mathrm{M}$ e $\mathrm{KNO}_{3}$ 0,1 M. (a) $\mathrm{H}_{2} \mathrm{O}$ e (b) $\mathrm{D}_{2} \mathrm{O}$. Referência 0,9 V. Espectros compostos por 200 scans com resolução de $4 \mathrm{~cm}^{-1}$. Luz "p". 
Alguns picos que apareceram entre 1500 e $1750 \mathrm{~cm}^{-1}$ em $\mathrm{H}_{2} \mathrm{O}$ (Figuras 19a e 20a) aparecem também em $D_{2} \mathrm{O}$ (Figuras 19b e 20b), o que indica que são espécies não hidrogenadas, uma vez que estas teriam seu número de onda deslocado com a substituição de hidrogênio por deutério [54]. Dentre os produtos esperados, $\mathrm{NH}_{4}{ }^{+} \mathrm{e}$ NO são as espécies que tem vibração nessa região de números de onda, mas eliminada a possibilidade da espécie ser hidrogenada, conclui-se que existe a formação de NO durante a redução de nitrato. Em estudos usando a luz "s" não foi observada a presença de picos nesse mesmo número de onda, o que indica que são espécies adsorvidas, possivelmente $\mathrm{NO}_{(\text {ads) }}$. Espécies adsorvidas podem ter seu número de onda deslocado com a mudança do potencial. Isso explica os picos em diferentes números de onda, dependendo do potencial.

Curiosamente, quando o solvente é $\mathrm{D}_{2} \mathrm{O}$, nota-se indícios da presença de picos em $2232 \mathrm{~cm}^{-1}$, correspondentes à formação de $\mathrm{N}_{2} \mathrm{O}$, especialmente em $\mathrm{H}_{2} \mathrm{SO}_{4}$ (Figura 19b). A formação dessa espécie não deveria ser influenciada pelo solvente, mas os resultados sugerem que a troca de hidrogênio por deutério leva a uma mudança no mecanismo de reação, favorecendo a formação de $\mathrm{N}_{2} \mathrm{O}$. Esse tipo de mudança de mecanismo já foi observada anteriormente em outros sistemas [64] e também foi observada neste trabalho para a redução de nitrato em $\operatorname{Pt}(100)$ com multicamadas de Pd, conforme será visto mais adiante.

A presença de $\mathrm{ND}_{4}{ }^{+}$seria identificada por um pico em $1215 \mathrm{~cm}^{-1}$ [54], como ocorre em $\operatorname{Pt}(111)$ (Figura 11), mas esta região está sobreposta à da região de adsorção de ânions $\left(\mathrm{SO}_{4}{ }^{2-}\right.$ e $\left.\mathrm{ClO}_{4}{ }^{-}\right)$, o que dificulta a sua identificação. 


\subsection{2 $\mathrm{Pt}(100)$ modificado por paládio}

Assim como Pd em Pt(111), o depósito de paládio em Pt(100) também já foi estudado $[28,32,58,63]$ e apresenta um perfil semelhante. A primeira camada de Pd possui um par de picos de adsorção em torno de $0,17 \mathrm{~V}$, conforme pode ser visto na Figura 21. Os picos com pequenas magnitudes em $0,27 \mathrm{~V}$ que aparecem na curva da Figura 21 correspondem à adsorção de hidrogênio e ânions na segunda camada de paládio, que, diferentemente do caso anterior, começa a ser formada antes que a primeira esteja completa e a platina totalmente coberta (picos ainda visíveis em $0,360 \mathrm{~V})$.

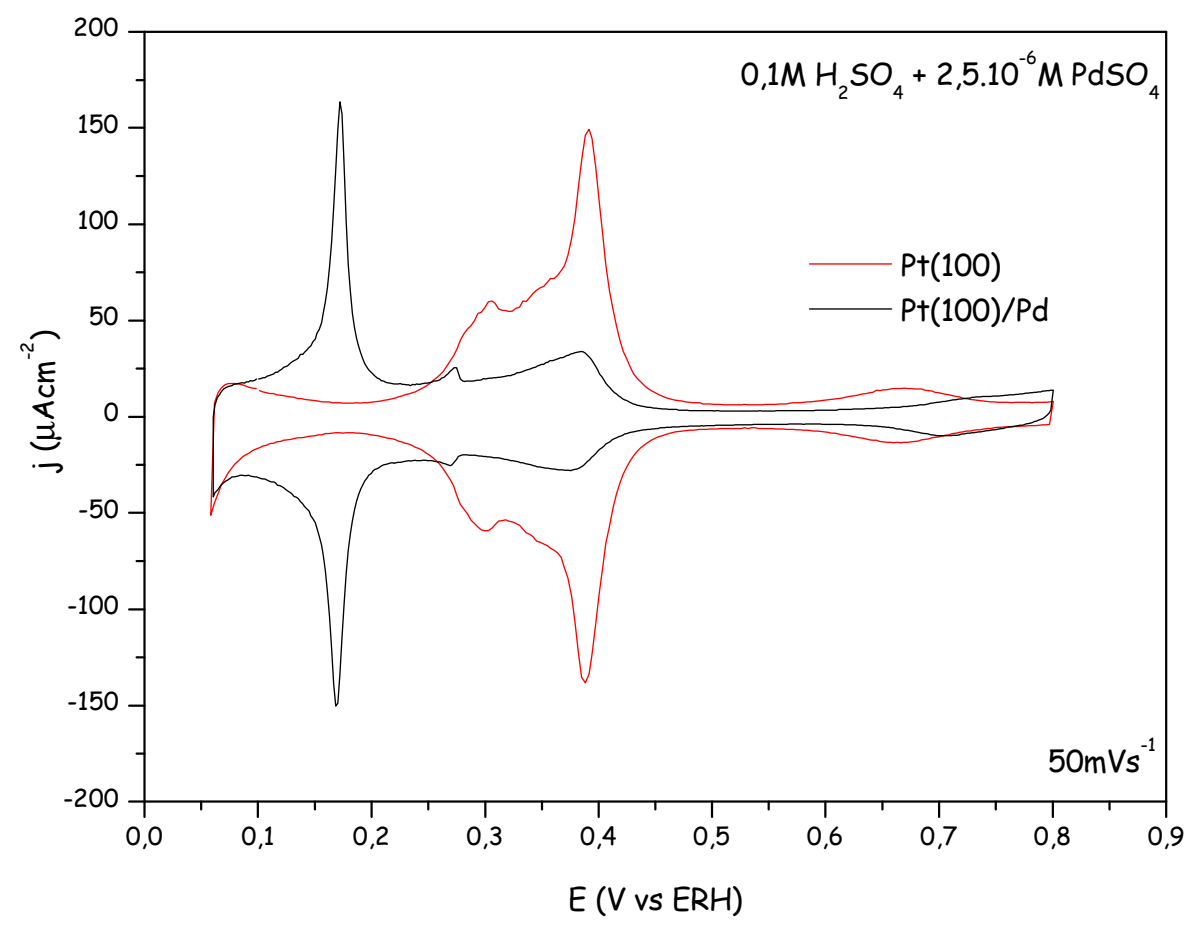

Figura 21: Depósito de paládio em $\mathrm{Pt}(100)$. $\theta<1$. Solução: $2,510^{-6} \mathrm{M} \mathrm{PdSO}_{4} \mathrm{em} \mathrm{H}_{2} \mathrm{SO}_{4} 0,1 \mathrm{M}$ (linha preta). Linha vermelha: branco $\mathrm{Pt}(100)$. Velocidade de varredura $50 \mathrm{mVs}^{-1}$.

Álvarez et al. [58] observaram que o depósito de Pd pode ser ordenado pela redução de uma camada saturada de NO adsorvido. Eles depositaram Pd na 
superfície da $\mathrm{Pt}(100)$ até que a presença da segunda camada de $\mathrm{Pd}$ estivesse bastante visível e observaram que, após a redução do NO adsorvido, a camada de Pd se reorganizava para formar uma monocamada completa, cobrindo toda a Pt. A voltametria posterior à redução de $\mathrm{NO}$ apresentou somente os picos em $0,17 \mathrm{~V}$, sem sinal dos picos da Pt em 0,36 V ou da segunda camada de Pd, em 0,27 V [58].

Para o estudo apresentado nesta tese somente interessam multicamadas de Pd, portanto o procedimento de redução de NO para organizar a primeira camada de $\mathrm{Pd}$ não foi feito. O depósito de $\mathrm{Pd}$ foi feito até que não houvesse mais a presença dos picos da $\mathrm{Pt}(100)$ e, simultaneamente, que os picos da primeira camada de $\mathrm{Pd}$ tivessem contribuição mínima, conforme mostrado na Figura 22 para $\mathrm{H}_{2} \mathrm{SO}_{4} \quad 0,1 \mathrm{M}$ como eletrólito e na Figura 23 onde se apresenta o perfil voltamétrico do eletrodo de $\mathrm{Pt}(100)$ modificado com multicamadas de paládio em $\mathrm{HClO}_{4}$ 0,1 M.

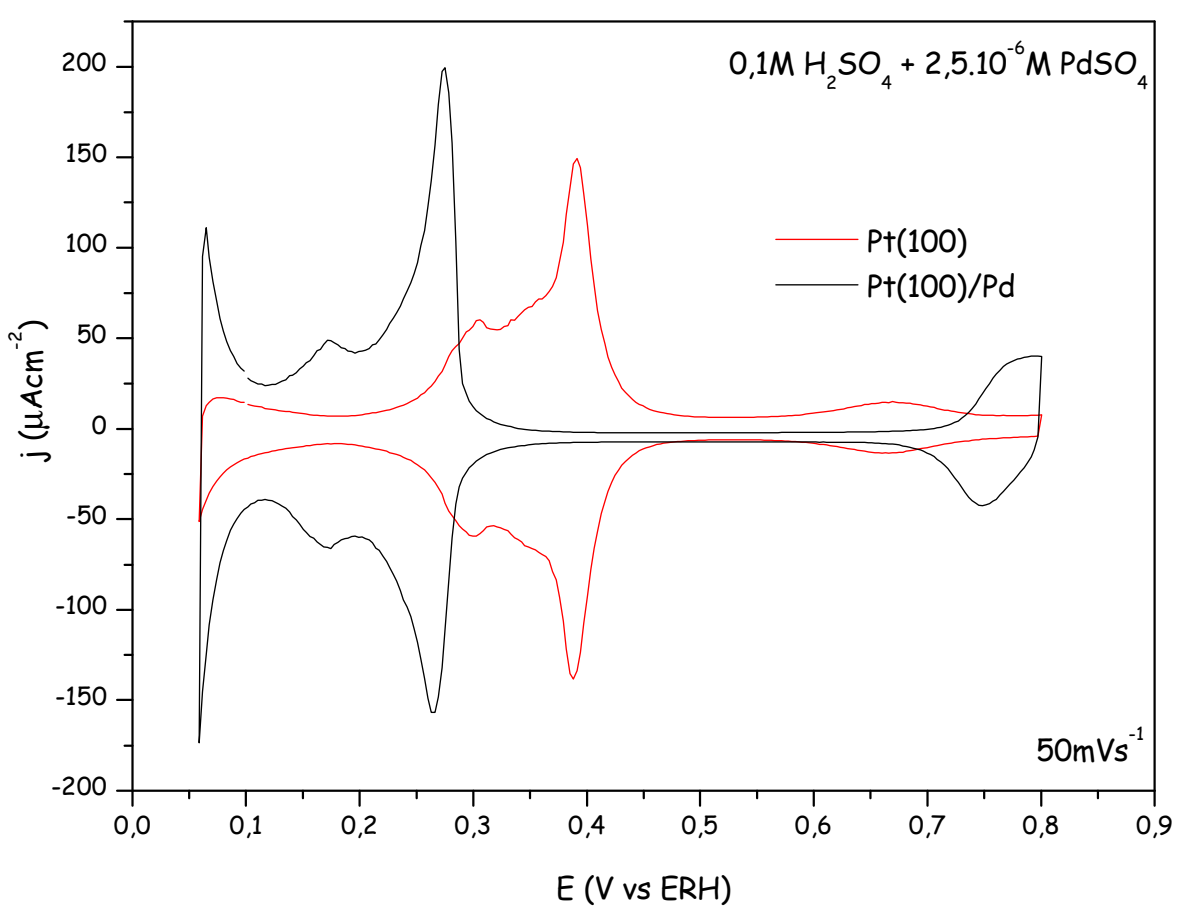

Figura 22: Voltametria cíclica de multicamadas de paládio em $\mathrm{Pt}(100)$. Solução: $2,510^{-6} \mathrm{M} \mathrm{PdSO}_{4} \mathrm{em}$ $\mathrm{H}_{2} \mathrm{SO}_{4} 0,1 \mathrm{M}$ (linha preta). Linha vermelha: branco Pt(100). Velocidade de varredura $50 \mathrm{mVs}^{-1}$. 


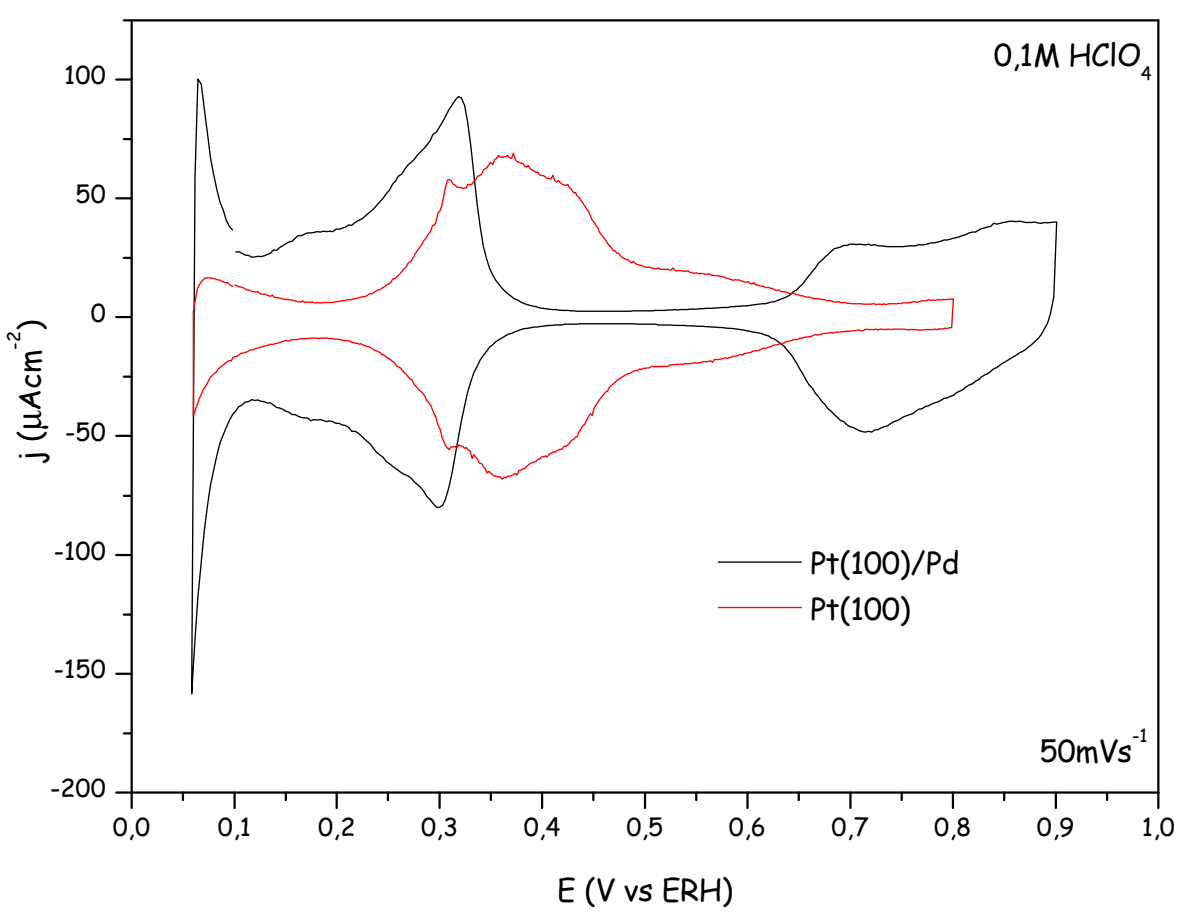

Figura 23: Voltametria cíclica de multicamadas de paládio em $\mathrm{Pt}(100)$ em $\mathrm{HClO}_{4} 0,1 \mathrm{M}$ (linha preta). Linha vermelha: branco Pt(100). Velocidade de varredura $50 \mathrm{mVs}^{-1}$.

\subsubsection{Redução de Nitrato}

Os resultados voltamétricos da redução de nitrato em $\mathrm{Pt}(100)$ recoberto com multicamadas de Pd são mostrados na Figura 24. Diferente do que ocorre com $\mathrm{Pt}$ (111) com multicamadas de $\mathrm{Pd}$, que tem perfis de redução de nitrato semelhantes em $\mathrm{H}_{2} \mathrm{SO}_{4}$ e $\mathrm{HClO}_{4}$ (Figura 16), em $\mathrm{Pt}(100)$ com multicamadas de $\mathrm{Pd}$ a redução de nitrato a $2 \mathrm{mVs}^{-1}$ é diferente nos dois eletrólitos. Em $\mathrm{HClO}_{4}$ (Figura 24a) observa-se um pico de redução na varredura negativa em $0,11 \mathrm{~V}$ e um segundo pico, na varredura positiva, em $0,27 \mathrm{~V}$. Já em $\mathrm{H}_{2} \mathrm{SO}_{4}$ (Figura 24b), nota-se a presença de dois picos na varredura negativa, em 0,23 e $0,11 \mathrm{~V}$, mas nenhum pico na varredura positiva. Além da diferença entre os perfis, a carga de redução em ácido perclórico é em torno de 3 vezes maior que em ácido sulfúrico, conforme apresentado na Figura 
25a. Por estes resultados também nota-se que o bloqueio da superfície é bem menos pronunciado em $\mathrm{HClO}_{4}$ que em $\mathrm{H}_{2} \mathrm{SO}_{4}$.
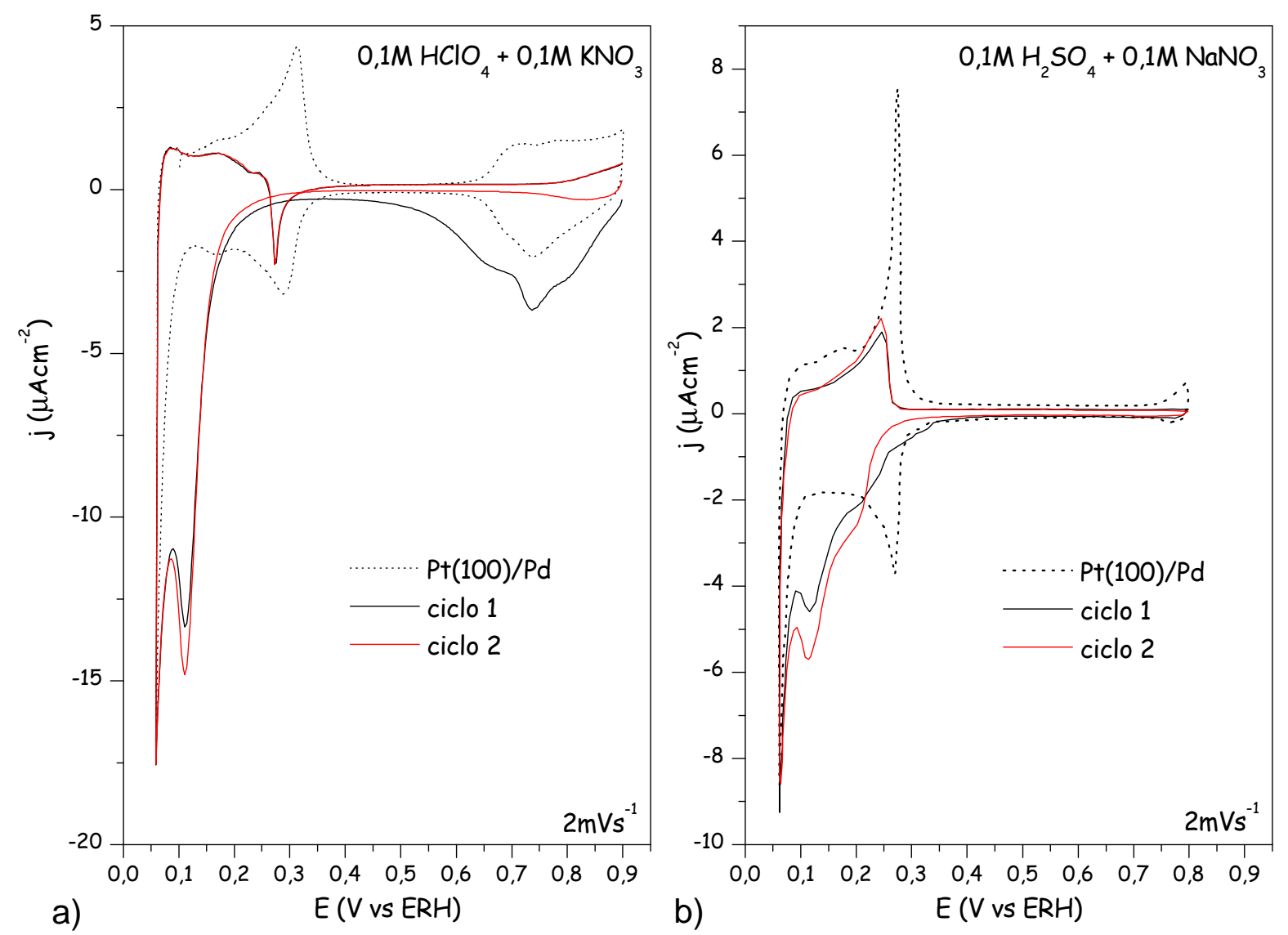

Figura 24: Voltamogramas de redução de nitrato em $\mathrm{Pt}(100)$ com multicamadas de $\mathrm{Pd}$. (a) $\mathrm{HClO}_{4}$ $0,1 \mathrm{M}+\mathrm{KNO}_{3} 0,1 \mathrm{M}$ e (b) $\mathrm{H}_{2} \mathrm{SO}_{4} 0,1 \mathrm{M}+\mathrm{NaNO}_{3}$ 0,1 M. Velocidade de varredura: $2 \mathrm{mVs}^{-1}$. Curva pontilhada: branco sem nitrato.

A voltametria cíclica da redução de nitrato $\mathrm{em}_{2} \mathrm{SO}_{4} 0,1 \mathrm{M}$ a $20 \mathrm{mVs}^{-1}$ (Figura 25b) mostra um pequeno pico em $0,21 \mathrm{~V}$, juntamente com um claro bloqueio da superfície. Entretanto a carga de redução abaixo de 0,35 V na ausência de nitrato é maior que na presença de nitrato. Já em $\mathrm{HClO}_{4} 0,1 \mathrm{M}$, a redução de nitrato pode ser vista independente da velocidade de varredura, como mostra a Figura 26 . O inserto na Figura 26 mostra o cálculo do coeficiente de Tafel pelo gráfico do potencial do pico versus o logaritmo da velocidade de varredura $[65,66]$. Os coeficientes 
calculados para os picos da varredura negativa e positiva foram 41 e $35 \mathrm{mV} /$ década, respectivamente. Estes valores estão muito próximos a $40 \mathrm{mV} /$ década, que corresponde a sistemas com a transferência de dois elétrons, sendo que a primeira transferência não é a etapa determinante [67].
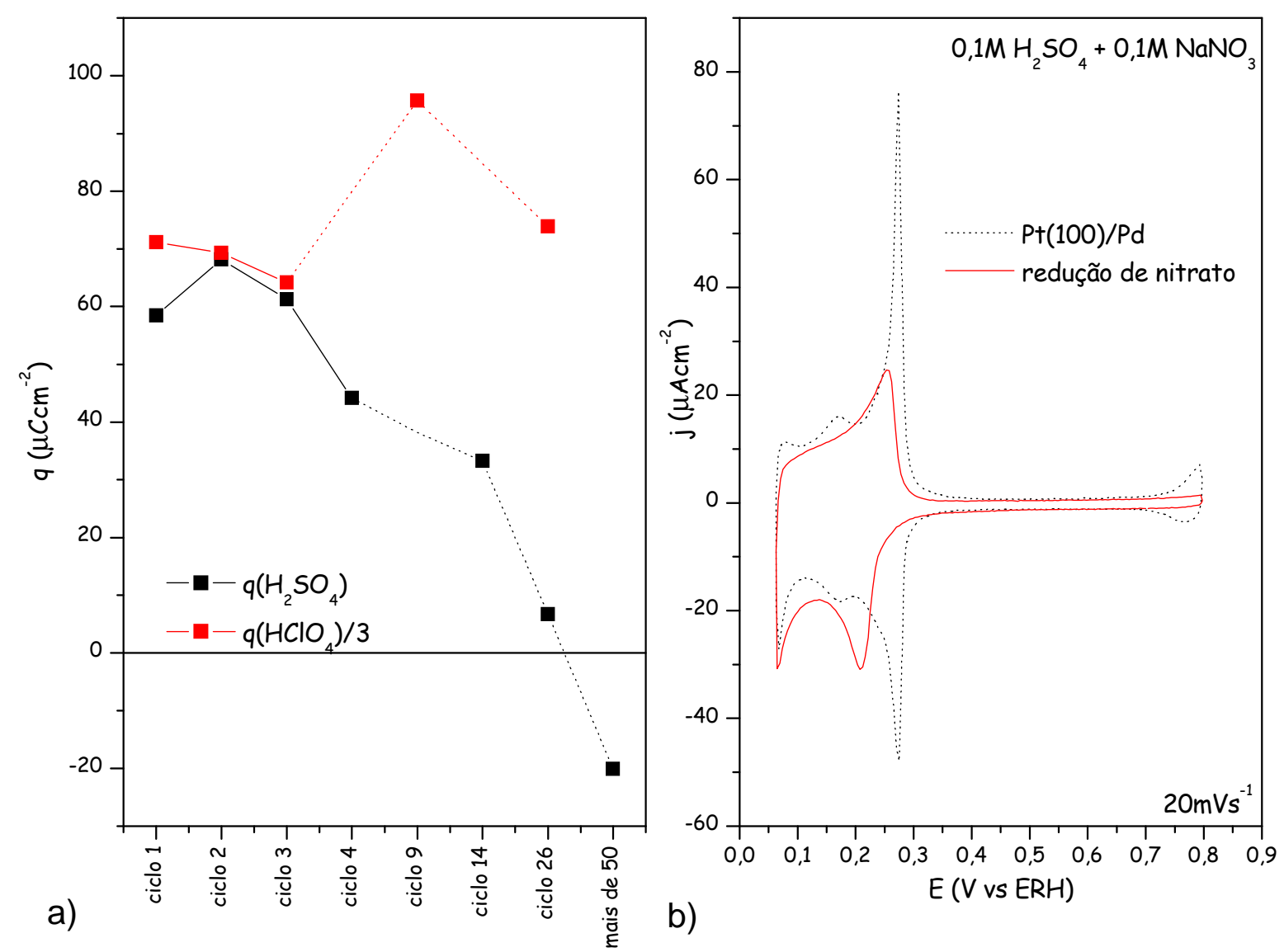

Figura 25: (a) Carga referente à redução de nitrato em $\mathrm{Pt}(100)$ modificada por $\mathrm{Pd}$ a $2 \mathrm{mVs}^{-1}$ em $\mathrm{H}_{2} \mathrm{SO}_{4}$ 0,1 M (preto) e $\mathrm{HClO}_{4}$ 0,1 M (vermelho - carga dividida por 3); (b) Voltamograma de redução de nitrato em $\mathrm{Pt}(100)$ com multicamadas de $\mathrm{Pd}$ em $\mathrm{H}_{2} \mathrm{SO}_{4} 0,1 \mathrm{M}+\mathrm{NaNO}_{3} 0,1 \mathrm{M}^{2} 20 \mathrm{mVs}^{-1}$ e branco sem nitrato (curva pontilhada). 


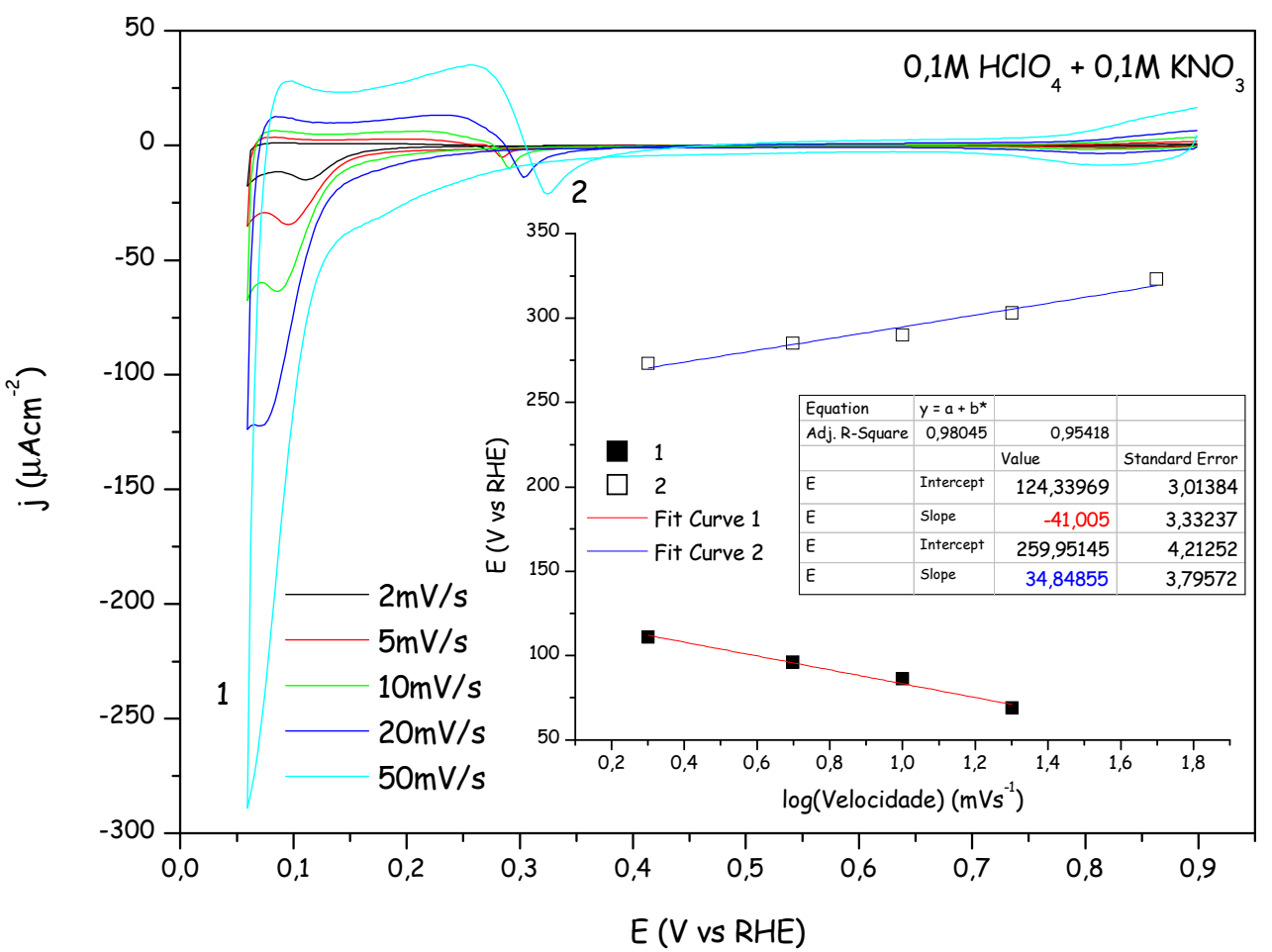

Figura 26: Voltamogramas de redução de nitrato em $\mathrm{Pt}(100)$ com multicamadas de $\mathrm{Pd}$ em $\mathrm{HClO}_{4}$ $0,1 \mathrm{M}+\mathrm{KNO}_{3} 0,1 \mathrm{M}$ em diferentes velocidades de varredura. Inserto: cálculo do coeficiente de Tafel (potencial do pico versus o logaritmo da velocidade de varredura).

Assim como no caso da $\mathrm{Pt}(111) / \mathrm{Pd}$, também é possível correlacionar um dos picos de redução do nitrato com a redução de $\mathrm{NO}_{(\mathrm{ads})}$. A Figura 27 mostra a redução de uma camada saturada de $\mathrm{NO}_{(\text {ads }}$ em Pt(100) com multicamadas de Pd em ácido sulfúrico. Nota-se que o potencial de redução está de acordo com o pico que aparece em $0,11 \mathrm{~V}$ durante a redução de nitrato $\mathrm{em}_{2} \mathrm{SO}_{4}$ 0,1 M (Figura 24b), o que sugere que este seria o pico de redução do NO enquanto que o pico que aparece antes em $0,23 \vee$ seria a redução do nitrato a NO. 


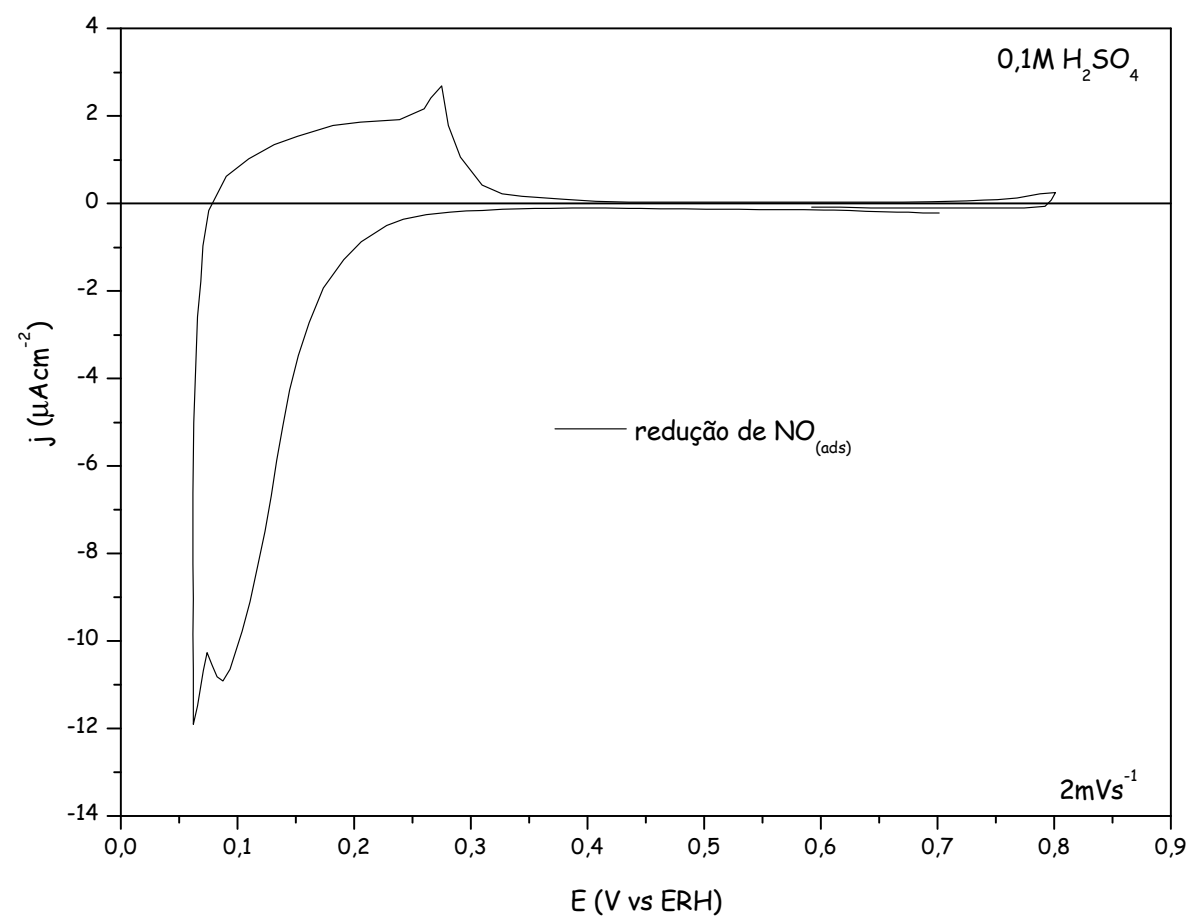

Figura 27: Redução de uma camada de $\mathrm{NO}_{(\text {ads })}$ em Pt(100) com multicamadas de $\mathrm{Pd}$ em $\mathrm{H}_{2} \mathrm{SO}_{4}$ 0,1 M a $2 \mathrm{mVs}^{-1}$.

Os experimentos de FTIR (Figuras 28 e 29) apresentam resultados similares aos observados para $\mathrm{Pt}(111) / \mathrm{Pd}$. Em $\mathrm{H}_{2} \mathrm{SO}_{4}$ o consumo de nitrato $\left(1370 \mathrm{~cm}^{-1}\right)$ se verifica abaixo de $0,30 \mathrm{~V}$ e os produtos tem vibração entre 1450 e $1700 \mathrm{~cm}^{-1}$, que somente podem ser vistas em $\mathrm{D}_{2} \mathrm{O}$ (Figura 28b). A espécie que aparece nessa região, conforme já discutido para $\mathrm{Pt}(111) / \mathrm{Pd}$ é provavelmente o NO. Assim como em $\mathrm{Pt}(111) / \mathrm{Pd}$, quando o solvente é $\mathrm{D}_{2} \mathrm{O}$ observa-se um indício da formação de $\mathrm{N}_{2} \mathrm{O}$, com a presença de um pequeno pico em $2232 \mathrm{~cm}^{-1}$. O pico correspondente à espécie $\mathrm{ND}_{4}{ }^{+}\left(1215 \mathrm{~cm}^{-1}\right)$ não está aparente, mas a formação de $\mathrm{NH}_{4}{ }^{+}$não pode ser descartada devido à mudança no mecanismo de reação que ocorre quando o solvente usado é $\mathrm{D}_{2} \mathrm{O}$, conforme discutido para $\mathrm{Pt}(111) / \mathrm{Pd}$. 


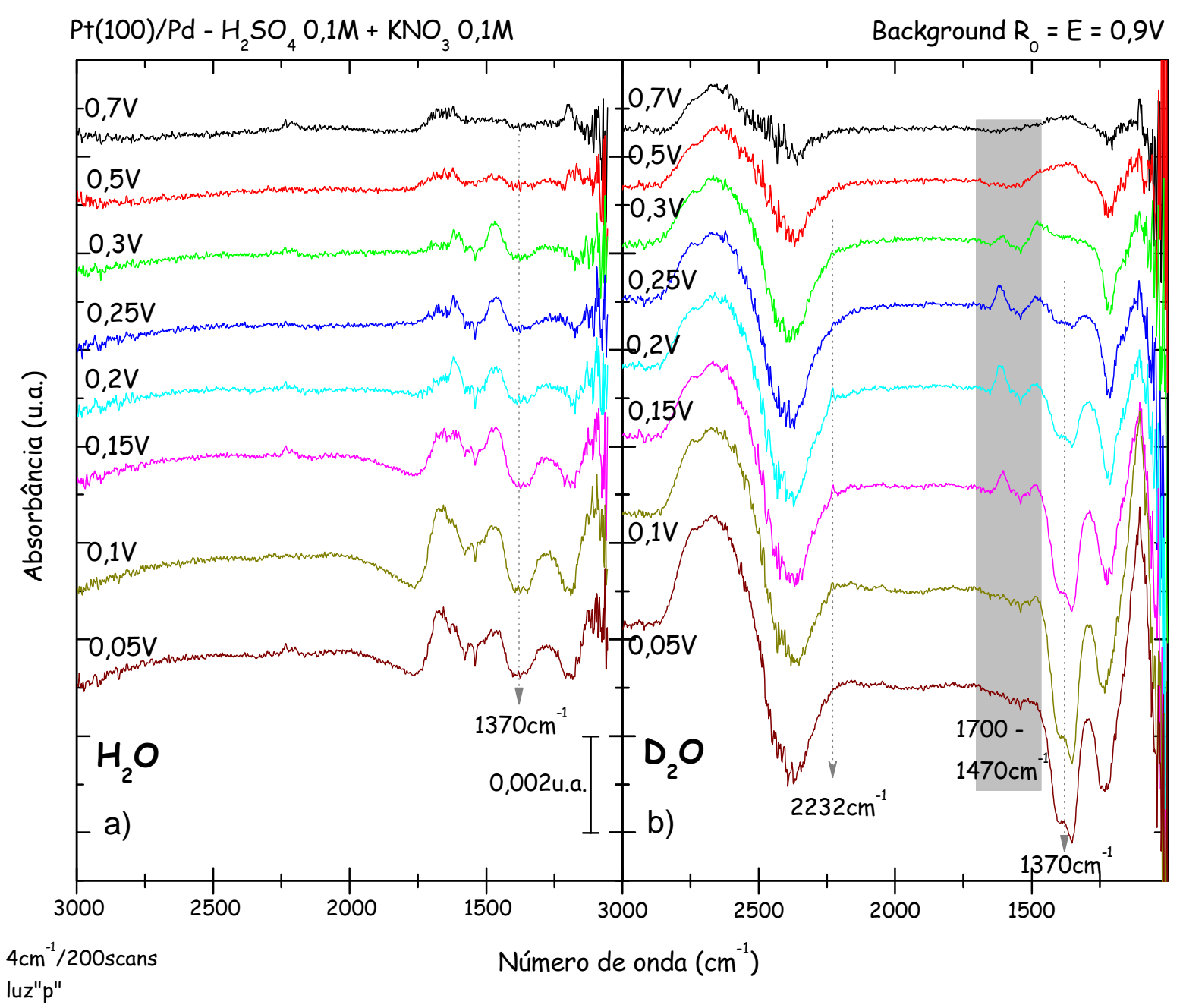

Figura 28: FTIR da redução de nitrato em $\mathrm{Pt}(100)$ com multicamadas de $\mathrm{Pd}$ em $\mathrm{H}_{2} \mathrm{SO}_{4}$ 0,1 $\mathrm{M}$ e $\mathrm{KNO}_{3}$ $0,1 \mathrm{M}$. (a) $\mathrm{H}_{2} \mathrm{O}$ e (b) $\mathrm{D}_{2} \mathrm{O}$. Referência 0,9 V. Espectros compostos por 200 scans com resolução de $4 \mathrm{~cm}^{-1}$. Luz "p".

Em ácido perclórico a formação de $\mathrm{N}_{2} \mathrm{O}$ também somente é observada quando o solvente é $\mathrm{D}_{2} \mathrm{O}$ (Figura 29b). O consumo de nitrato se inicia em potenciais mais positivos que em ácido sulfúrico $\left(>0,3 \mathrm{~V}\right.$ em $D_{2} \mathrm{O}$ e possivelmente antes em $\mathrm{H}_{2} \mathrm{O}$ - Figura 29a). Neste caso, o aparecimento de um pico em $1209 \mathrm{~cm}^{-1}\left(\mathrm{em} \mathrm{D}_{2} \mathrm{O}\right)$ sugere que possa haver a formação de $\mathrm{ND}_{4}{ }^{+}$, mas a proximidade com o pico de $\mathrm{ClO}_{4}^{-}$coloca uma certa dúvida na identificação dessa espécie. 


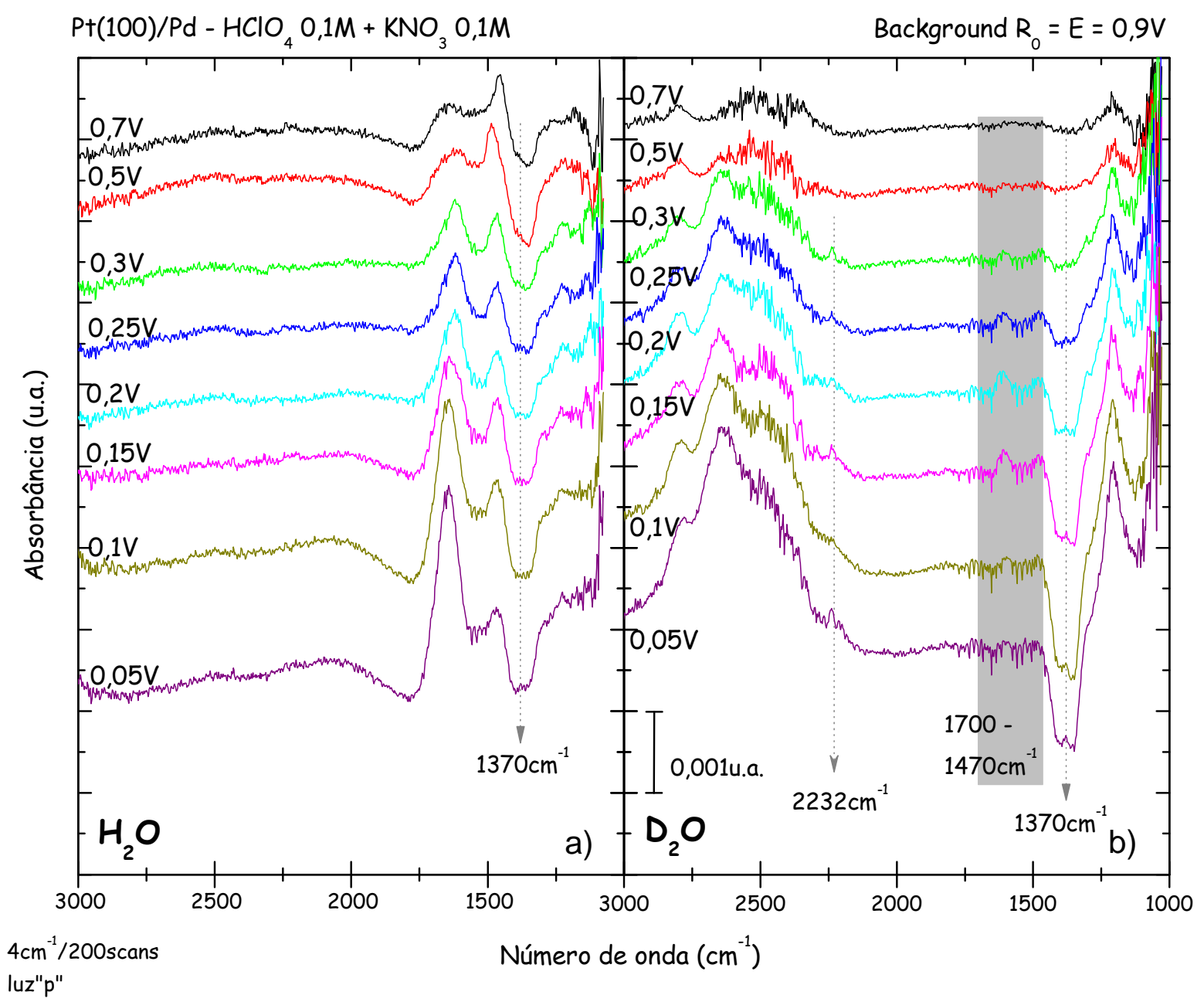

Figura 29: FTIR da redução de nitrato em $\mathrm{Pt}(100)$ com multicamadas de $\mathrm{Pd}$ em $\mathrm{HClO}_{4}$ 0,1 $\mathrm{M}$ e $\mathrm{KNO}_{3}$ $0,1 \mathrm{M}$. (a) $\mathrm{H}_{2} \mathrm{O}$ e (b) $\mathrm{D}_{2} \mathrm{O}$. Referência 0,9 V. Espectros compostos por 200 scans com resolução de $4 \mathrm{~cm}^{-1}$. Luz "p".

\subsubsection{Pt(110) modificado por paládio}

Diferentemente dos casos anteriores, o depósito de paládio em Pt(110) ainda não está totalmente claro na literatura [28, 32]. Foi então feito um estudo para entender melhor este processo e se certificar que a quantidade de paládio depositada para o estudo da redução de nitrato era correspondente a multicamadas. 
Assim como para $\mathrm{Pt}(111)$ e $\mathrm{Pt}(100)$, o paládio foi depositado pelo método eletroquímico. Para acompanhar todas as etapas do depósito, assim como nos demais casos, foi utilizada uma concentração baixa de $\mathrm{PdSO}_{4}\left(2,5 \times 10^{-6} \mathrm{M}\right)$, para que o depósito fosse lento. Em concentrações maiores de $\mathrm{Pd}^{2+}$, a deposição se tornava rápida demais, não sendo possível observar a diminuição dos picos referentes à $\mathrm{Pt}(110)$.

A Figura 30 mostra a evolução do depósito de paládio em $\operatorname{Pt}(110)$, sendo mostrada uma curva para cada 20 ciclos. É possível ver que os picos correspondentes à adsorção de ânions e hidrogênio em $\operatorname{Pt}(110)$ diminuem, mas nenhum pico definido que possa ser atribuído ao $\mathrm{Pd}$ aparece. Dois pontos isopotenciais podem ser vistos na varredura catódica: o primeiro, em baixos recobrimentos, em 0,17 $\mathrm{V}$ e o segundo, em recobrimentos mais altos, em $0,19 \mathrm{~V}$.

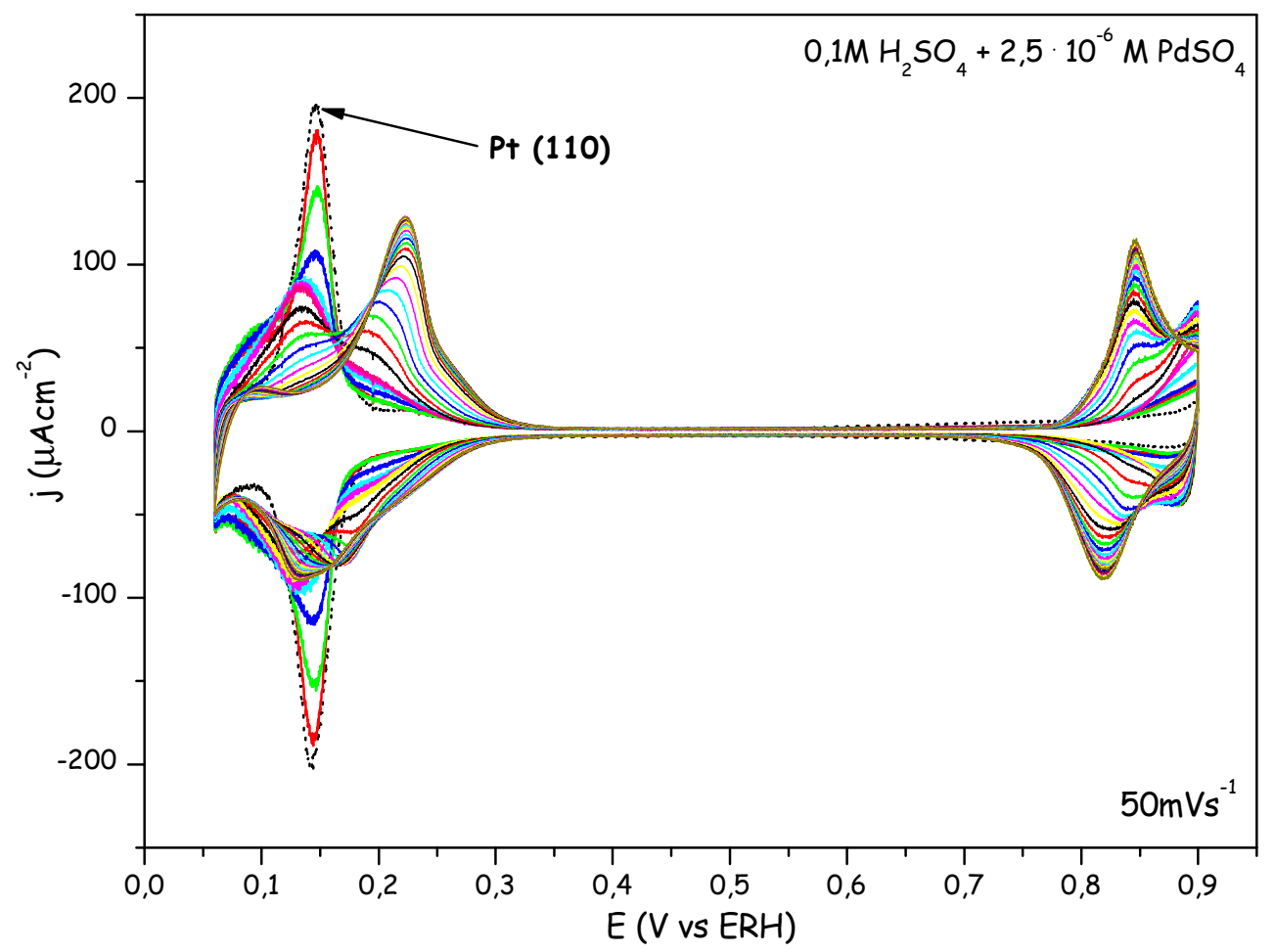

Figura 30: Depósito de paládio em $\mathrm{Pt}(110)$. Solução: $2,510^{-6} \mathrm{M} \mathrm{PdSO}_{4}$ em $\mathrm{H}_{2} \mathrm{SO}_{4} 0,1 \mathrm{M}$. Uma curva mostrada para cada 20. Velocidade de varredura $50 \mathrm{mVs}^{-1}$. 
A informação obtida a partir dos resultados voltamétricos apresentados na Figura 30 não é suficiente para determinar quando a primeira camada de Pd está completa ou se o depósito atingiu o nível de multicamadas. Assim, para tentar entender as mudanças durante o depósito de paládio, as cargas totais dos voltamogramas, entre 0,06 e 0,4 V foram medidas e são graficadas na Figura 31 em função do número de ciclos. A carga total diminui até um mínimo quando começa a crescer e, finalmente, depois de vários ciclos, permanece praticamente estável. O ponto de mínima carga pode estar relacionado com uma mudança na superfície do eletrodo, talvez quando a primeira monocamada está completa, mas é necessário obter-se informações adicionais para esclarecer esta etapa.

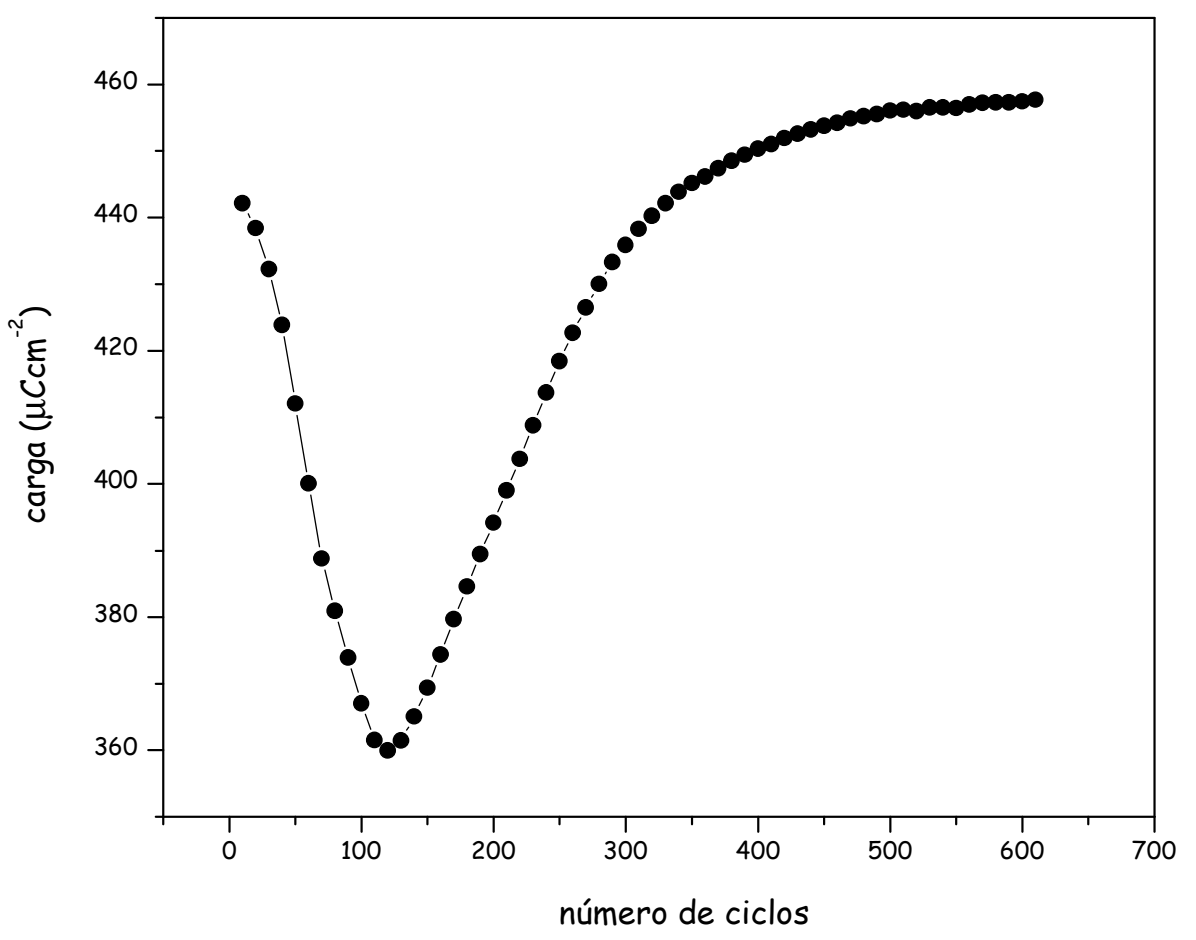

Figura 31: Carga total entre 0,06 e $0,4 \mathrm{~V}$ dos voltamogramas apresentados na Figura 30 para o depósito de Pd em Pt(111).

A Figura 32 mostra voltamogramas de depósitos com diferentes quantidades de paládio. As curvas vermelha e verde coincidem com o aparecimento do primeiro 
$(0,17)$ e do segundo $(0,19 \mathrm{~V})$ pontos de isopotencial, respectivamente. Experimentos envolvendo medidas de carga deslocada por CO e de oxidação de CO adsorvido foram efetuados tendo como meta entender essas mudanças.

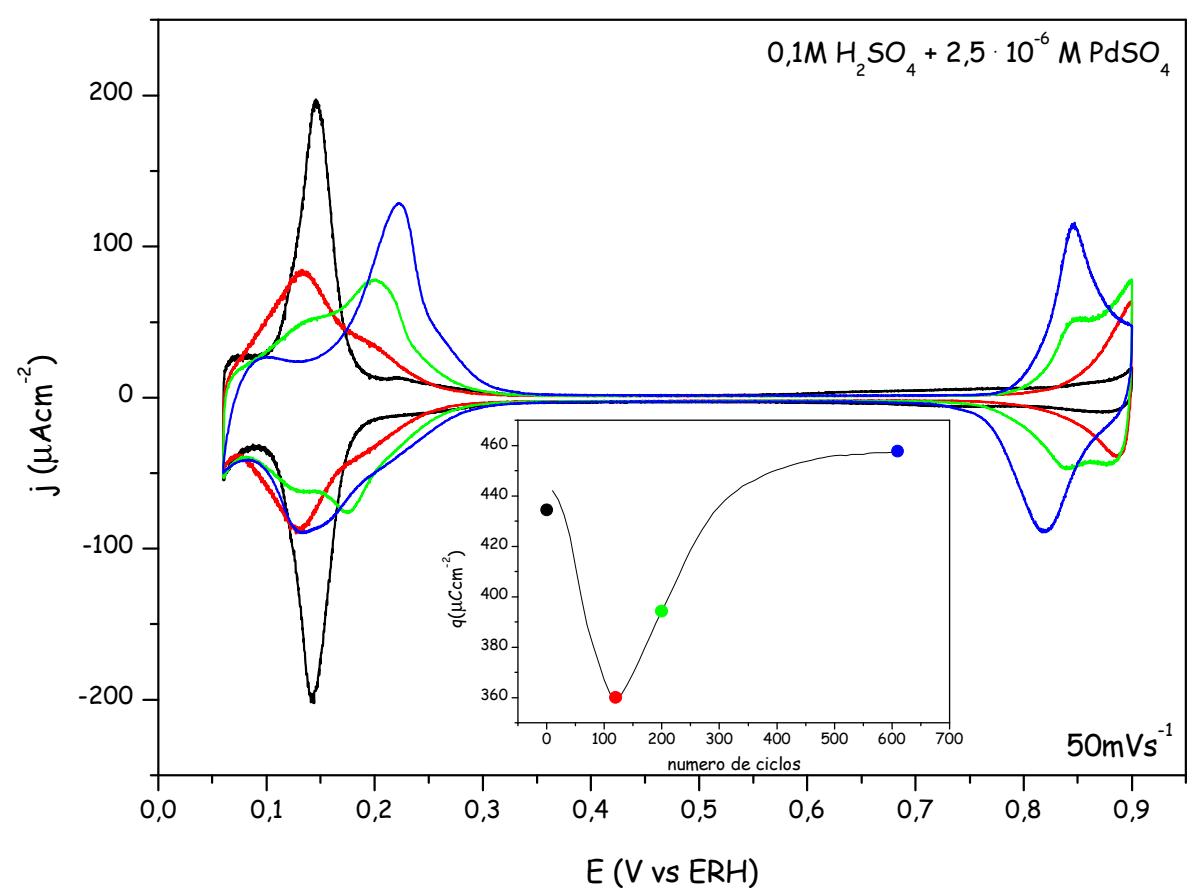

Figura 32: Voltamogramas de $\mathrm{Pt}(110)$ modificado por diferentes quantidades de Pd. Inserto: evolução da carga total como mostrada na Figura 31 e as cargas de cada voltamograma estão indicadas com a mesma

\subsubsection{Carga deslocada por CO}

As cargas deslocadas por $\mathrm{CO}$ a $0,1 \mathrm{~V}$, em $\mathrm{Pt}(110)$ com diferentes coberturas de Pd são apresentadas na Figura 33a. É possível ver que a carga mínima deslocada coincide com a carga mínima total entre 0,06 e 0,4 V. 

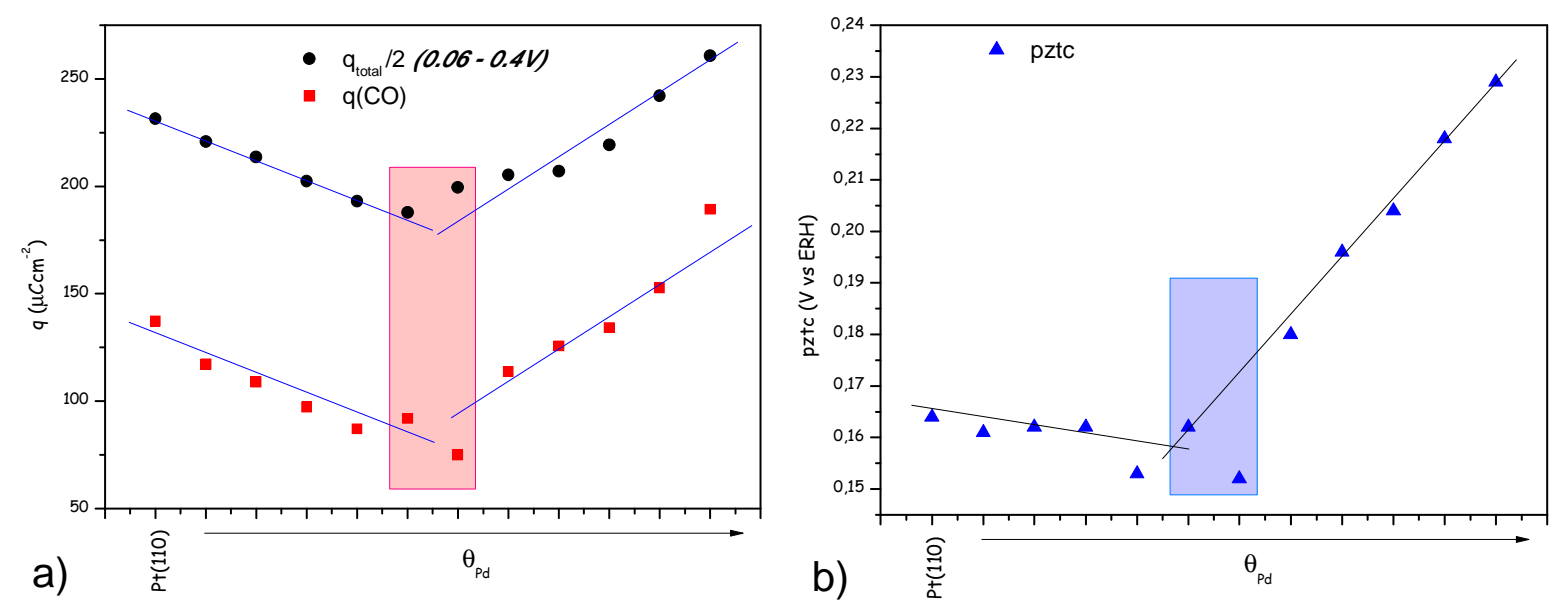

Figura 33: a) Carga deslocada por $\mathrm{CO}$ a $0,1 \mathrm{~V}$ em 0,1 $\mathrm{M} \mathrm{H}_{2} \mathrm{SO}_{4}(\mathrm{q}(\mathrm{CO})$ ) e a carga total entre $0,06 \mathrm{e}$ $0,4 \mathrm{~V}$ dividida por 2 ( $\left.\mathrm{q}_{\mathrm{total}} / 2\right)$ de eletrodos de $\mathrm{Pt}(110)$ com diferentes coberturas de $\left(\theta_{\mathrm{Pd}}\right)$. b) Potencial de Carga Total (pctz) dos mesmos eletrodos de (a).

Usando as cargas deslocadas como constante de integração das curvas voltamétricas é possível determinar o Potencial de Carga Total Zero (pctz) de cada um dos eletrodos com os diferentes recobrimentos de Pd (Equação 14) sendo este resultado apresentado na Figura 33b. Foi utilizada a média entre os valores obtidos entre as duas varreduras (positiva e negativa).

Estes resultados mostram uma mesma tendência em todos os casos, sendo o mínimo sempre correspondente a mesma quantidade de paládio depositado, mas estes dados apresentados até o momento ainda não são suficientes para determinar o que ocorre nesse ponto.

\subsubsection{Oxidação de CO}

A Figura 34 mostra a oxidação de $\mathrm{CO}$ em $\mathrm{Pt}(110)$ com diferentes coberturas de $\mathrm{Pd}$. A oxidação é deslocada para potenciais mais positivos com o aumento da 
quantidade de paládio. Os resultados apresentados na Figura 34 sugerem que o CO adsorvido em Pd é oxidado em potenciais mais positivos que o $\mathrm{CO}$ adsorvido em Pt. Alguns experimentos de FTIR - in situ foram feitos para se obter maiores informações sobre esse processo.

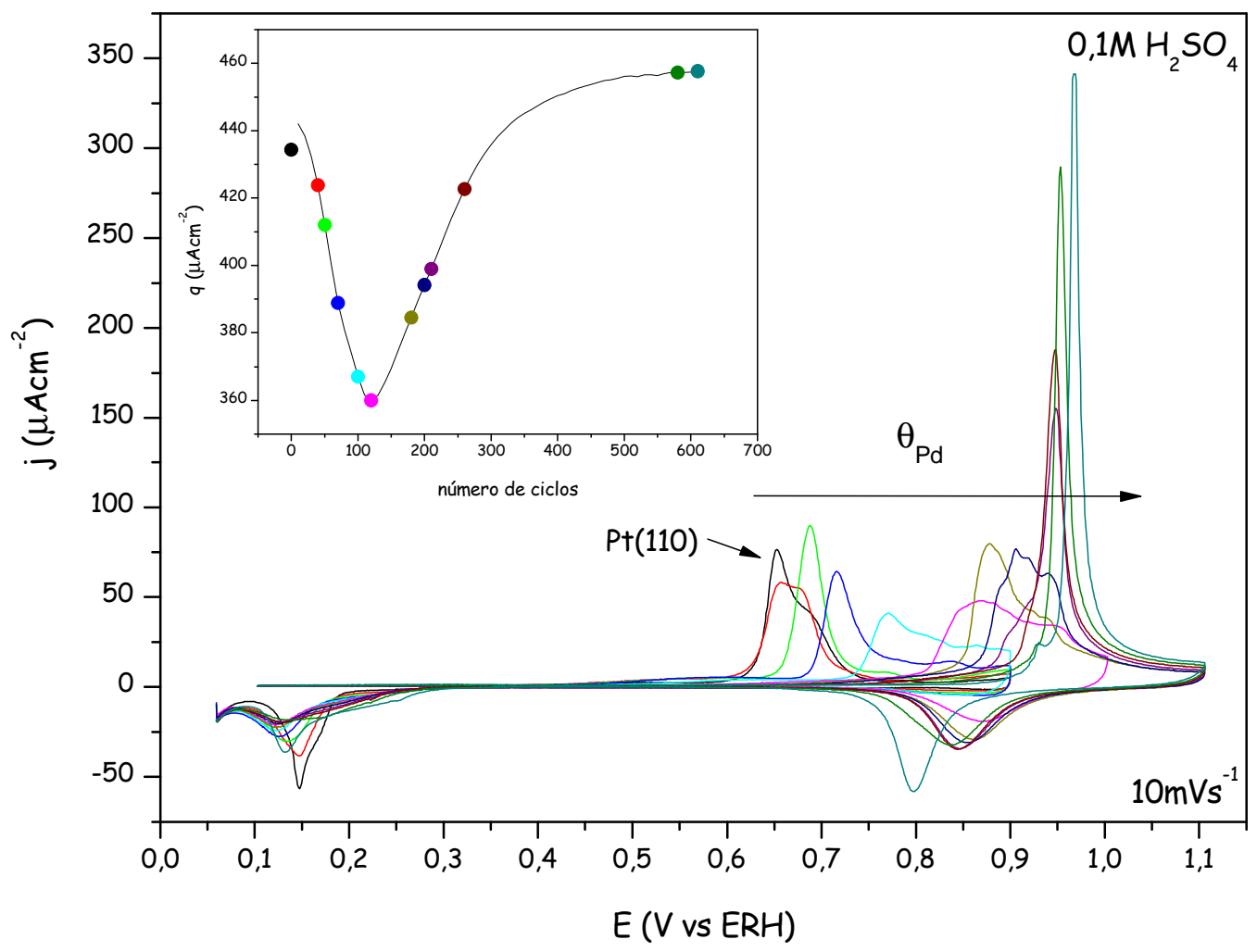

Figura 34: Oxidação de $\mathrm{CO}$ em $\mathrm{Pt}(110)$ modificada por Pd. Inserto: mesmo que a Figura 31 e os símbolos indicam a carga correspondente à cobertura de $\mathrm{Pd}$ de cada oxidação de $\mathrm{CO}$.

\subsubsection{Experimentos de FTIR}

Dois experimentos diferentes foram feitos usando FTIR. O primeiro visava observar a adsorção de $\mathrm{CO}$ em $\mathrm{Pt}$ e $\mathrm{Pd}, \mathrm{a} \mathrm{E}=0,1 \mathrm{~V}$, que aparecem em números de onda diferentes, e os resultados são apresentados na Figura 35. O segundo tinha com objetivo acompanhar o deslocamento do potencial de oxidação do $\mathrm{CO}$, no qual os espectros foram registrados (1 espectro a cada $5 \mathrm{mV}$ ) durante a oxidação de CO 
(feita a $1 \mathrm{mVs}^{-1}$ ). A Figura 36 mostra os resultados para $\mathrm{Pt}(110)$ e para três eletrodos de $\operatorname{Pt}(110)$ modificados por paládio: antes da carga total mínima, na carga mínima e depois da carga mínima total.
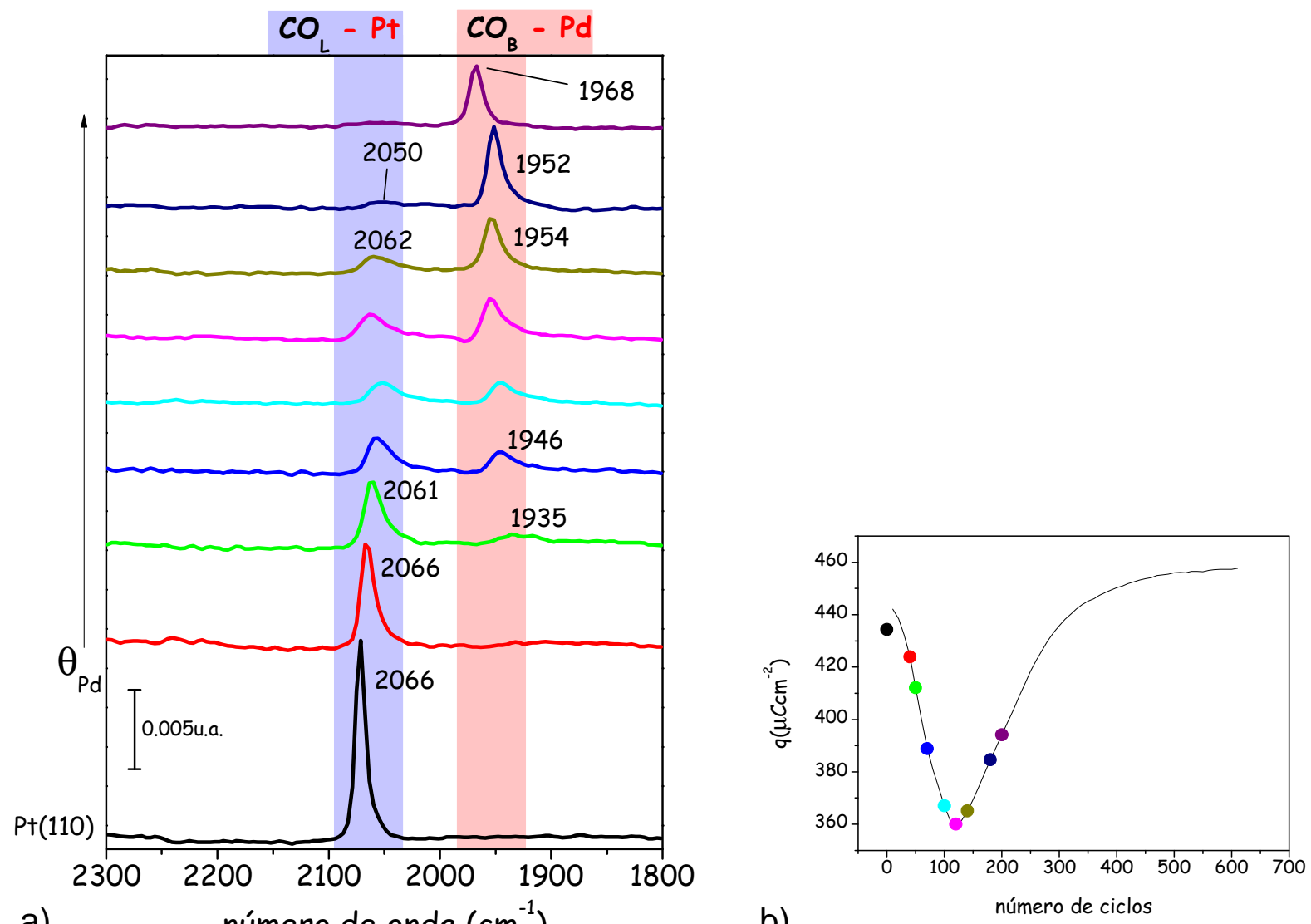

Figura 35: a) Espectro de FTIR in situ registrado em 0,10 V para uma camada saturada de CO adsorvido em diferentes coberturas de $\mathrm{Pd}$; potencial de referência: $1.0 \mathrm{~V}$ após a oxidação do $\mathrm{CO}$; Eletrólito suporte: $0,1 \mathrm{M} \mathrm{H}_{2} \mathrm{SO}_{4}$. b) Mesmo que Figura 31 e os símbolos indicam a carga correspondente a cada cobertura de Pd para cada espectro apresentado em (a).

A partir dos resultados espectroeletroquímicos apresentados na Figura 35 é possível concluir que a cobertura de paládio que apresenta a mínima carga não corresponde a primeira camada completa. Neste ponto ainda é possível ver o pico correspondente ao CO adsorvido em Pt (em torno de $2066 \mathrm{~cm}^{-1}$ ). Este pico somente desaparece quando uma maior quantidade de paládio é depositada, isto é, depois 
que a carga mínima foi obtida. Isso está de acordo com o aparecimento do segundo ponto de isopotencial apresentado na Figura 32.

O ponto mínimo pode estar relacionado ao começo do depósito de $\mathrm{Pd}$ em átomos de Pd já depositados na superfície, com o crescimento da segunda camada antes que a primeira esteja completa, assim como acontece com a $\mathrm{Pt}(100)$ [58]. Isso não pode se comprovado até agora, mas é possível assegurar que, depois do aparecimento do segundo ponto de isopotencial, não existem mais sítios de Pt na superfície do eletrodo e somente a contribuição de átomos de Pd pode ser vista.
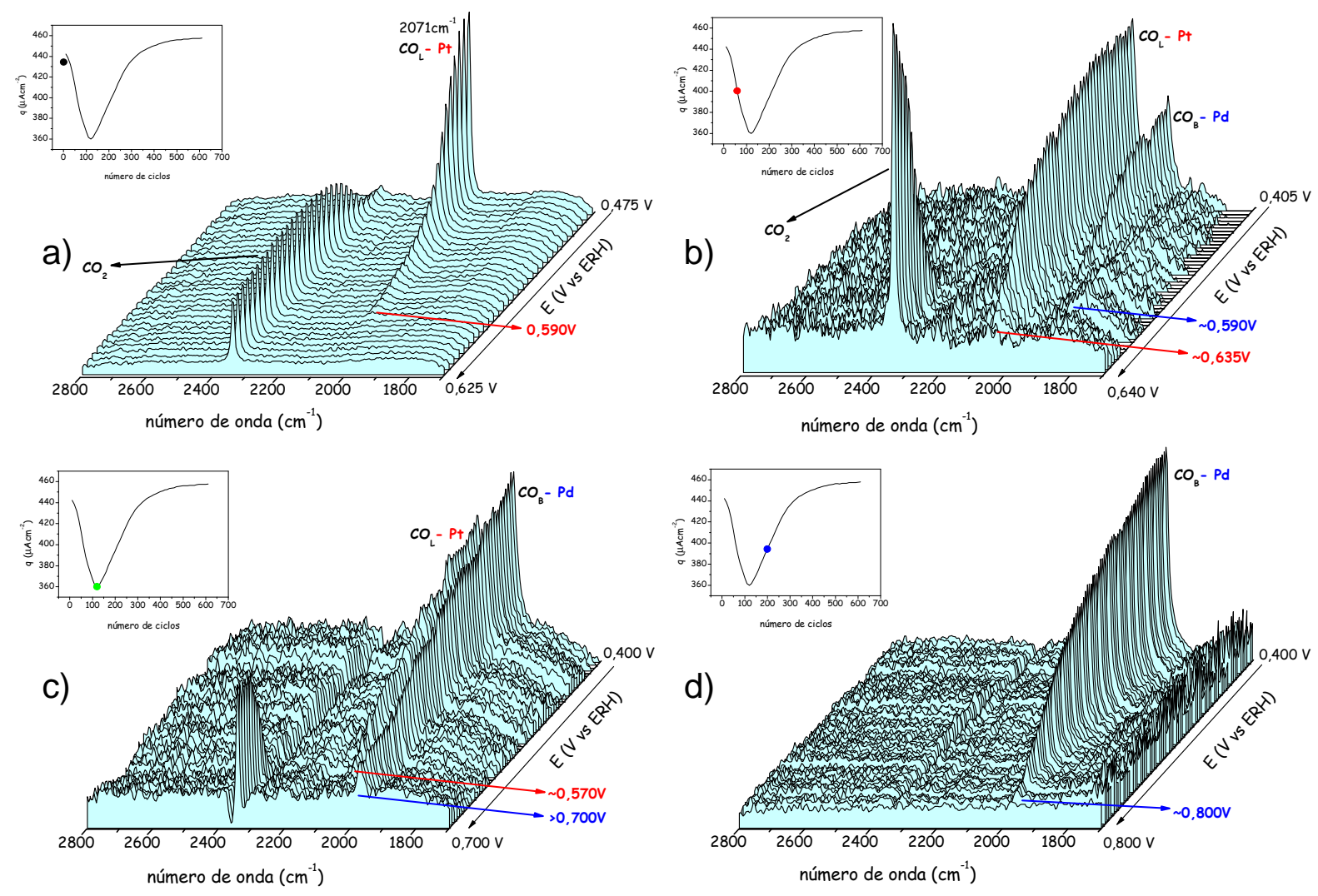

Figura 36: Séries de espectros de FTIR obtidos durante a oxidação de CO: a) Pt(110); b) Pt(110) modificado por $\mathrm{Pd}$ com carga total anterior à mínima; c) $\mathrm{Pt}(110)$ modificado por $\mathrm{Pd}$ com carga total mínima; d) $\mathrm{Pt}(110)$ modificado por $\mathrm{Pd}$ com carga total posterior à mínima (somente $\mathrm{Pd}$ na superfície do eletrodo). Insertos em b-d mostram a carga total de cada depósito de Pd. Eletrólito suporte: $\mathrm{H}_{2} \mathrm{SO}_{4}$ $0,1 \mathrm{M}$, velocidade de varredura $1 \mathrm{mVs}^{-1}, 1$ espectro a cada $5 \mathrm{mV}$, resolução $8 \mathrm{~cm}^{-1}$. 
$\mathrm{Na}$ Figura 36a $(\mathrm{Pt}(110))$ é possível ver o pico correspondente ao CO adsorvido linearmente em Pt, em $2071 \mathrm{~cm}^{-1}$. Este pico diminui com o aumento do potencial, indicando a oxidação do $\mathrm{CO}$, e um segundo pico aparece em $2345 \mathrm{~cm}^{-1}$, correspondente ao $\mathrm{CO}_{2}$ formado pela oxidação do $\mathrm{CO}$. A oxidação do $\mathrm{CO}$ termina em torno de 0,59 V. Quando a superfície do eletrodo de Pt(110) é modificada com paládio (uma quantidade correspondente a uma carga total anterior à mínima), dois picos podem ser vistos em 0,1 V (Figura 36b), um correspondente ao CO adsorvido em Pt (linear) e outro correspondente ao CO adsorvido em Pd (ponte). Ambos os picos diminuem com o aumento do potencial como resultado da oxidação do $\mathrm{CO}$, mas o pico de $\mathrm{CO}$ adsorvido em Pd desaparece primeiro que o pico de $\mathrm{CO}$ em $\mathrm{Pt}$, indicando que CO-Pd é oxidado antes do CO-Pt. Quando a cobertura de paládio é maior (Figura 36c), o inverso ocorre, ou seja, o pico de CO adsorvido em Pd é o último a desaparecer. Finalmente, quando há somente átomos de Pd na superfície do eletrodo (Figura 36d) o potencial da oxidação total do CO é mais alto que nos casos anteriores.

Estes resultados mostram que a presença de Pd não melhora a oxidação de $\mathrm{CO}$ e que $\mathrm{CO}$ adsorvido em Pd se oxida em diferentes potenciais dependendo da cobertura de Pd.

Os resultados obtidos na investigação do depósito de paládio em $\operatorname{Pt}(110)$ apresentados na Figura 32 mostram que após o segundo ponto isopotencial, a superfície do eletrodo já está totalmente coberta por Pd. Frente a isso, neste estudo, o depósito de paládio foi feito por mais vários ciclos após este ponto, chegando num estágio de carga constante, conforme mostrado na Figura 31, garantindo assim uma 
contribuição majoritária de átomos de $\mathrm{Pd}$ de camadas posteriores à primeira. $\mathrm{O}$ voltamograma cíclico para este eletrodo em $\mathrm{H}_{2} \mathrm{SO}_{4}$ 0,1 M é mostrado na Figura 37. O voltamograma em $\mathrm{HClO}_{4}$ 0,1 $\mathrm{M}$ é apresentado na Figura 38. Os perfis observados são similares ao que já foi anteriormente apresentado em outros trabalhos [25, 28] para sistemas e condições experimentais equivalentes, em particular para $\mathrm{H}_{2} \mathrm{SO}_{4}$.

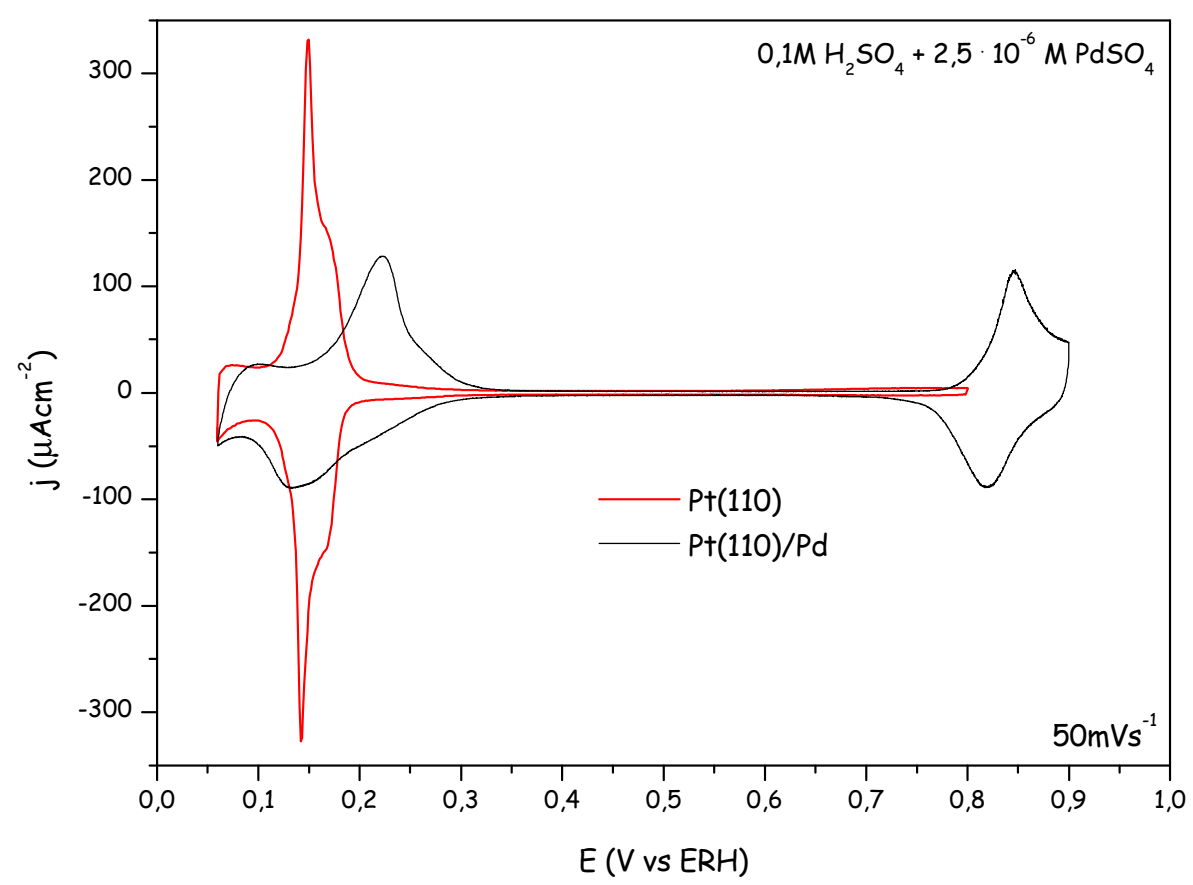

Figura 37: Voltametria cíclica de multicamadas de paládio em $\mathrm{Pt}(110)$. Solução: $2,510^{-6} \mathrm{M} \mathrm{PdSO}_{4}$ em $\mathrm{H}_{2} \mathrm{SO}_{4} 0,1 \mathrm{M}$ (linha preta). Linha vermelha: branco Pt(110). Velocidade de varredura $50 \mathrm{mVs}^{-1}$.

Nota-se que o voltamograma não apresenta nenhuma simetria em relação ao potencial do pico e as correntes envolvidas. O pico de oxidação de hidrogênio atômico aparece em torno de $0,22 \mathrm{~V}$, enquanto que o pico de redução aparece em $0,13 \mathrm{~V}$, com ombros em 0,15 e $0,21 \mathrm{~V}$, aproximadamente. Apesar da falta de simetria, as cargas elétricas de oxidação e de redução da região de adsorçãodessorção de hidrogênio, já descontada a contribuição da dupla camada, são muito próximas, em torno de $220 \mu \mathrm{Ccm}^{-2}$. $\mathrm{Em} \mathrm{HClO}_{4} 0,1 \mathrm{M}$ há o aparecimento de outro par 
redox localizado em $0,05 / 0,1 \mathrm{~V}$, provavelmente relacionado à reação de formação e oxidação de hidrogênio molecular.

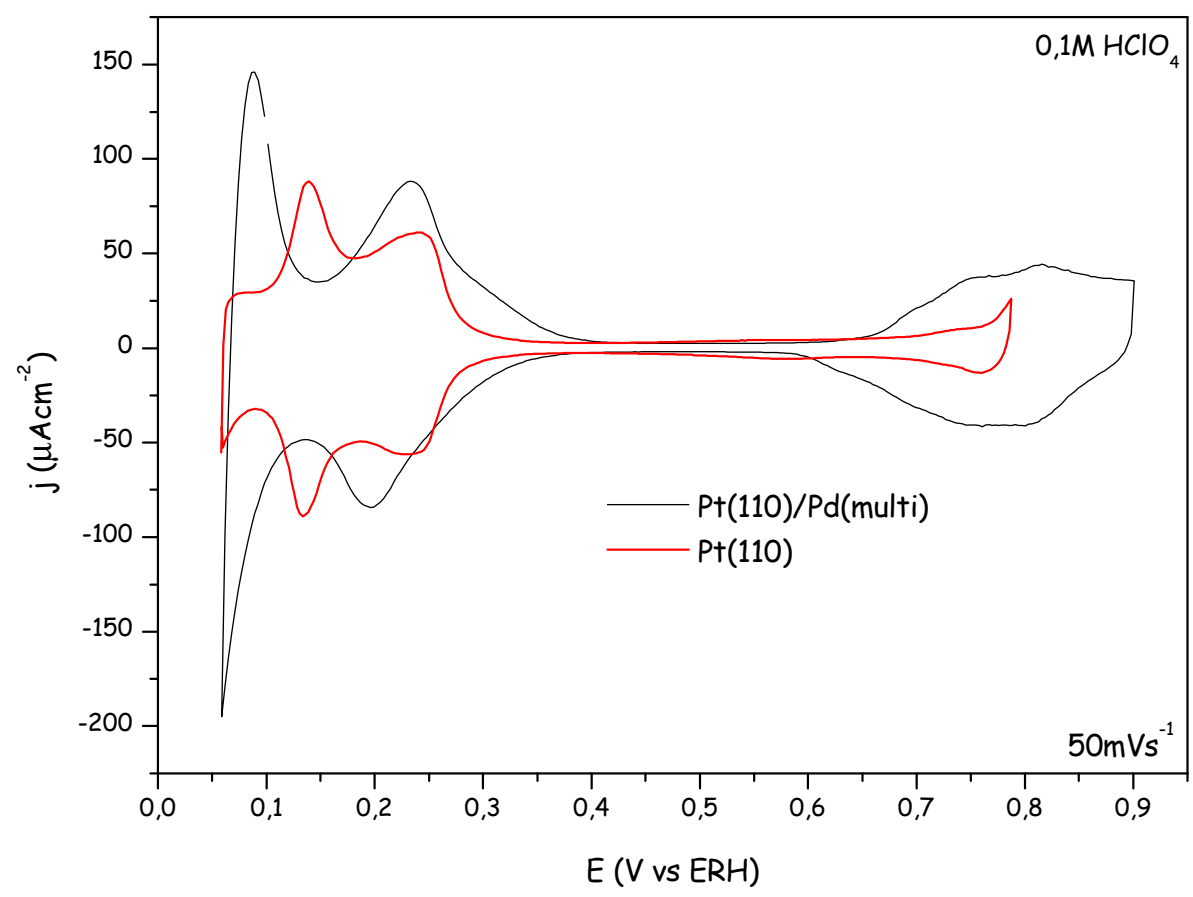

Figura 38: Voltametria cíclica de multicamadas de paládio em $\mathrm{Pt}(110)$ em $\mathrm{H}_{2} \mathrm{SO}_{4} 0,1 \mathrm{M}$ (linha preta). Linha vermelha: branco Pt(110). Velocidade de varredura $50 \mathrm{mVs}^{-1}$.

\subsubsection{Redução de Nitrato}

A Figura 39 apresenta as voltametrias cíclicas para a redução de nitrato em $\mathrm{Pt}(110)$ com multicamadas de paládio em $\mathrm{HClO}_{4}$ 0,1 M (Figura 39a) e em $\mathrm{H}_{2} \mathrm{SO}_{4}$ 0,1 M (Figura 39b). A redução ocorre em potenciais menos positivos que o pctz do eletrodo (pctz $=0,23 \mathrm{~V}$, conforme mostrado na Figura 33b). É possível calcular a carga de redução a partir dos voltamogramas a $2 \mathrm{mVs}^{-1}$ e estas são apresentadas na Figura 40a. A carga em ácido perclórico chega a ser cerca de 10 vezes maior que em ácido sulfúrico, assim como ocorre com a Pt (110) (Figura 9). A mesma explicação dada para o caso da $\mathrm{Pt}(110)$ pode ser usada neste caso: a adsorção de 
$\mathrm{SO}_{4}^{2-}$ compete com a de $\mathrm{NO}_{3}^{-}$enquanto que a adsorção de $\mathrm{ClO}_{4}^{-}$é fraca e não compete com o nitrato. Essa competição leva à adsorção de um número menor de moléculas de $\mathrm{NO}_{3}{ }^{-}$, gerando uma menor corrente de redução.
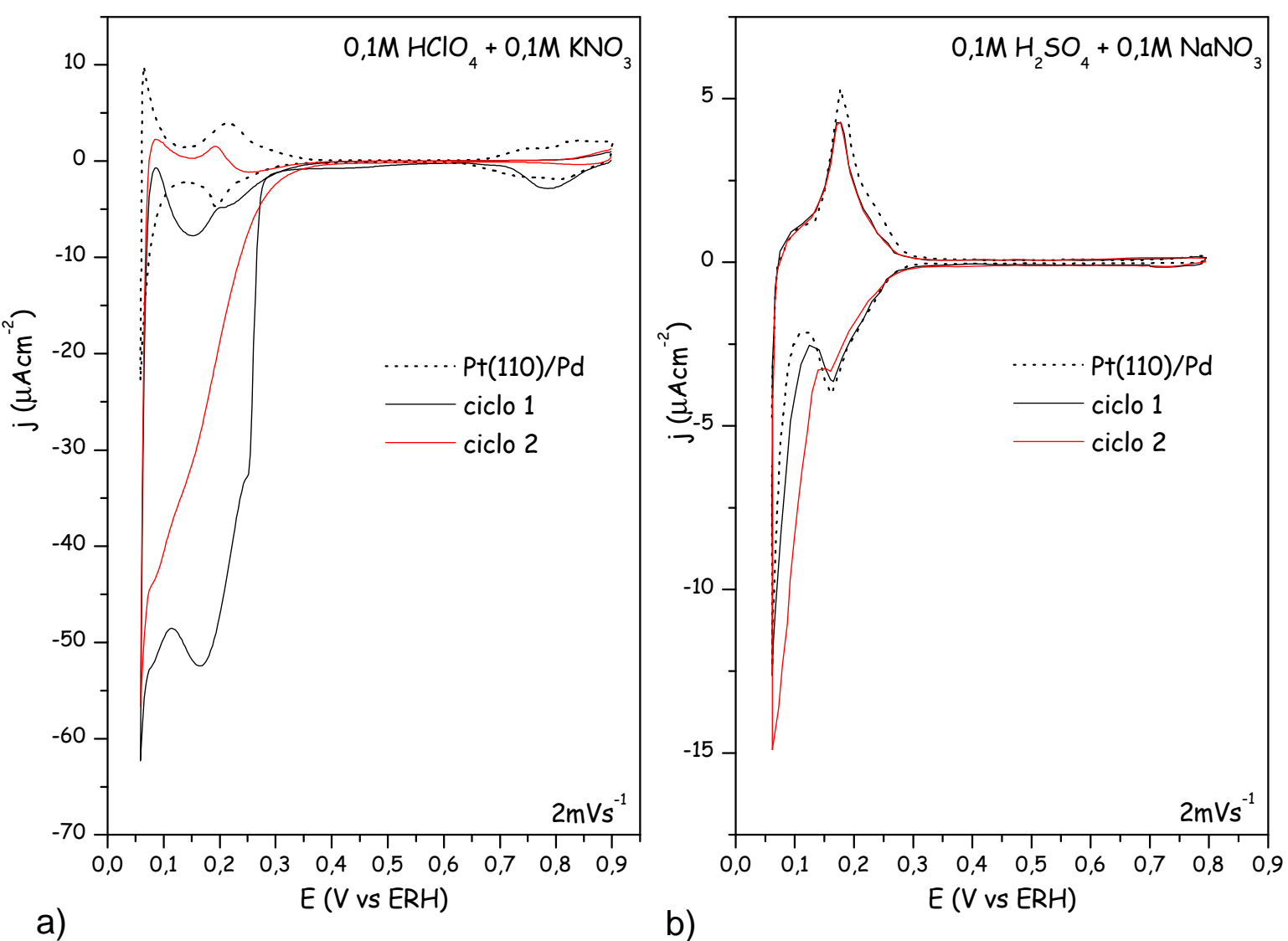

Figura 39: Voltamogramas de redução de nitrato em $\mathrm{Pt}(110)$ com multicamadas de $\mathrm{Pd}$. (a) $\mathrm{HClO}_{4}$ $0,1 \mathrm{M}+\mathrm{KNO}_{3} 0,1 \mathrm{M}$ e (b) $\mathrm{H}_{2} \mathrm{SO}_{4} 0,1 \mathrm{M}+\mathrm{NaNO}_{3} 0,1 \mathrm{M}$. Velocidade de varredura: $2 \mathrm{mVs}^{-1}$. Curva pontilhada: branco sem nitrato.

A $20 \mathrm{mVs}^{-1}$ a redução é muito lenta para ser vista em $\mathrm{H}_{2} \mathrm{SO}_{4}$, apresentando um voltamograma que sugere apenas o bloqueio da superfície, conforme pode ser visto na Figura 40b. Em $\mathrm{HClO}_{4}$ a reação parece ser mais rápida, sendo possível identificar correntes de redução mesmo a $10 \mathrm{mVs}^{-1}$, como mostrado na Figura 41a. No entanto a $50 \mathrm{mVs}^{-1}$, assim como em ácido sulfúrico, o que se vê é um bloqueio da superfície que pode ser observado na Figura 41b. 

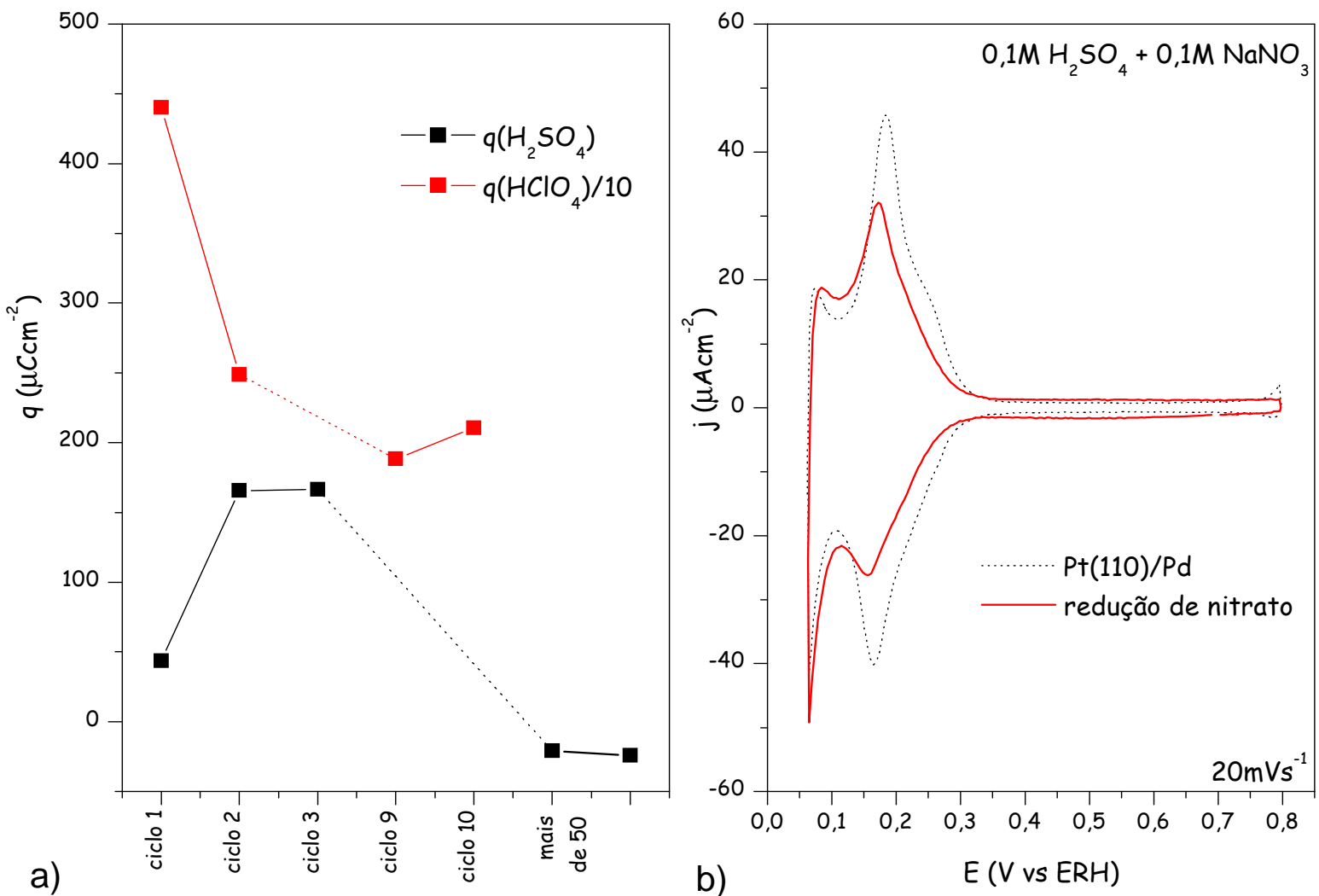

Figura 40: (a) Carga referente à redução de nitrato em $\mathrm{Pt}(110)$ modificada por $\mathrm{Pd}$ a $2 \mathrm{mVs}^{-1} \mathrm{em}$ $\mathrm{H}_{2} \mathrm{SO}_{4}$ 0,1 M (preto) e $\mathrm{HClO}_{4}$ 0,1 M (vermelho); (b) Voltamograma de redução de nitrato em $\mathrm{Pt}(110)$ com multicamadas de $\mathrm{Pd}$ em $\mathrm{H}_{2} \mathrm{SO}_{4} 0,1 \mathrm{M}+\mathrm{NaNO}_{3} 0,1 \mathrm{M} \mathrm{a} 20 \mathrm{mVs}^{-1}$ e branco sem nitrato (curva pontilhada).
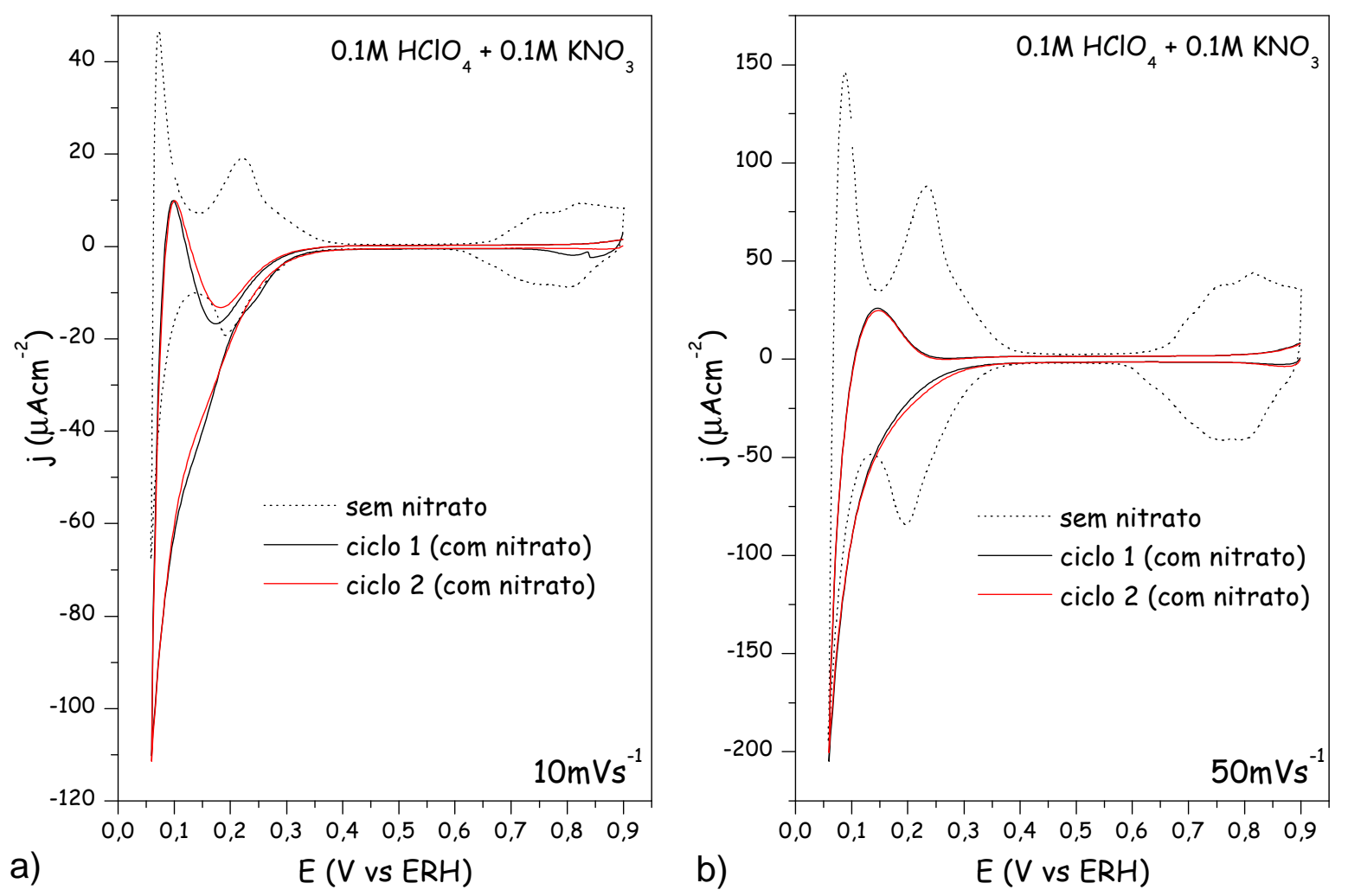

Figura 41: Voltamogramas de redução de nitrato em $\mathrm{HClO}_{4} 0,1 \mathrm{M}+\mathrm{KNO}_{3} 0,1 \mathrm{M}$ em $\mathrm{Pt}(110)$ com multicamadas de Pd. (a) $10 \mathrm{mVs}^{-1}$ e (b) $50 \mathrm{mVs}^{-1}$. Curva pontilhada: branco sem nitrato. 
A redução de uma camada saturada de $\mathrm{NO}_{(\text {ads) }}$ em $\mathrm{H}_{2} \mathrm{SO}_{4} \quad 0,1 \mathrm{M}$ em $\mathrm{Pt}(110) / P d$ é mostrada na Figura 42. O pico de redução aparece no mesmo potencial no qual a redução de nitrato é observada. Isso está de acordo com os casos anteriores, reforçando a sugestão que em multicamadas de paládio em platina o $\mathrm{NO}_{(\text {ads })}$ é um dos intermediários na redução de nitrato.

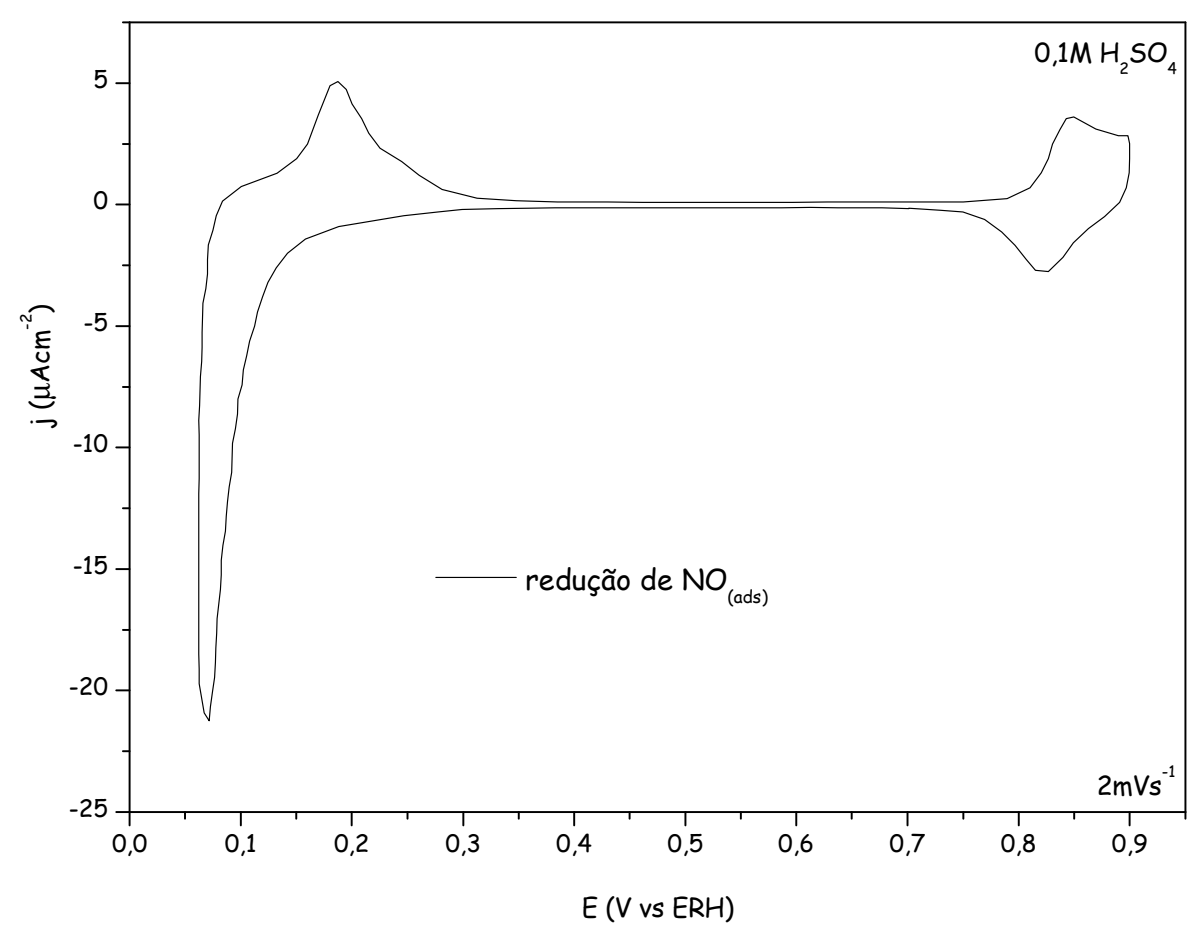

Figura 42: Redução de uma camada de $\mathrm{NO}_{(\text {ads })}$ em $\mathrm{Pt}(110)$ com multicamadas de $\mathrm{Pd}$ em $\mathrm{H}_{2} \mathrm{SO}_{4}$ 0,1 M a $2 \mathrm{mVs}^{-1}$.

Os resultados dos experimentos de FTIR para o eletrodo de $\mathrm{Pt}(110)$ com multicamadas de paládio podem ser vistos nas Figuras 43 e 44 . Em ácido sulfúrico o consumo de nitrato é notado em potenciais mais baixos que $0,2 \mathrm{~V}$ (Figura 43). Já em ácido perclórico o consumo de nitrato se inicia antes, em torno de 0,3 V (Figura 44).

Diferentemente dos casos anteriores, a formação de $\mathrm{N}_{2} \mathrm{O}$, que é identificado por um pico em $2232 \mathrm{~cm}^{-1}$, ocorre tanto em $\mathrm{H}_{2} \mathrm{O}$ como em $\mathrm{D}_{2} \mathrm{O}$, em ambos os 
eletrólitos, com picos mais intensos que nos casos anteriores. Outra diferença é a formação de um produto a potenciais mais baixos que $0,1 \mathrm{~V}$, com vibração em $2732 \mathrm{~cm}^{-1}$, que pode ser visto nas Figuras 43a e 44a. Esta banda é vista somente quando o solvente é $\mathrm{H}_{2} \mathrm{O}$, o que indica que se trata de um produto hidrogenado. Uma possibilidade é que este produto seja hidroxilamina, que tem uma banda nesse mesmo número de onda, conforme mostrado na Figura 2.

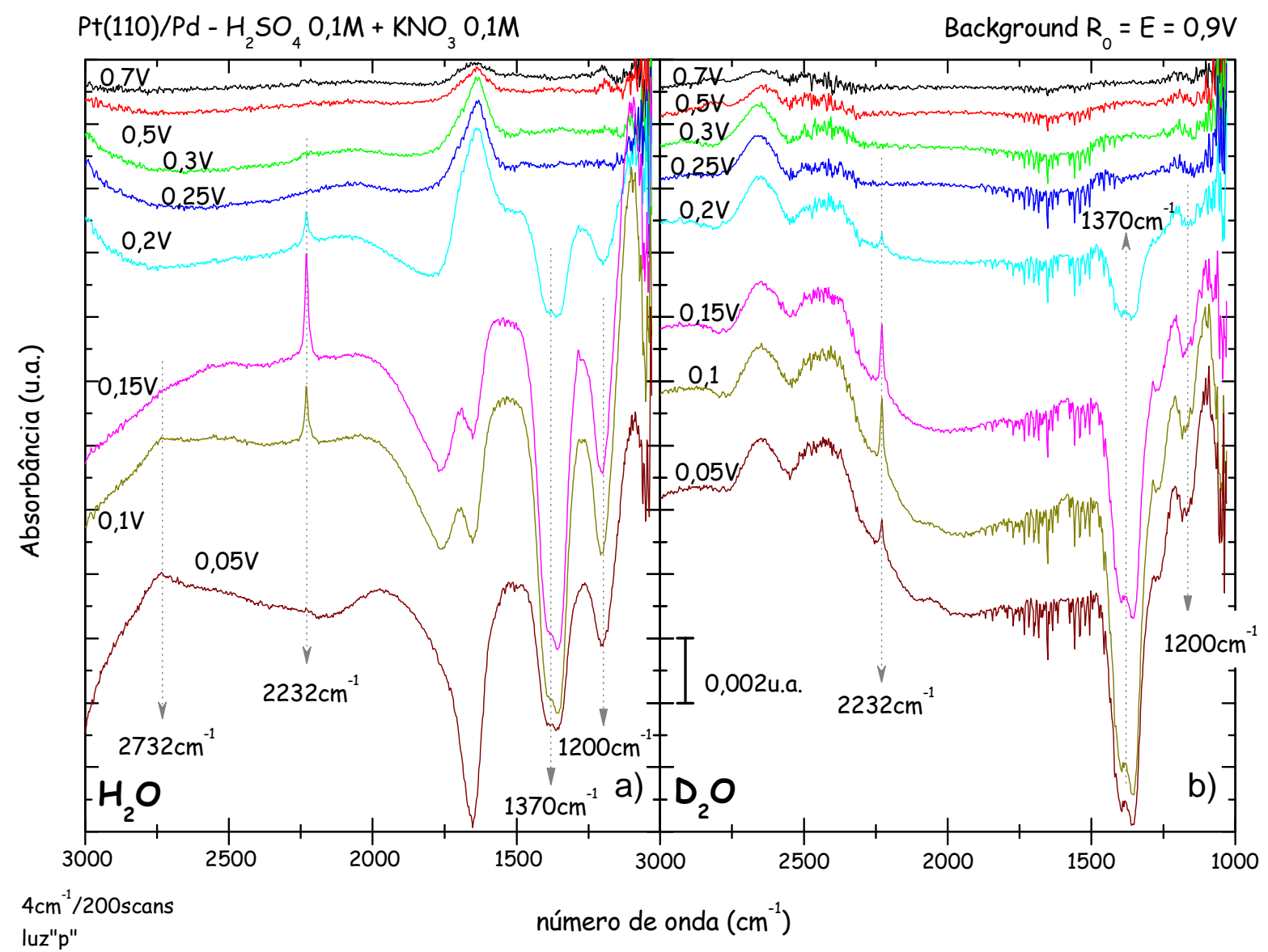

Figura 43: FTIR da redução de nitrato em $\mathrm{Pt}(110)$ com multicamadas de $\mathrm{Pd}$ em $\mathrm{H}_{2} \mathrm{SO}_{4}$ 0,1 $\mathrm{M} \mathrm{e} \mathrm{KNO}_{3}$ $0,1 \mathrm{M}$. (a) $\mathrm{H}_{2} \mathrm{O}$ e (b) $\mathrm{D}_{2} \mathrm{O}$. Referência 0,9 V. Espectros compostos por 200 scans com resolução de $4 \mathrm{~cm}^{-1}$. Luz "p".

$\mathrm{Em} \mathrm{HClO}_{4}$ 0,1 M não foi observado o aparecimento da banda em $1215 \mathrm{~cm}^{-1}$ em $\mathrm{D}_{2} \mathrm{O}$, que seria correspondente à formação de $\mathrm{ND}_{4}{ }^{+}$. Por outro lado, um pico nesta região $\left(1200 \mathrm{~cm}^{-1}\right)$ é observado em $\mathrm{H}_{2} \mathrm{SO}_{4}$ 0,1 M, o qual torna-se mais intenso 
abaixo de $0,2 \mathrm{~V}$. Porém, como este pico é negativo e aparece tanto em $\mathrm{H}_{2} \mathrm{O}$ como em $\mathrm{D}_{2} \mathrm{O}$, não é possível relacioná-lo ao $\mathrm{ND}_{4}{ }^{+}$. Este pico está provavelmente relacionado à vibração de $\mathrm{SO}_{4}{ }^{2-}$ adsorvido. Da mesma forma que nos casos anteriores, uma série de picos pode ser vista na região entre 1470 e $1700 \mathrm{~cm}^{-1}$, sendo vistos mais claramente quando o eletrólito é ácido perclórico e o solvente $D_{2} \mathrm{O}$ (Figura 44b).

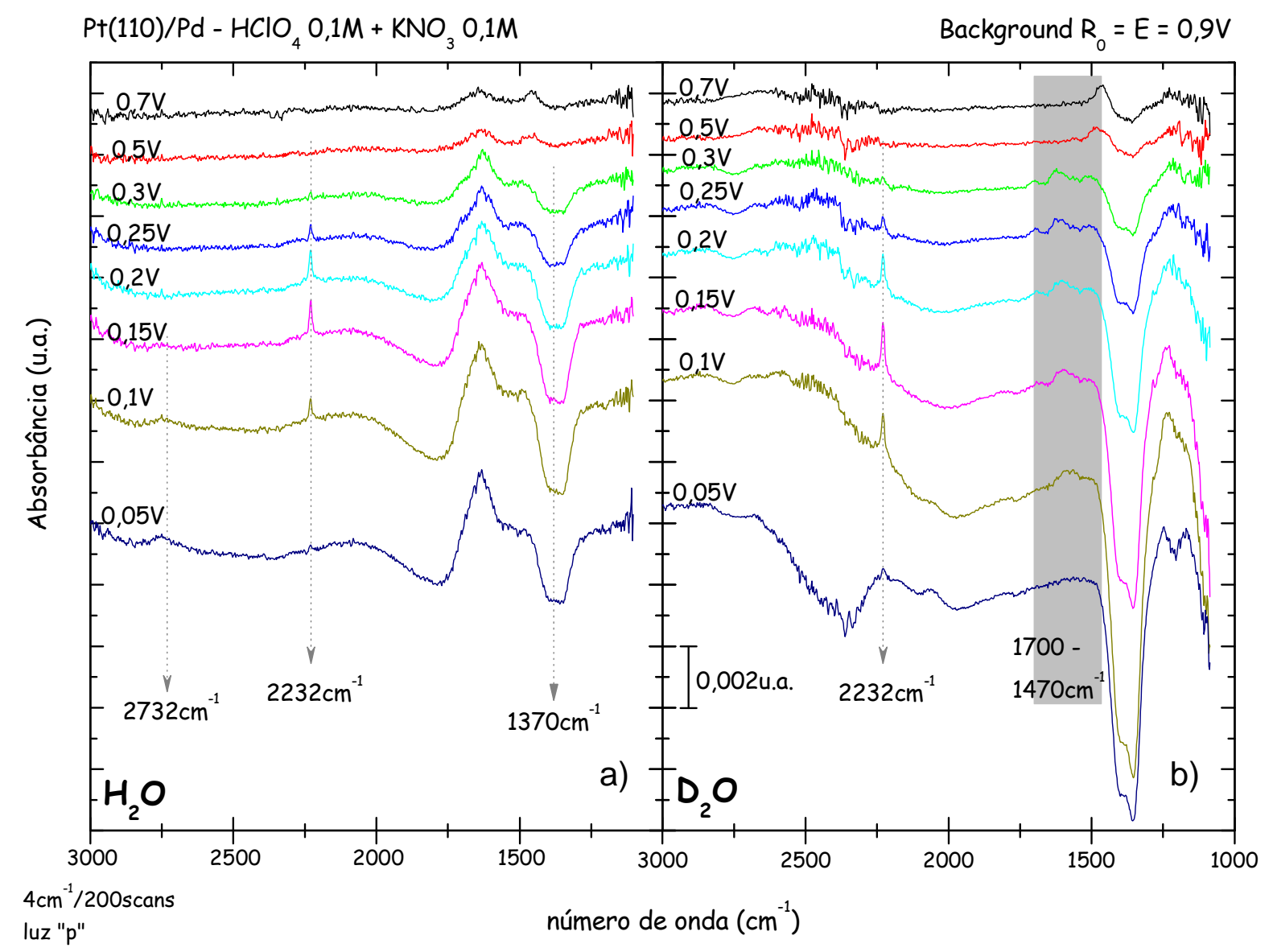

Figura 44: FTIR da redução de nitrato em $\mathrm{Pt}(110)$ com multicamadas de $\mathrm{Pd}$ em $\mathrm{HClO}_{4}$ 0,1 $\mathrm{M}$ e $\mathrm{KNO}_{3}$ $0,1 \mathrm{M}$. (a) $\mathrm{H}_{2} \mathrm{O}$ e (b) $\mathrm{D}_{2} \mathrm{O}$. Referência 0,9 V. Espectros compostos por 200 scans com resolução de $4 \mathrm{~cm}^{-1}$. Luz "p".

Para entender melhor a região entre 1700 e $1470 \mathrm{~cm}^{-1}$ foram feitos experimentos saltando diretamente de 0,9 para 0,15 V, com luz "p" e luz "s" para identificar as espécies em solução, sendo estes resultados mostrados na Figura 45. 
O pico correspondente ao $\mathrm{N}_{2} \mathrm{O}\left(2232 \mathrm{~cm}^{-1}\right)$ pode ser visto tanto em água como em água deuterada e em ambas as polarizações, confirmando a sua presença na solução. Com luz "s", além do $\mathrm{N}_{2} \mathrm{O}$, a única outra espécie observada é o $\mathrm{NO}_{3}{ }^{-}$em $1370 \mathrm{~cm}^{-1}$, que está sendo consumido em $0,15 \mathrm{~V}$ em relação a 0,9 V. Já com luz "p" e em $D_{2} \mathrm{O}$, são vistos picos em 1500, 1580 e $1700 \mathrm{~cm}^{-1}$, que não são distinguíveis em $\mathrm{H}_{2} \mathrm{O}$ por estarem na mesma região da vibração desta. Nessa região, entre os possíveis produtos, somente aparecem $\mathrm{NO}_{(\text {ads) }}, \mathrm{NO}_{(\text {sol) }}$ e $\mathrm{NH}_{4}{ }^{+}$. $\mathrm{NO}_{(\text {sol) }}$ pode ser descartado por não ter aparecido no experimento com luz "s". $\mathrm{NH}_{4}{ }^{+}$seria formado como $\mathrm{ND}_{4}{ }^{+}$, uma vez que o solvente é $\mathrm{D}_{2} \mathrm{O}$, e a vibração deste se desloca para $1215 \mathrm{~cm}^{-1}$, portanto também não pode ser a espécie observada. Isso confirma a formação de $\mathrm{NO}_{(\mathrm{ads})}$, mas como não foi observado $\mathrm{NO}$ em solução, não é possível confirmar que o mecanismo proposto para a formação de $\mathrm{N}_{2} \mathrm{O}$ e $\mathrm{N}_{2}$ em Pt se aplique a Pt modificada por Pd, pois no primeiro caso postula-se a necessidade da presença de NO em solução para que o processo se complete [2, 41, 42]. 


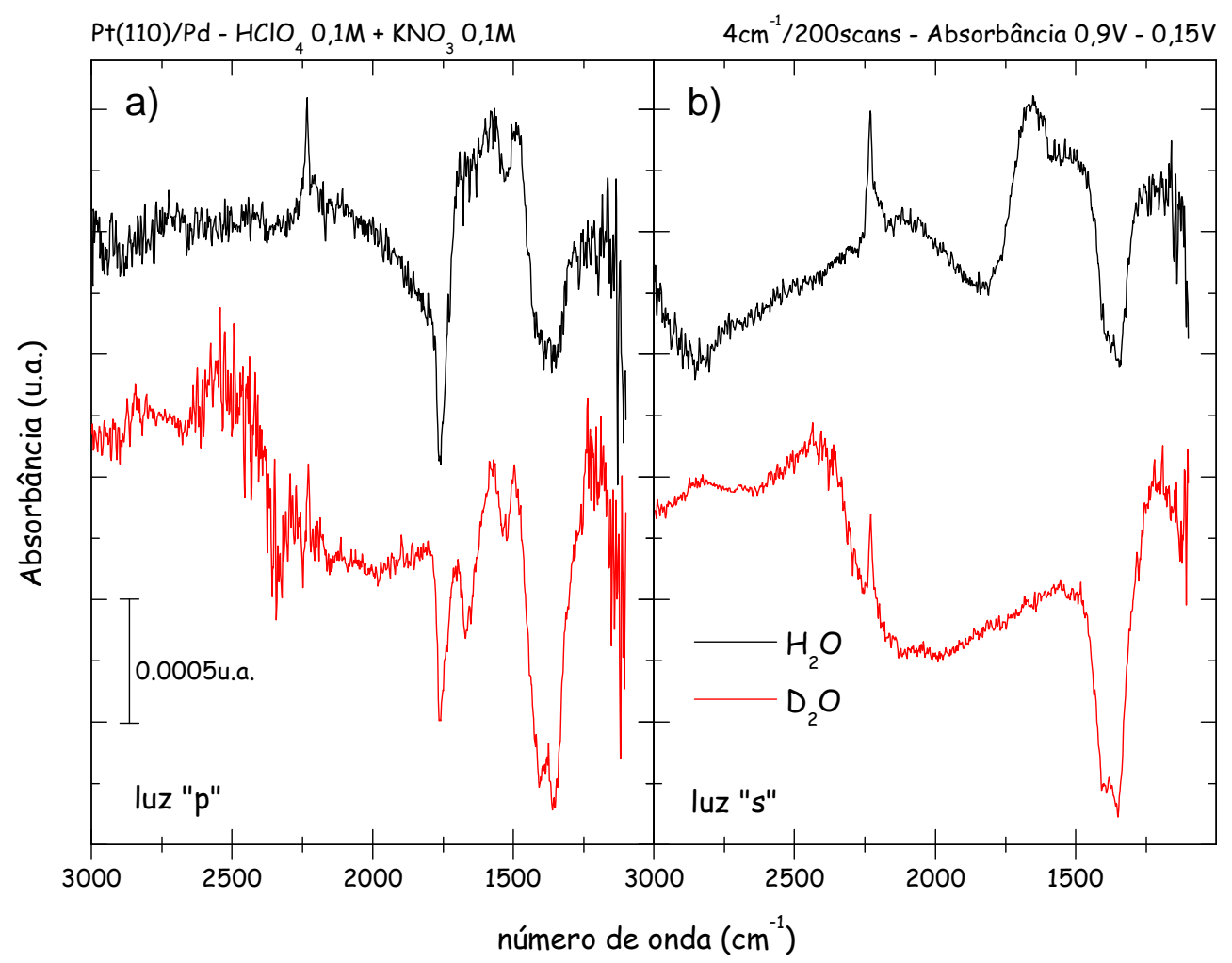

Figura 45: FTIR da redução de nitrato em $\mathrm{Pt}(110)$ com multicamadas de $\mathrm{Pd}$ em $\mathrm{HClO}_{4}$ 0,1 $\mathrm{M}$ e $\mathrm{KNO}_{3}$ 0,1 M. Preto: $\mathrm{H}_{2} \mathrm{O}$; vermelho: $\mathrm{D}_{2} \mathrm{O}$; (a) luz "p" e (b) luz "s". $\mathrm{E}=0,15 \mathrm{~V}$ e $\mathrm{E}_{\text {ref }}=0,9 \mathrm{~V}$. Espectros compostos por 200 scans com resolução de $4 \mathrm{~cm}^{-1}$.

\subsubsection{Discussão geral dos resultados}

O estudo da eletrorredução de nitrato em eletrodos nanoparticulados de Pt, $\mathrm{Pd}$ e $\mathrm{Pt} / \mathrm{Pd}$ suportados em carbono mostrou que a platina é mais ativa que o paládio para esta reação e que a modificação das nanopartículas de platina com uma monocamada de paládio não melhora a atividade das mesmas. Para entender melhor a atividade de cada um dos metais, foram feitos estudos com eletrodos monocristalinos de Pt, Pd e Pt com multicamadas de Pd.

Os resultados eletroquímicos obtidos para os eletrodos de Pt(hkl) estão de acordo com aqueles publicados por Dima et al. [51]. Os estudos de FTIR deste trabalho mostraram a presença de $\mathrm{ND}_{4}{ }^{+}$, confirmando a sugestão dos autores que, 
baseados nos estudos de redução de $\mathrm{NO}_{(\text {ads })}$ em $\mathrm{Pt}(\mathrm{hkl})$ [49], sugeriram que a amônia deveria ser um dos produtos da redução do nitrato nestes eletrodos [51].

No caso dos eletrodos de Pt(hkl) modificados por paládio, uma conclusão que pode ser atingida é que a reação de redução de nitrato é um processo sensível à estrutura. Entretanto, não é possível distinguir se essa sensibilidade está relacionada com as propriedades eletrônicas da superfície ou induzida pela adsorção específica de hidrogênio e ânions, como proposto na literatura [51]. Foi proposto que o primeiro estágio da redução do nitrato seria a etapa de adsorção e que a razão para a baixa reatividade das superfícies de platina seria a baixa entalpia de adsorção desta etapa, que deve competir com a adsorção de hidrogênio e ânions [51]. A interação mais forte do sulfato com as superfícies metálicas pode explicar a menor reatividade dos eletrodos para a redução de nitrato nesse eletrólito e a maior atividade observada em ácido perclórico, porque a interação do perclorato é mais fraca.

Devido à competição com a adsorção de ânions a reação ocorre abaixo do pctz. Isso significa que o ânion $\mathrm{NO}_{3}{ }^{-}$se adsorve na interface quando esta está carregada negativamente. Essa etapa é difícil, explicando porque a redução de nitrato é um processo lento. Em ácido perclórico, onde a competição com ânions é menor, a reação pode ser notada mesmo a velocidades de varredura um pouco mais altas, além de apresentar carga de redução maior.

Em todos dos casos a redução procede através da formação de intermediários adsorvidos. A partir da similaridade entre a redução de nitrato e $\mathrm{NO}_{(\text {ads) }}$ e seguindo os resultados análogos para eletrodos de platina [51], pode ser antecipado que o intermediário adsorvido é NO. Os estudos espectroscópicos de FTIR, embora não tenham identificado a presença de NO em solução, confirmam a 
formação de NO adsorvido. No entanto, a acumulação de NO leva ao bloqueio progressivo da superfície. Esse efeito é ainda mais aparente em eletrodos maciços de paládio onde o potencial inferior limite deve ser maior para evitar uma absorção significativa de hidrogênio. A formação de outros produtos nitrogenados adsorvidos irreversivelmente não pode ser excluída. Em $\mathrm{Pt}(110) / \mathrm{Pd}$ foi observada a formação de um produto com vibração em $2732 \mathrm{~cm}^{-1}$ que provavelmente se refere a hidroxilamina, mas a formação de $\mathrm{NH}_{4}{ }^{+}$somente foi observada em $\mathrm{Pt}(111)$, confirmando sugestões da literatura [49, 51].

Foi observada a formação de $\mathrm{N}_{2} \mathrm{O}$ em $\mathrm{Pt}(110) / \mathrm{Pd}$, em ambos os eletrólitos e solventes. Contudo, o pico em $2232 \mathrm{~cm}^{-1}$, correspondente à vibração do $\mathrm{N}_{2} \mathrm{O}$, somente foi observada em $\mathrm{D}_{2} \mathrm{O}$ nos eletrodos de $\mathrm{Pt}(111)$ e $\mathrm{Pt}(100)$ modificados por $\mathrm{Pd}$. Isso indica que o solvente influencia de alguma forma a reação, sendo a via de formação de $\mathrm{N}_{2} \mathrm{O}$ favorecida na presença de $\mathrm{D}_{2} \mathrm{O}$. Essa mudança no mecanismo dificulta a determinação do mesmo, uma vez que, assim como a formação de $\mathrm{N}_{2} \mathrm{O}$ somente ocorre em $\mathrm{D}_{2} \mathrm{O}$, algum outro produto pode ser formado apenas em $\mathrm{H}_{2} \mathrm{O}$, mas com vibração na região da água. Por exemplo: se em água ocorre a formação de $\mathrm{NH}_{4}{ }^{+}$, esta não seria observada por apresentar vibração na região da água e, em $\mathrm{D}_{2} \mathrm{O}$ não é observada a presença do pico em $1215 \mathrm{~cm}^{-1}$, correspondente a $\mathrm{ND}_{4}{ }^{+}$, não se pode afirmar que não existe a formação e $\mathrm{NH}_{4}{ }^{+}$em $\mathrm{H}_{2} \mathrm{O}$ por causa da mudança no mecanismo (a formação de $\mathrm{N}_{2} \mathrm{O}$ pode estar sendo favorecida em $\mathrm{D}_{2} \mathrm{O}$ enquanto a de $\mathrm{ND}_{4}{ }^{+}$é desfavorecida).

Um detalhe que merece comentários é o aumento da carga de redução, em ácido sulfúrico, do primeiro para o segundo ciclo. Isso pode estar relacionado com a redução de nitrato a $\mathrm{NO}_{(\text {ads) }}$ inicial. É sabido que a adsorção seguida da redução de NO em camadas de paládio pode ter um efeito de reorganizar a camada [58]. As 
mudanças na estrutura da superfície induzidas pela formação e redução de NO no primeiro ciclo poderiam explicar o aumento da carga de redução do primeiro para o segundo ciclo. Depois disso, o eletrodo é envenenado por algum produto e a atividade diminui. 


\section{CONCLUSÕES}

Nanopartículas de Pd suportadas em carbono (Pd 20\% em carbono Vulcan ${ }^{\circledR}$ E-TEK $^{\oplus}$ ) são menos ativas que as de Pt suportadas em carbono para a reação de redução de nitrato em $\mathrm{H}_{2} \mathrm{SO}_{4}$. A modificação das nanopartículas de $\mathrm{Pt}$ com uma monocamada de Pd diminui a atividade das mesmas, mas estudos com monocristais de $\mathrm{Pt}(\mathrm{hkl})$ com multicamadas de $\mathrm{Pd}$ mostraram que a seletividade para $\mathrm{N}_{2} \mathrm{O}$ aumenta, embora a atividade seja menor se comparada à da $\mathrm{Pt}(\mathrm{hkl})$.

Os estudos de FITR para Pt(111) mostraram a formação de $\mathrm{NO}_{(\text {ads })}$ e $\mathrm{ND}_{4}{ }^{+}$, comprovando a hipótese sugerida por Dima et al. [51] que o nitrato se reduz a $\mathrm{NO}_{(\text {ads) }}$ e este a $\mathrm{NH}_{4}{ }^{+}$.

Eletrodos monocristalinos de $\mathrm{Pd}(\mathrm{hkl})$ apresentam grande bloqueio frente à reação de redução de nitrato, provavelmente devido ao fato de não serem levados a potenciais abaixo de $0,2 \vee$ para evitar a absorção de hidrogênio.

Em monocristais de Pt(hkl) modificados por multicamadas de $\mathrm{Pd}$, a redução de nitrato ocorre em potenciais abaixo do pctz, o que significa que a adsorção de $\mathrm{NO}_{3}{ }^{-}$ocorre quando a superfície está carregada negativamente, explicando porque a reação é lenta. A competição da adsorção do ânion com a do nitrato também influencia na velocidade da reação, sendo esta mais rápida em ácido perclórico que em ácido sulfúrico, uma vez que a adsorção do sulfato é mais forte que a do perclorato. A reatividade dos eletrodos varia dependendo do meio, sendo a atividade da face $(110)>>(100)>(111)$ em $\mathrm{HClO}_{4}$ e $(111)>(110)>(100)$ em $\mathrm{H}_{2} \mathrm{SO}_{4}$.

O mecanismo de reação é diferente em $\mathrm{Pt}(110)$ com multicamadas de $\mathrm{Pd}$ comparado com $\mathrm{Pt}(111)$ e $\mathrm{Pt}(100)$ modificados com $\mathrm{Pd}$. No primeiro eletrodo é 
observada a formação de $\mathrm{N}_{2} \mathrm{O}$ em ambos os eletrólitos $\left(\mathrm{H}_{2} \mathrm{O}\right.$ e $\left.\mathrm{D}_{2} \mathrm{O}\right)$. Já nos dois outros, a formação de $\mathrm{N}_{2} \mathrm{O}$ somente foi observada quando o solvente é $\mathrm{D}_{2} \mathrm{O}$. Além disso, em $\mathrm{Pt}(110) / \mathrm{Pd}$, foi observada a formação de um produto hidrogenado com vibração em $2732 \mathrm{~cm}^{-1}$, que é atribuída à hidroxilamina. Em todos os casos foi observada a presença de bandas entre 1470 e $1700 \mathrm{~cm}^{-1}$, atribuídas ao $\mathrm{NO}_{(\mathrm{ads})}$. Como a presença de NO em solução não foi observada, não é possível afirmar que, no caso de $\mathrm{Pt}(\mathrm{hkl}) / \mathrm{Pd}$, o mecanismo da formação de $\mathrm{N}_{2} \mathrm{O}$ ocorre através de $\mathrm{NO}_{(\text {sol) }}$, como sugerido na literatura $[41,42,51]$.

Um ponto interessante é a mudança que ocorre no mecanismo de reação quando a água é substituída por $\mathrm{D}_{2} \mathrm{O}$. Em $\mathrm{Pt}(111)$ e $\mathrm{Pt}(100)$ modificados por $\mathrm{Pd}$, foi observada a formação de $\mathrm{N}_{2} \mathrm{O}$ somente quando o solvente era $\mathrm{D}_{2} \mathrm{O}$. A mudança do solvente, de alguma forma, favorece a formação de $\mathrm{N}_{2} \mathrm{O}$ e, possivelmente, desfavorece a formação de produtos hidrogenados. Experimentos com $D_{2} \mathrm{O}$ são feitos para identificar os produtos com vibração na mesma região que a água, supondo que a mudança do solvente não interfere na reação, mas como nesse caso existe influência deste, a definição de um mecanismo de reação é difícil.

A redução do $\mathrm{NO}_{\text {(ads) }}$ formado durante o primeiro ciclo de redução pode reorganizar a camada de $\mathrm{Pd}$, aumentando a carga de redução no segundo ciclo. Depois disso, a reatividade diminui uma vez que a superfície é bloqueada progressivamente com a acumulação de algum produto, ou produtos, incluindo NO.

Em geral, conclui-se que o paládio é um catalisador pouco ativo para a reação de redução do nitrato, assim como reportado [2, 68]. Os experimentos com multicamadas de Pd levam à mesma conclusão, entretanto indicam que o Pd é mais seletivo para a formação de $\mathrm{N}_{2} \mathrm{O}$ que a Pt. 


\section{REFERÊNCIAS BIBLIOGRÁFICAS}

1. DE GROOT, M. T.; KOPER, M. T. M. The influence of nitrate concentration and acidity on the electrocatalytic reduction of nitrate on platinum. Journal of Electroanalytical Chemistry, v. 562, p. 81-94, 2004.

2. DIMA, G. E.; DE VOOYS, A. C. A.; KOPER, M. T. M. Electrocatalytic reduction of nitrate at low concentration on coinage and transition-metal electrodes in acid solutions. Journal of Electroanalytical Chemistry, v. 554-555, p. 15-23, 2003.

3. DA CUNHA, M. C. P. M.; WEBER, M.; NART, F. C. On the adsorption and reduction of $\mathrm{NO}_{3}{ }^{-}$ions at $\mathrm{Au}$ and Pt electrodes studied by in situ FTIR spectroscopy. Journal of Electroanalytical Chemistry, v. 414, p. 163-170, 1996.

4. GOOTZEN, J. F. E.; PEETERS, P. G. J. M.; DUKERS, J. M. B.; LEFFERTS, L.; VISSCHER, W.; VAN VEEN, J. A. R. The electrocatalytic reduction of $\mathrm{NO}_{3}{ }^{-}$on Pt, $\mathrm{Pd}$ and $\mathrm{Pt}+\mathrm{Pd}$ electrodes activated with $\mathrm{Ge}$. Journal of Electroanalytical Chemistry, v. 434, p. $171-183,1997$.

5. DA CUNHA, M. C. P. M.; DE SOUZA, J. P. I.; NART, F. C. Reaction pathways for reduction of nitrate ions on platinum, rhodium, and platinum-rhodium alloy electrodes. Langmuir, v. 16, p. 771-777, 2000.

6. PETRII, O. A.; SAFONOVA, T. Y. Electroreduction of nitrate and nitrite anions on platinum metals: a model process for elucidating the nature of the passivation by hydrogen adsorption. Journal of Electroanalytical Chemistry, v. 331, p. 897-912, 1992.

7. GAUTHARD, F.; EPRON, F.; BARBIER, J. Palladium and platinum-based catalysts in the catalytic reduction of nitrate in water: Effect of copper, silver, or gold addition. Journal of Catalysis, v. 220, p. 182-191, 2003.

8. PINTAR, A. Catalytic processes for the purification of drinking water and industrial effluents. Catalysis Today, v. 77, p. 451-465, 2003.

9. EPRON, F.; GAUTHARD, F.; BARBIER, J. Catalytic reduction of nitrate in water on a monometallic $\mathrm{Pd} / \mathrm{CeO} 2$ catalyst. Journal of Catalysis, v. 206, p. 363-367, 2002.

10. BRASIL. Agência Nacional de Vigilância Sanitária. CNNPA. Resolução $n^{\circ} 12$ de 1978. Diário Oficial da União, Brasília, 24 de julho de 1978. Disponível em: $<$ http://anvisa.gov.br/legis/resol/12 78.pdf>. Acesso em: 27 fev. 2009.

11. ANGELUCCI, C. A. Alguns aspectos da eletroxidação de monóxido de carbono em superfícies monocristalinas de platina de baixo e alto índice de Miller. 2007. 90 f. Tese (Doutorado) - Instituto de Química de São Carlos, Universidade de São Paulo, São Carlos, 2007. 
12. ZEI, M. S. Effect of chloride anions on Cu electrodeposition onto $\mathrm{Pt}(110)$ and $\operatorname{Pd}(110)$ surfaces. Zeitschrift fur Physikalische Chemie - International Journal of Research in Physical Chemistry \& Chemical Physics, v. 208, p. 77-91, 1999.

13. HSIEH, S. J.; GEWIRTH, A. A. Nitrate reduction catalyzed by underpotentially deposited $\mathrm{Cd}$ on $\mathrm{Au}(111)$ : Identification of the electroactive surface structure. Langmuir, v. 16, p. 9501-9512, 2000.

14. ENDO, O.; IKEMIYA, N.; ITO, M. The structural transformation of the Pt(110) electrode during the $\mathrm{Cu}$ underpotential deposition process. Surface Science, v. 514, p. 234-240, 2002.

15. OKADA, J.; INUKAI, J.; ITAYA, K. Underpotential and bulk deposition of copper on $\mathrm{Pd}(111)$ in sulfuric acid solution studied by in situ scanning tunneling microscopy. Physical Chemistry Chemical Physics, v. 3, p. 3297-3302, 2001.

16. RIGANO, P. M.; MAYER, C.; CHIERCHIE, T. Structural investigation of the initial stages of copper electrodeposition on polycrystalline and single crystal palladium electrodes. Electrochimica Acta, v. 35, p. 1189-1194, 1990.

17. MARKOVIC, N.; ROSS, P. N. Effect of anions on the underpotential deposition of Cu on Pt(111) and Pt(100) surfaces. Langmuir, v. 9, p. 580-590, 1993.

18. MARKOVIC, N.; ROSS, P. N. Electrodeposition of Copper on Pt(111) and Pt(100) Single Crystal Surfaces. Journal of Vacuum Science \& Technology A - Vacuum Surfaces and Films, v. 11, p. 2225-2231, 1993.

19. CHIERCHIE, T.; MAYER, C. Voltammetric study of the underpotential deposition of copper on polycrystalline and single crystal palladium surfaces. Electrochimica Acta, v. 33, p. 341-345, 1988.

20. HOYER, R.; KIBLER, L. A.; KOLB, D. M. The initial stages of palladium deposition onto Pt(111). Electrochimica Acta, v. 49, p. 63-72, 2003.

21. TANG, J.; PETRI, M.; KIBLER, L. A.; KOLB, D. M. Pd deposition onto Au(111) electrodes from sulphuric acid solution. Electrochimica Acta, v. 51, p. 125-132, 2005.

22. KIBLER, L. A.; KLEINERT, M.; RANDLER, R.; KOLB, D. M. Initial stages of Pd deposition on $\mathrm{Au}(\mathrm{hkl}) \mathrm{Part}$ I: Pd on $\mathrm{Au}(111)$. Surface Science, v. 443, p. 19-30, 1999.

23. KIBLER, L. A.; KLEINERT, M.; KOLB, D. M. Initial stages of Pd deposition on $\mathrm{Au}(\mathrm{hkl}) \mathrm{Part}$ II: Pd on Au(100). Surface Science, v. 461, p. 155-167, 2000.

24. HOYER, R.; KIBLER, L. A.; KOLB, D. M. Electrochemical Pd deposition onto $\mathrm{Rh}(111)$ : From cluster to monolayer growth. Surface Science, v. 562, p. 275-283, 2004. 
25. GÓMEZ, R.; RODES, A.; PÉREZ, J. M.; FELIU, J. M.; ALDAZ, A. Electrochemical and in situ FTIR studies of the $C O$ adsorption at palladium and rhodium multilayers deposited on platinum single crystal surfaces. I. Pt(110) substrate. Surface Science, v. 327, p. 202-215, 1995.

26. CLAVILIER, J.; FERNANDEZ-VEGA, A.; FELIU, J. M.; ALDAZ, A. Heterogeneous electrocatalysis on well defined platinum surfaces modified by controlled amounts of irreversibly adsorbed adatoms. Part I. Formic acid oxidation on the Pt (111)-Bi system. Journal of Electroanalytical Chemistry, v. 258, p. 89-100, 1989.

27. ATTARD, G. A.; BANNISTER, A. The electrochemical behaviour of irreversibly adsorbed palladium on $\mathrm{Pt}(111)$ in acid media. Journal of Electroanalytical Chemistry, v. 300, p. 467-485, 1991.

28. LLORCA, M. J.; FELIU, J. M.; ALDAZ, A.; CLAVILIER, J. Electrochemical structure-sensitive behaviour of irreversibly adsorbed palladium on $\mathrm{Pt}(100), \mathrm{Pt}(111)$ and $\mathrm{Pt}(110)$ in an acidic medium. Journal of Electroanalytical Chemistry, v. 351, p. 299-319, 1993.

29. ATTARD, G. A.; PRICE, R.; AL-AKL, A. Palladium adsorption on Pt(111): a combined electrochemical and ultra-high vacuum study. Electrochimica Acta, v. 39, p. 1525-1530, 1994.

30. FELIU, J. M.; ALVAREZ, B.; CLIMENT, V.; RODES, A. Electrochemical properties of $\mathrm{Pd} / \mathrm{Pt}(111)$ adlayers. In: SORIAGA, M. P.; STICKNEY, J.; BOTTOMLEY, L. A.; KIM, Y. G. (Eds). Thin films: preparation, characterization, applications. New York: Kluwer Academic/ Plenum Publishers, 2002. p. 37-52.

31. CLAVILIER, J.; FAURE, R.; GUINET, G.; DURAND, R. Preparation of monocrystalline Pt microelectrodes and electrochemical study of the plane surfaces cut in the direction of the 111 and 110 planes. Journal of Electroanalytical Chemistry, v. 107, p. 205-209, 1980.

32. ÁLVAREZ, B.; RODES, A.; PEREZ, J. M.; FELIU, J. M.; RODRIGUEZ, J. L.; PASTOR, E. Spectroscopic study of the nitric oxide adlayers formed from nitrous acid solutions on palladium-covered platinum single-crystal electrodes. Langmuir, v. 16, p. $4695-4705,2000$.

33. BRANKOVIC, S. R.; WANG, J. X.; ADZIC, R. R. Metal monolayer deposition by replacement of metal adlayers on electrode surfaces. Surface Science, v. 474, p. L173-L179, 2001.

34. ZHANG, J.; MO, Y.; VUKMIROVIC, M. B.; KLIE, R.; SASAKI, K.; ADZIC, R. R. Platinum Monolayer Electrocatalysts for $\mathrm{O}_{2}$ Reduction: Pt Monolayer on $\mathrm{Pd}(111)$ and on Carbon-Supported Pd Nanoparticles. Journal of Physical Chemistry B, v. 108, p. 10955-10964, 2004.

35. CAMPBELL, C. T. Bimetallic surface chemistry. Annual Review of Physical Chemistry, v. 41, p. 775-837, 1990. 
36. ALVAREZ, B. Reactividad electroquímica de adcapas de paladio depositadas sobre monocristales de platino. 2001. $316 \mathrm{f}$. Tese (Doctorado) Departamento de Química Física, Universidad de Alicante, Alicante, 2001.

37. ÁLVAREZ, B.; CLIMENT, V.; RODES, A.; FELIU, J. M. Anion adsorption on Pd$\mathrm{Pt}(111)$ electrodes in sulphuric acid solution. Journal of Electroanalytical Chemistry, v. 497, p. 125-138, 2001.

38. CLAVILIER, J.; LLORCA, M. J.; FELIU, J. M.; ALDAZ, A. Preliminary study of the electrochemical adsorption behaviour of a palladium modified Pt(111) electrode in the whole range of coverage. Journal of Electroanalytical Chemistry, v. 310, p. 429435, 1991.

39. EL-AZIZ, A. M.; HOYER, R.; KIBLER, L. A.; KOLB, D. M. Potential of zero free charge of Pd overlayers on Pt( 11 1 1). Electrochimica Acta, v. 51, p. 2518-2522, 2006.

40. AL-AKL, A.; ATTARD, G. A. Anion effects in the UPD of copper on $\mathrm{Pd} / \mathrm{Pt}(111)$ bimetallic electrodes. Journal of Physical Chemistry B, v. 101, p. 4597-4606, 1997.

41. DE VOOYS, A. C. A.; KOPER, M. T. M.; VAN SANTEN, R. A.; VAN VEEN, J. A. $R$. Mechanistic study on the electrocatalytic reduction of nitric oxide on transitionmetal electrodes. Journal of Catalysis, v. 202, p. 387-394, 2001.

42. DE VOOYS, A. C. A.; BELTRAMO, G. L.; VAN RIET, B.; VAN VEEN, J. A. R.; KOPER, M. T. M. Mechanisms of electrochemical reduction and oxidation of nitric oxide. Electrochimica Acta, v. 49, p. 1307-1314, 2004.

43. SOUZA-GARCIA, J.; TICIANELLI, E. A.; CLIMENT, V.; FELIU, J. M. Nitrate reduction on Pt single crystals with Pd multilayer. Electrochimica Acta, v. 54, p. 2094-2101, 2009.

44. NISHIMURA, K.; MACHIDA, K.; ENYO, M. On-line mass spectroscopy applied to electroreduction of nitrite and nitrate ions at porous Pt electrode in sulfuric acid solutions. Electrochimica Acta, v. 36, p. 877-880, 1991.

45. DE VOOYS, A. C. A.; VAN SANTEN, R. A.; VAN VEEN, J. A. R. Electrocatalytic reduction of $\mathrm{NO}_{3}$ on palladium/copper electrodes. Journal of Molecular Catalysis A: Chemical, v. 154, p. 203-215, 2000.

46. RODES, A.; CLIMENT, V.; ORTS, J. M.; PE?REZ, J. M.; ALDAZ, A. Nitric oxide adsorption at $\mathrm{Pt}(100)$ electrode surfaces. Electrochimica Acta, v. 44, p. 1077-1090, 1998.

47. ROSCA, V.; BELTRAMO, G. L.; KOPER, M. T. M. Reduction of NO adlayers on $\mathrm{Pt}(110)$ and $\mathrm{Pt}(111)$ in acidic media: Evidence for adsorption site-specific reduction. Langmuir, v. 21, p. 1448-1456, 2005. 
48. RODES, A.; GÓMEZ, R.; ORTS, J. M.; FELIU, J. M.; ALDAZ, A. An electrochemical study in perchloric acid medium of adlayers formed from irreversible adsorption of nitrite on $\mathrm{Pt}(100)$. Journal of Electroanalytical Chemistry, v. 359, p. 315-323, 1993.

49. BELTRAMO, G. L.; KOPER, M. T. M. Nitric Oxide Reduction and Oxidation on Stepped Pt[n(111)×(111)] Electrodes. Langmuir, v. 19, p. 8907-8915, 2003.

50. CLIMENT, V.; GÓMEZ, R.; FELIU, J. M. Effect of increasing amount of steps on the potential of zero total charge of $\mathrm{Pt}(111)$ electrodes. Electrochimica Acta, v. 45, p. 629-637, 1999.

51. DIMA, G. E.; BELTRAMO, G. L.; KOPER, M. T. M. Nitrate reduction on singlecrystal platinum electrodes. Electrochimica Acta, v. 50, p. 4318-4326, 2005.

52. TAGUCHI, S.; FELIU, J. M. Electrochemical reduction of nitrate on $\operatorname{Pt}(S)[n(111) \times(111)]$ electrodes in perchloric acid solution. Electrochimica Acta, v. 52, p. 6023-6033, 2007.

53. TAGUCHI, S.; FELIU, J. M. Kinetic study of nitrate reduction on $\mathrm{Pt}(110)$ electrode in perchloric acid solution. Electrochimica Acta, v. 53, p. 3626-3634, 2008.

54. NAKAMOTO, K. Infrared and raman spectra of inorganic and coordination compounds New York: John Wiley, 1986. 484 p.

55. HARA, M.; LINKE, U.; WANDLOWSKI, T. Preparation and electrochemical characterization of palladium single crystal electrodes in $0.1 \mathrm{M} \mathrm{H}_{2} \mathrm{SO}_{4}$ and $\mathrm{HClO}_{4}$. Part I. Low-index phases. Electrochimica Acta, v. 52, p. 5733-5748, 2007.

56. HOSHI, N.; KAGAYA, K.; HORI, Y. Voltammograms of the single-crystal electrodes of palladium in aqueous sulfuric acid electrolyte: $\mathrm{Pd}(\mathrm{S})-[\mathrm{n}(111) \times(111)]$ and $\operatorname{Pd}(S)-[n(100) \times(111)]$. Journal of Electroanalytical Chemistry, v. 485, p. 55-60, 2000.

57. HOSHI, N.; KURODA, M.; HORI, Y. Voltammograms of stepped and kinked stepped surfaces of palladium: $\mathrm{Pd}(\mathrm{S})-[\mathrm{n}(111) \times(100)]$ and $\mathrm{Pd}(\mathrm{S})-[\mathrm{n}(100) \times(110)]$. Journal of Electroanalytical Chemistry, v. 521, p. 155-160, 2002.

58. ÁLVAREZ, B.; BERNÁ, A.; RODES, A.; FELIU, J. M. Electrochemical properties of palladium adlayers on $\mathrm{Pt}(100)$ substrates. Surface Science, v. 573, p. 32-46, 2004.

59. ÁLVAREZ, B.; FELIU, J. M.; CLAVILIER, J. Long-range effects on palladium deposited on $\mathrm{Pt}(111)$. Electrochemistry Communications, v. 4, p. 379-383, 2002.

60. ÁLVAREZ, B.; RODES, A.; PÉREZ, J. M.; FELIU, J. M. Two-dimensional effects on the in situ infrared spectra of $\mathrm{CO}$ adsorbed at palladium-covered $\mathrm{Pt}(111)$ electrode surfaces. Journal of Physical Chemistry B, v. 107, p. 2018-2028, 2003. 
61. ÁLVAREZ, B.; CLIMENT, V.; RODES, A.; FELIU, J. M. Potential of zero total charge of palladium modified $\mathrm{Pt}(111)$ electrodes in perchloric acid solutions.

Physical Chemistry Chemical Physics, v. 3, p. 3269-3276, 2001.

62. GIL, A.; CLOTET, A.; RICART, J. M.; ILLAS, F.; ÁLVAREZ, B.; RODES, A.; FELIU, J. M. Adsorption of $\mathrm{CO}$ at palladium monolayers deposited on $\mathrm{Pt}(111)$ electrodes. Combined spectroelectrochemical and theoretical study. Journal of Physical Chemistry B, v. 105, p. 7263-7271, 2001.

63. GÓMEZ, R.; RODES, A.; PÉREZ, J. M.; FELIU, J. M.; ALDAZ, A. Electrochemical and in situ FTIRS studies of the $C O$ adsorption at palladium and rhodium multilayers deposited on platinum single crystal surfaces II. $\mathrm{Pt}(100)$ substrate. Surface Science, v. 344, p. 85-97, 1995.

64. KRISHNAMOORTHY, S.; TU, M.; OJEDA, M. P.; PINNA, D.; IGLESIA, E. An Investigation of the Effects of Water on Rate and Selectivity for the Fischer-Tropsch Synthesis on Cobalt-Based Catalysts. Journal of Catalysis, v. 211, p. 422-433, 2002.

65. KOPER, M. T. M.; JANSEN, A. P. J.; VAN SANTEN, R. A.; LUKKIEN, J. J.; HILBERS, P. A. J. Monte Carlo simulations of a simple model for the electrocatalytic CO oxidation on platinum. Journal of Chemical Physics, v. 109, p. 6051-6062, 1998.

66. KOPER, M. T. M. Stripping voltammetry and chronoamperometry of an adsorbed species with repulsive lateral interactions. Zeitschrift fur Physikalische Chemie, v. 217, p. 547-556, 2003.

67. THIRSK, H. R.; HARRISON, J. A. A guide to the study of electrode kinetics London: Academic Press, 1972. 174p.

68. PETRII, O. A.; SAFONOVA, T. Y. Electroreduction of nitrate and nitrite anions on platinum metals: A model process for elucidating the nature of the passivation by hydrogen adsorption. Journal of Electroanalytical Chemistry, v. 331, p. 897-912, 1992. 